استخدام مدخل قياس التكاليف للمحاسبة عن استهلاك الموارد(RCA) وبلسلة التوريد البيئية مع عمليات المصادر الخارجية (BPO) في دعم القدرة التنافسية لمنشآت الأعمال الصناعية

$$
\text { " دراسة ميدانية" }
$$

Using the Cost Measurement Approaches for Resource Consumption Accounting (RCA) and the Environmental Supply Chain with Outsourcing Operations (BPO) in Supporting the Competitiveness of Industrial Businesses " Empirical Study"

$$
\begin{aligned}
& \text { د. / اينـاس جمعسة فهمسي شكر } \\
& \text { مدرس - قسم المحاسبة التئية } \\
& \text { المعهد العالي للاراسات النوعية }
\end{aligned}
$$

https://jsst.journals.ekb.eg/ رابط المجلة 
استخدام مدخل قياس التكاليف للمحاسبة عن استهلاك الموارد(RCA) ......... د.. ايناس جمعه شكر

\section{الملخص (Abstract):}

هاف البحث الي التعرف علي مدي تطبيق أبعاد المحاسبة عن استهلاك الموارد(RCA) ، وإدارة تكاليف سلسلة التوريد البيئية - ومدي تأثيرهم علي عمليات المصادر الخارجية (BPO) في الشركات الصناعية ، وذلك من خلال بناء واقتراح إطار محاسبي يساعد في تحقيق العديد من المزايا الكبيرة والهامة لتي يحققها هذا التكامل في تقديم معلومات حيوية تساعد الإدارة في

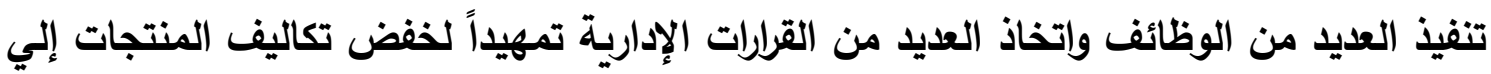
المستويات التنافسية، لتحقيق أهداف الدراسة حدد الباحثة مجتمع البحث شملت الإدارة العليا(المدير العام ورؤساء الأقسام والعاملين في قسم الجودة، والمتوسطة باعتبارهم الفئة المنوط بها البحث، وقد تم تحديد حجم العينة في حدود 170 شركة، وقد تم توزيع 120 استمارة عليهم. وتوصلت الدراسة الي تم قبول الفرض الأول، وهو: " لا يوجد اختلافا معنويا حول دور مدخل المحاسبة عن استهلاك الموارد (RCA) وسلسلة التوريد البيئية مع عمليات المصادر الخارجية (BPO) وهو : "'لا يوجد اختلافا معنويا حول تطبيق المحاسبة عن استهلاك الموارد(RCA) وسلسلة التوريد البيئية مع عمليات المصادر الخارجية (BPO) إلى إعطاء الثركة القدرة على إنتاج منتجات متعددة تفي بمتطلبات العملاء ، وتم قبول الفرض الثالث: وهو هناك تأثير جوهري ذو دلاكلة إلة الثاء إحصائية بين تكامل نظام المحاسبة عن استهلاك الموارد(RCA) وسلسلة التوريد البيئية مع فيول عمليات المصادر الخارجية (BPO) ودعم المركز التنافسي للشركات الصناعية الكلمات المفتاحية:

المحاسبة عن استهلاك الموارد ، سلسلة التوريد البيئية، عمليات المصادر الخارجية ،خفض التكاليف، القدرة التنافسية. 
مجلة البحوث المالية والتجارية ـ المجلد (22) - العدد الثاني - إبريل 2021

\section{Abstract:-}

The aim of the research is to identify the extent of the application of the dimensions of resource consumption accounting (RCA), environmental supply chain cost management - and the extent of their impact on the operations of external sources (BPO) in industrial companies, through building and proposing an accounting framework that helps in achieving many large and important advantages. In order for this integration to be achieved by providing vital information that helps the administration in the implementation of many functions and to take many administrative decisions in preparation for reducing the costs of products to competitive levels, to achieve the objectives of the study, the researcher identified the research community that included the senior management) the general manager, heads of departments and workers in the quality and medium department as The category entrusted with the research, and the sample size has been determined in the range of 170 companies, and 120 questionnaires have been distributed to them. The study concluded that the first hypothesis was accepted, which is: "There is no significant difference regarding the role of the Resource Consumption Accounting Approach (RCA) and the environmental supply chain with external source operations (BPO) in achieving savings in the costs of industrial companies." The second hypothesis was also accepted. It is: "There is no significant difference regarding the application of resource consumption accounting (RCA) and the environmental supply chain with external sourcing operations (BPO) to giving the company the ability to produce multiple products that meet customer requirements. The third hypothesis has been accepted: and there is a significant significant effect. A statistic between the integration of the Resource Consumption Accounting (RCA) system and the environmental supply chain with Outsourcing Operations (BPO) and the competitive position support for industrial firms

key words:

Accounting for resource consumption, environmental supply chain, outsourcing operations, cost reduction, competitiveness 


$$
\text { الإطار العام للبحث: الأول: }
$$

اولاًا :مقدمة ومشكلة البحث:

تتعرض الشركات الصناعية المصرية للعديد من المشكلات التي تحد من قدرتها التنافسية، مثل: تدنى حصتها في الأسواق العالمية والمحلية، وتدني مستوى الأرباح وإطالة فترة الإنتاج والتسليم مما يؤدي إلى زيادة تكاليف الإنتاج، ويتبع ذلك تدنى مستوى الجودة للمنتجات وعدام

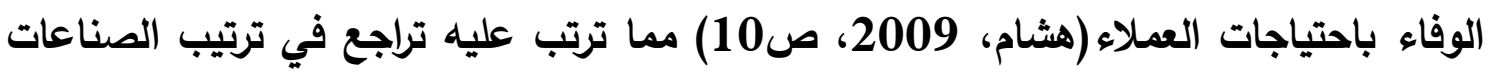

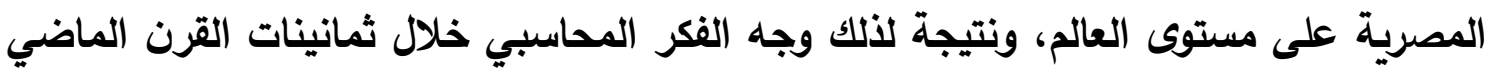
العديد من الانتقادات لمداخل قياس التكلفة التقليدية التي أفرزتها الممارسة العملية الناتجة عن التهائه التطورات الكبيرة والمتلاحقة في نظم التصنيع وأساليب الإنتاج الفنية مثل نظم الإنتاج المرنة "

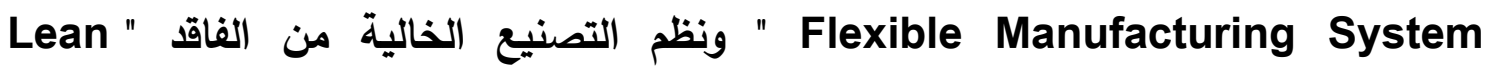
Manufacturing System ومحاسبة التكاليف على أساس ABC، حيث ركزت تلك الانتقادات علي التخصيص غير الدقيق للتكاليف غير المباشرة علي أهداف التكلفة خاصة مع زيادة نسبة هذه التكاليف الي إجمالي تكلفة

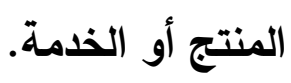
وبالتالي تسعي الوحدات الاقتصادية إلى إيجاد ميزة تنافية في أسواق المنتجات والخدمات من خلال تحقيق الاستغلال الأمثل للإمكانيات وجميع أنواع الموارد الفنية والمادية والمالية والتنظيمية المتاحة. حيث تركز الثركات على ثلاث عناصر لتحقيق ميزة تنافسية هي التكلفة والجودة والأداء. وأصبح من الواضح تماما أن المحددات التنافسية للشركات أصبحت تتمثل في تركي تخفيض تكاليف الإنتاج والاتجاه نحو الريادة في تخفيض تكاليفها في السوق، وتستطيع الثركات إنجاز ذلك من خلال الاستخدام الكفء للموارد بهاف تخفيض الأنثطة التي لا تضيف قيمة وتعظيم الأنثطة التي يكون لها قيمة مضافة للعملاء. ولذلك يجب أن تبحث إدارة الثركات عن أفضل الأدوات والأساليب التي تمكنها من خفض التكلفة مع الحفاظ على مستوي الجودة المطلوبة من خلال تحديد تكلفة الوحدة المنتجة بثكل دقيق. وعلى الرغم من الإسهامات القيمة لنظامABC في تطوير أنظمة التكاليف التقليدية، إلا أنه (Rahimi, 2014, p 533), فثل في المحافظة على الأهداف التي كانت السبب في ظهوره 
وقد أوضحت دراسة ( keys et al., 2001 الى أن تخصيص التكاليف في ظل نظام ABC) يعاني من أوجه قصور تتعلق بإدارة الموارد وتكاليفها وهي:

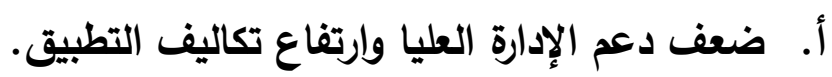

ب. جمود المدخل وعدم قرتهه على الاستجابة للتغيرات في عمليات التثغيل والموارد.

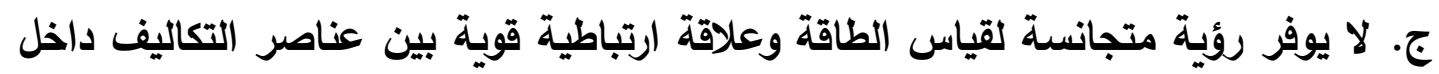
مجمع التكلفة وبين سبب التكلفة الذي يتم اختياره.

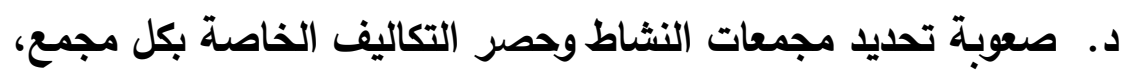
هـ هـ لا يحب الطاقة العاطلة على نحو سليم. و. لا يوفر معلومات دقيقة فيما يتعلق بإدارة الموارد بفعالية، واتخاذ قرارات استراتيجية محددة.

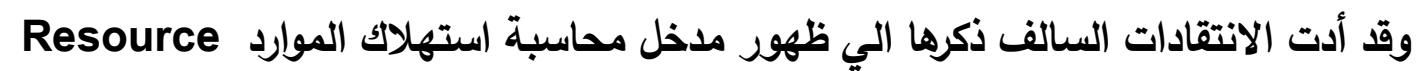
(RCA) Consumption Accounting

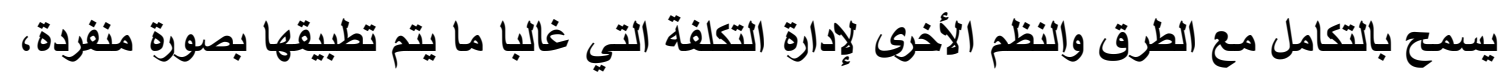
كما يتفادى العيوب والانتقادات التي توجه إلى نظم قياس التكاليف التقليدية ويدمج بين أهم الافتراضات التي يقوم عليها أسلوب التكلفة على أساس النشاط "ABC" وأسلوب التكلفة الألمانية. كما تثكل نظم التكاليف، ممثلة في مدخلي محاسبة استهلاك الموارد ، وسلسلة التوريد البيئية

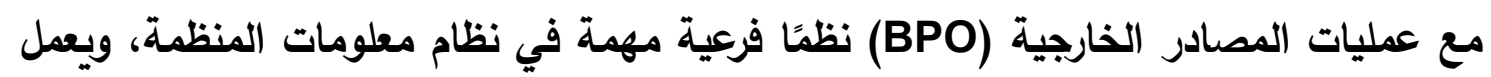
محللو النظم على تحقيق التكامل بينهما، لوجود العديد من الأسباب التي تثجع على تحقيق

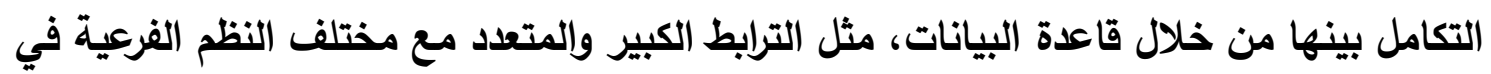

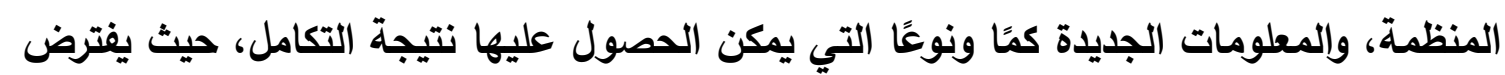
أن تؤدي إلى تغيير كبير في دور نظم التكاليف من نظم تصدر تقارير وتقدم معلومات عما جرى في الماضي، إلى نظم تسهم في رسم خريطة المنظمة الاقتصادية المستقبلية. إلا أن نظام تكاليف محاسبة استهلاك الموارد ونظام سلسلة التوريد البيئية مع عمليات المصادر الخارجية (BPO) هم نظم مختلفة من حيث الأهداف ومفهوم التكاليف وأساليب قياسها وتصنيفها، مما يجعل عملية تحقيق التكامل بينهما بحاجة إلى بحث ودراسة من أجل خلق التوافق المنطقي بين النظم وبقية الأنظمة الفرعية المرتبطة بهما داخل المنظمة مثل نظام التخطيط الفني والمالي ونظام المحاسبة المالية، وذلك بهدف دعم القدرة التنافسية لمنثآت الأعمال الصناعية. 
استخدام مدخل قياس التكاليف للمحاسبة عن استهلاك الموارد(RCA) ......... د.. ايناس جمعه شكر

وتأسيساً علي ما سبق تتبلور مشكلة البحث في التعرف علي دور مدخل محاسبة استهلاك الموارد في تحقيق التكامل بينها وبين سلسلة التوريد البيئية مع عمليات المصادر الخارجية (BPO). ويمكن التعبير عن مشكلة البحث بالتساؤلات التالية:1- هل يسهم تطبيق مدخل محاسبة استهلاك الموارد في استغلال طاقة الشركات الصناعية المصريةج؟ 2- عدم قرة الثركات الصناعية المصرية على استيعاب وتطبيق مفاهيم السوق كنقطة انطلاق للبدء في إنتاج ما يلبي احتياجات العملاء حيث ظهر مفهوم الإدارة الموجهة من السوق Market - Driven Management

مثل:

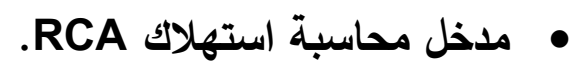

سلسلة التوريد البيئية SH GREEN.

BPO نظام عمليات المصادر الخارجية •

3- ما أهم المعوقات اللاتي تحول دون تطبيق هذا الإطار؟

4- هل يوفر الإطار المقترح تحقيق التكامل بين محاسبة استهلاك الموارد (RCA)ونظام سلسلة

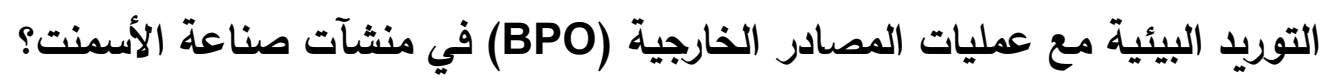
5- عدم اهتمام الثركات الصناعية المصرية بالاقتداء بالثركات الرائدة في مجال الصناعة وكأنها تعمل في جزر منعزلة مما يضعف قدرتها في التنافس على المستوى العالمي. ثانياً: أهمية الدراسة: يكتسب هذا البحث أهمية علمية وعملية تتمثل في الاتي: -

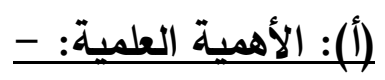

- يتناول هذا البحث تطوير أساليب المحاسبة الإدارية وأدوات إدارة التكلفة لخدمة إدارة ربحية العملاء، حيث أنه يتناول كلا من نظام محاسبة استهلاك الموارد ونظام سلسلة التوريد البيئية

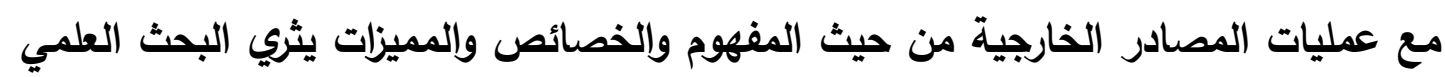
ويفتح الباب للباحثين لإجراء العديد من الأبحاث. 


\section{مجلة البحوث المالية والتجارية ـ المجلد (22) ـ العدد الثاني - إبريل 2021}

- الإطار المقترح يزيد من أهمية البحث العلمية، وذلك لأهمية وجود إطار نظري ييرز أوجه

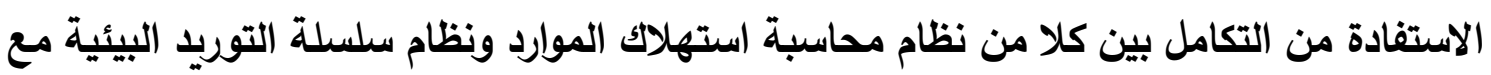
عمليات المصادر الخارجية. (ب) الأهمية العملية: - قد يسهم تطبيق الإطار المقترح في جعل منشأة الأعمال تواكب التطور في البيئة العملية

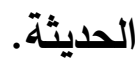
- - تطبيق الإطار المقترح من المتوقع أن يفيد العديد من الثركات في زيادة القدرة التنافسية كمزيج لإعطاء الثركات الصناعية المصرية بعض الميزات التنافسية ليساعدها في دعم مركزها التنافسي على المستوى المحلي والدولي، لأنه لا بديل عن التقدم بمصر في الوقت الحالي إلا

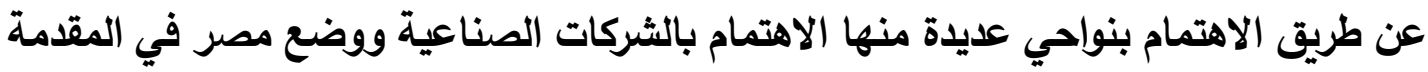

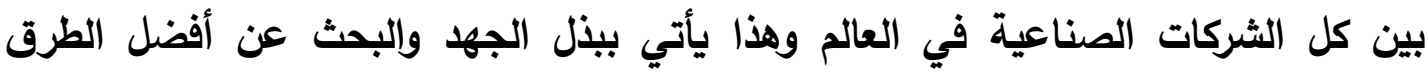
والممارسات في الصناعة واتباع الأساليب المتطورة التي تنتهجها الدول المتقدمة. ثالثاً: أهداف البحث:

يهاف هذا البحث بثكل أساسي إلي وضع إطار مقترح للتكامل بين مدخل المحاسبة عن استهلاك الموارد (RCA) وسلسلة التوريد البيئية مع عمليات المصادر الخارجية (BPO) لتدعم القدرة التنافسية لمنشآت الأعمال الصناعية. ويمكن تحقيق هذا الهذف من خلال تحقيق الأهداف

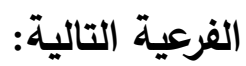

1- التعرف على طبيعة محاسبة استهلاك الموارد (RCA) والأسس التي تقوم عليها ومبادئها وإطارها.

2-تحليل أوجه الثبه والاختلاف بين أسلوبي محاسبة استهلاك الموارد وسلسلة التوريد البيئية مع عمليات المصادر الخارجية (BPO) 3- التعرف على ممارسات إدارة سلسلة التوريد ودورها في ودعم المركز التنافسي. 4-دور عمليات المصادر الخارجية(BPO) في دعم المركز التنافسي 5- محاولة وضع إطار للمزج بين مدخل محاسبة استهلاك الموارد (RCA) وبين سلسلة التوريد البيئية وعمليات المصادر الخارجية BPO للوصول بالشركات الصناعية المصرية إلى مركز المنافسة العالمية وإعطائها ميزات تنافسية. 
استخدام مدخل قياس التكاليف للمحاسبة عن استهلاك الموارد(RCA) ......... د.. ايناس جمعه شكر

6- التعرف على التحديات والصعوبات التي تواجه تطبيق محاسبة استهلاك الموارد (RCA) وسلسلة التوريد البيئية وعمليات المصادر الخارجية BPO لمحاولة التغلب عليها. 7- إجراء دراسة ميدانية لاختبار مدى تأثير الإطار المحاسبي المقترح على المركز التنافسي

$$
\begin{aligned}
& \text { للشركات الصناعية المصرية } \\
& \text { رابعاً : فروض البحث: }
\end{aligned}
$$

1- لا يوجد اختلافا معنويا حول دور مدخل المحاسبة عن استهلاك الموارد (RCA) وسلسلة

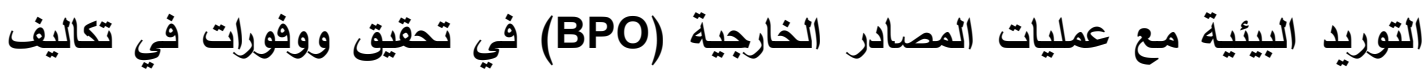

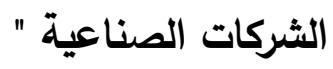

2- لا يوجد اختلافا معنويا حول دور تطبيق المحاسبة عن استهلاك الموارد (RCA) وسلسلة التوريد البيئية مع عمليات المصادر الخارجية (BPO) إلى إعطاء الثركة القدرة على إنتاج منتجات متعددة تفي بمتطلبات العملاء. 3- لا توجد علاقة ذات دلالة إحصائية بين تكامل نظام المحاسبة عن استهلاك الموارد (RCA) وسلسلة التوريد البيئية مع عمليات المصادر الخارجية (BPO) إلى زيادة الحصة السوقية للشركة الصناعية". 4- لا توجد علاقة ذات دلالة إحصائية بين تكامل نظام المحاسبة عن استهلاك الموارد (RCA) وسلسلة التوريد البيئية مع عمليات المصادر الخارجية (BPO) ودعم المركز التنافسي للشركات الصناعية. خامساً : منهرية البحث: تحقيقا لهذف البحث المتمثل في وضع إطار مقترح للتكامل بين نظام محاسبة عن استهلاك الموارد (RCA) وسلسلة التوريد البيئية مع عمليات المصادر الخارجية (BPO) لتدعم القدرة التنافسية لمنشآت الأعمال الصناعية، وفي ضوء الأسئلة البحثية التي تحاول الباحثة الإجابة عليها، سوف تعتمد الباحثة على المنهجين الاستنباطي والاستقرائي. حيث يستخدم المنهج الاستنباطي في مرحلة استعراض ودراسة وتحليل الفكر المحاسبي من خلال الدراسات السابقة المرتبطة بموضوع البحث في مجالات القدرة التنافسية للمنشآت ونظام محاسبة استهلاك الموارد ونظام سلسلة التوريد البيئية مع عمليات المصادر الخارجية، ويستخدم المنهج الاستقرائي لإتمام 
مجلة البحوث المالية والتجارية ـ المجلد (22) - العدد الثاني - إبريل 2021

الجانب الميداني من الدراسة للتحقق من صحة الفروض التي تم التوصل إليها من خلال الدراسة النظريـة. سادساً : خطة البحث : ــــــ لقد تخطيط البحث بالثكل التالي :-

$$
\text { القسم الأول: - الإطار العام للبحث. }
$$

القسم الثاني: - مدخل قياس التكاليف المحاسبة عن استهلاك الموارد (RCA). القسم الثالث: - ممارسات إدارة سلسلة التوريد ودورها في ودعم المركز التنافسي. القسم الرابع: - دور عمليات المصادر الخارجية(BPO) في دعم المركز التنافسي القسم الخامس: -الإطار المحاسبي المقترح لاعم المركز التنافسي للشركات الصناعية

$$
\text { • • الدارائج الميدانية. }
$$

$$
\text { القسم الثاني }
$$

مدخل قياس التكاليف المحاسبة عن استهلاك الموارد (RCA).

تقوم فلسفة نظام محاسبة استهلاك الموارد على أن السبب الأساسي لحدوث التكلفة هو استهلاك الموارد وان التكلفة تحدث، ويتم مراقبتها على مستوي الموارد وليس الأنثطة ويتم تنظيم

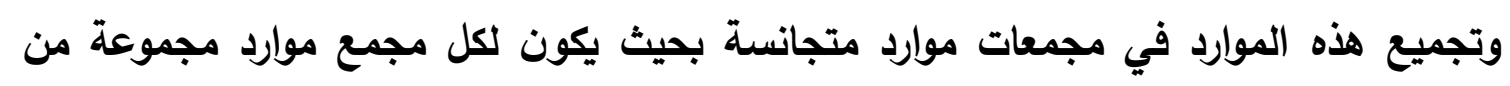

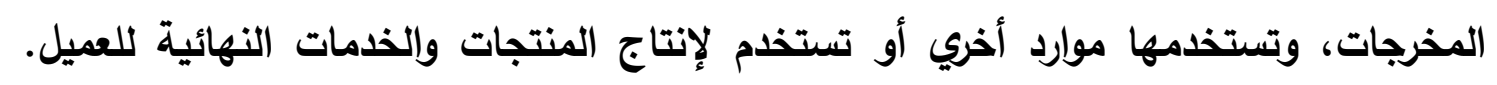

.( Mcnair, 2007; Syed\& Moosa , 2011)

كما يركز مدخل محاسبة استهلاك الموارد على الاقتصاديات الأساسية لنظام الأعمال، فهو

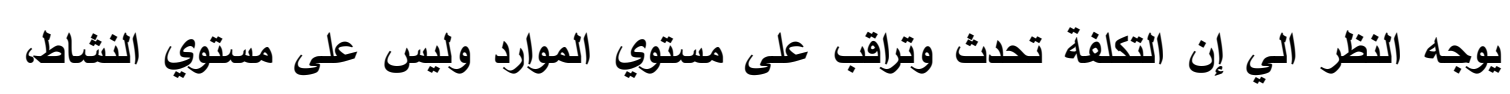

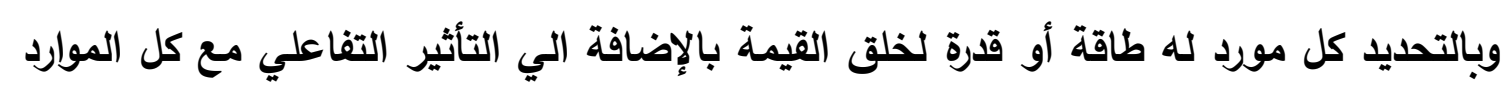
الأخرى.

تعد محاسـبة اسـتهلاك الموارد، بمثابة مدخل لإدارة التكاليف بثـكل شـامل، وديناميكي،

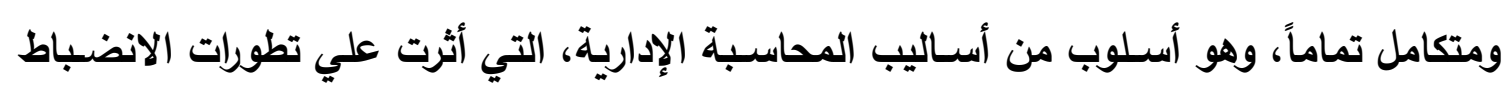

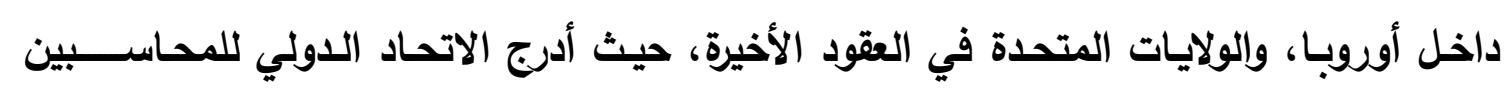

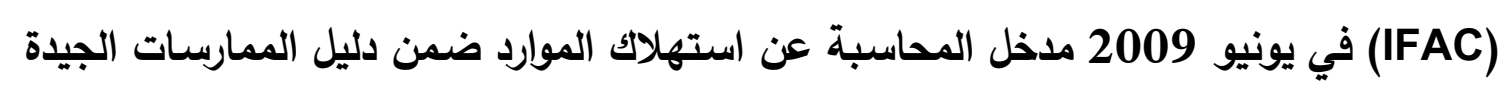


(Evaluating the Costing Journey: " لإدارة التكلفة في تقريره الذي جاء تحت عنوان .(IFAC, 2009) A Costing Levels Continuum Maturity Model). ويمكن توضيح الإطار النظري لمدخل المحاسبة عن استهلاك الموارد في الفكر المعاصر من خلال تناول كلا من: أولا: مفهوم المحاسبة عن استهلاك الموارد. ثانيا: دعم القدرة التنافسية باستخدام المحاسبة عن استهلاك الموارد. أولا: مفهوم المحاسبة عن استهلاك الموارد. تعددت وتنوعت المفاهيم والتعريفات لمدخل المحاسبة على استهلاك الموارد حيث أفادت (أمجاد، 2007، ص :182) بأن نموذج المحاسبة عن استهلاك الموارد RCA ما هو إلا أداة محاسبية لإدارة التكلفة نظراً لما يوفره من معلومات ملائمة عن كيفية الاستغلال الأمثل للموارد المتاحة وتوظيف الطاقة العاطلة، بما يساهم في زيادة الإنتاج وخفض تكلفة المنتجات، وبالتالي زيادة أرباح المنشآت ودعم مركزها التنافسي. وقد عرف Webber مدخل المحاسبة عن الموارد المستهلكة بأنه " الجيل القادم من نظم إدارة التكلفة يمزج بين مزايا أهم نظامين عالميين هما مدخل التكلفة الألمانية ومدخل التكلفة على بلى أساس النشاط، ويهدف توفير معلومات تثغيلية أكثر دقة تساعد في تحليل التكلفة عند أدني مستويات التشغيل.(Webber, \& Clinton. 2004, p:5) وأثشارت (صفاء، 2014، ص:7) انه يعد مدخلاً لإدارة التكلفة من خلال الاستخدام الأمثل لموارد المنثأة وعدم تحميل المنتجات بتكلفة الموارد غير المستخدمة من خلال تطبيق مبدأ السببية في عملية تخصيص تكلفة الموارد المستهلكة على أغراض التكلفة (منتجات / خدمات) التي مني

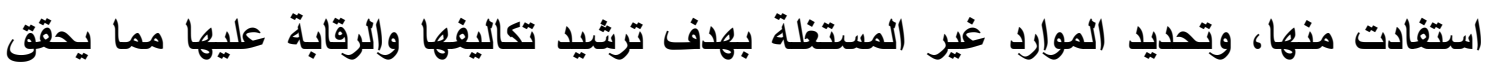
خفض التكلفة ودعم المركز التنافسي للمنشأة. كما أوضح (David \& Scott, 2011 , p:41) بأنه مدخل ذو نظرة مستقبلية عن استهلاك الموارد بناء على متطلبات موارد الأنثطة ووفقاً لرغبات العميل ومنافع الطلب على الخدمات وذلك بلاًا من الاعتماد على المعلومات التاريخية والفعلية.

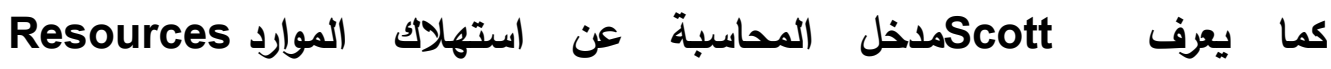
(RCA)Consumption Accounting بأنه " ذلك المدخل الذي يركز بثكل قعال على الموارد 


\section{مجلة البحوث المالية والتجارية ـ المجلد (22) ـ العدد الثاني - إبريل 2021}

التي يتم استهلاكها في الثركة وفقاً لرغبات العملاء ومنافع الطلب على خدماتها، وبما يؤدي الي الاستخدام الفعال للموارد المستهلكة وبالتالي زيادة كفاءة وفاعلية مداخل إدارة التكلفة". كما يعرف (محمد شاهين، 2010) مدخل المحاسبة عن استهلاك الموارد (RCA) بأنه " أداة محاسبية لإدارة التكلفة يقوم بتوفير المعلومات الملائمة عن الكيفية التي يتم من خلالها الاستغلال الكفه للموارد المتاحة وتوظيف الطاقات العاطلة /الفائضة وتدعيم اتخاذ القرارات الإدارية المتعددة بالثركة ويعظم استفادتها من نظم تخطيط الموارد من خلال قدرته علي حفظ وصيانة وتجميع المعلومات بثكل تفصيلي عن كافة الأنثطة التشغيلية والمالية، وبما يساهم في زيادة الإنتاجية وخفض تكلفة المنتج ، وبالتالي زيادة أرباح الثركة ودعم مركزها التنافسي". ويري (Larry White, 2009, p.64) أن مدخل المحاسبة عن استهلاك الموارد نموذجا لقياس التكلفة مصمم لإمداد المديرين بمعلومات التكاليف اللازمة لدعم عمليات اتخاذ القرارات بغرض تحسين الوضع التنافسي للمنشأة.

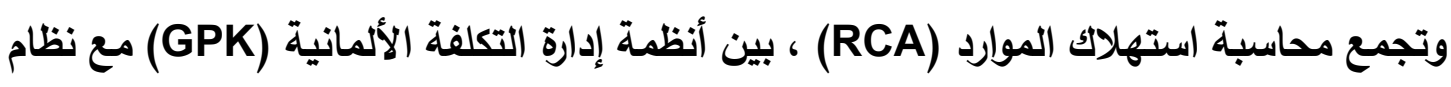
التكاليف علي أساس النشاط(ABC) ، ويعتمد علي الموارد بصفة أساسية، بدلاً من التركيز علي الأنثطة، وبالتالي يضمن توزيعا أكثر دقة للتكاليف غير المباشرة، فهو يفرق بين امتلاك الموارد

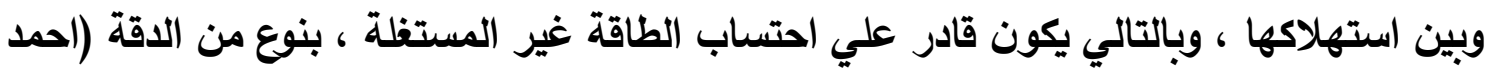
أمين ،2014، ص253) ، ويمكن توضيح ذلك من خلال الثكل التالي :-

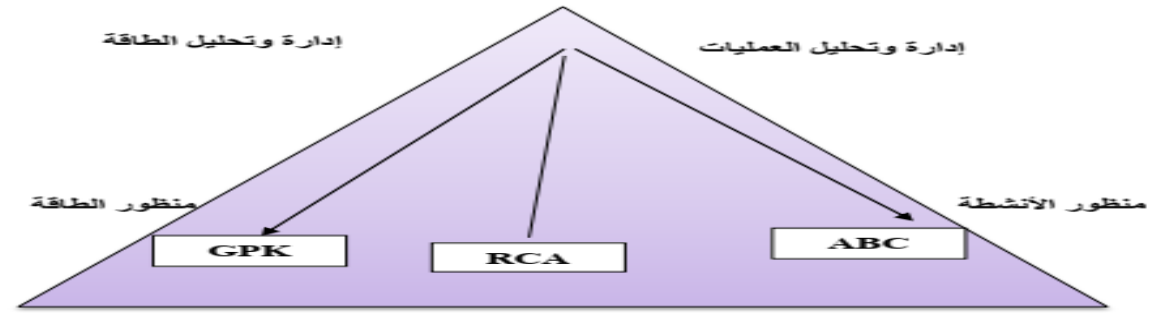

الثكل رقم (1) مفهوم مدخل المحاسبة عن استهلاك الموارد

المصدر: (Syed \& Mossa, 2011, p .760)

ويبين الثكل السابق منظورين لمدخل محاسبة استهلاك الموارد هما :-

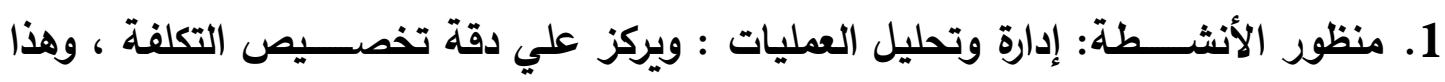
المنظور مستمد من مدخل التكلفة علي أساس النشاط. 2. منظور الطاقة: إدارة وتحليل الطاقة: ويركز علي إدارة طاقة الموارد وتحديد الموارد العاطلة والفصل بين التكاليف المتغيرة والثابتة وهذا المنظور مستمد من مدخل التكلفة الألمانية. 
ومن خلال التعريفات السابقة يتضح إن مدخل المحاسبة عن استهلاك الموارد يعد أحد مداخل

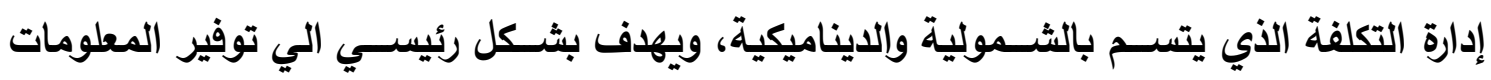

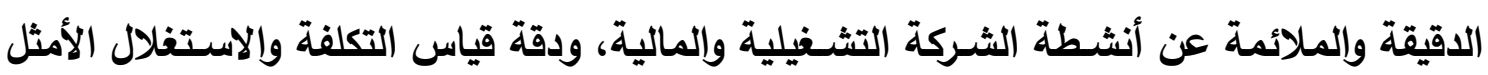
والكفء لمواردها المتاحة وتدعيم اســتغلال الطاقة العاطلة/ الفائضــة ودعم نظم تخطيط الموارد وتعظيم قيمة الثركة الاقتصادية ودعم قدرتها التنافسية". وقد أشارت العديد من الدراسات إلي أهمية مدخل محاسبة استهلاك الموارد، وذلك كما يلي:1. دراسة (Kbelah \& Almagtome, 2019): هدفت هذا الدراسة إلى استكثاف دور

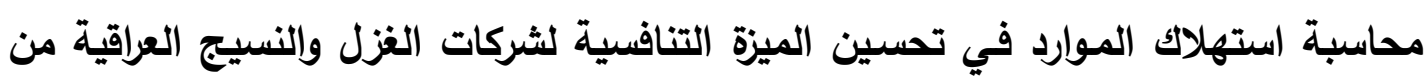
خلال دراسة حاله لأحل م صانع الغزل والنسيج الحكومية. حيث قامت الدراسة بتحليل وتقييم النظام المطبق في المصنع وهو النظام التقليدي ثم تم تطبيق نظام محاسبة استهلاك الموارد ومقارنة نتائج تطبيق كلا النظامين. أثارت نتائج الاراسة إلى أن محاسبة استهلاك الموارد تأخذ في الاعتبار الطاقة العاطلة من خلال تقسيم التكاليف الإجمالية إلى تكاليف متفيرة وتكاليف ثابتة وبالتالي تخصيص تكاليف أقل للمنتجات بالمقارنة بنظام التكاليف التقليدي. وكذلك أثارت الدراسة إلى أن نظام محاسبة استهلاك الموارد يوفر معلومـات أكثر دقة وموثوقية مما يؤدي إلي تحقيق الثركة ميزة تنافسية تتعلق بالتكاليف، وبالتالي في تساعد إدارة المنشآت في تسعير المنتج بسعر أقل من المنافسين. 2. دراسة (هند طولان،2018): هدفت هذه الدراسة إلي بيان استخدام نظام التكاليف علي أساس

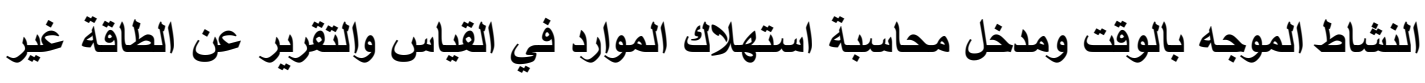
المستفلة، وذلك بهدف توفير معلومات تكاليفية تتسم بالموضوعية والملائمة يمكن استخدامها في إعداد التقارير المالية لخدمة جميع الأطراف مستخدمي هذه التقارير. واعتمدت الدراسـة علي إجراء دراسة حاله لمصنع غسالات توشيبا العربي. وقد أثارت نتائج الدراسة إلي اعتراف كلا من نظام التكاليف علي أساس النشاط الموجه بالوقت ونظام محاسبة استهلاك الموارد

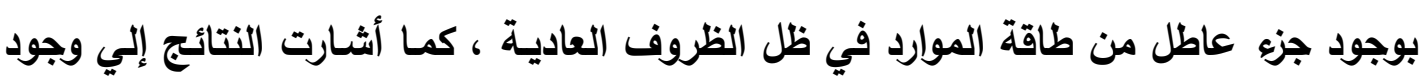
تأثير جوهري لكل من نظام التكاليف علي أساس النشاط الموجه بالوقت ونظام محاسبة استهلاك الموارد علي تحسين مخرجات نظام المحاسبة عن التكلفة ، حيث يعتمد نظام محاسبة استهلاك الموارد في قياس التكلفة علي كميات الموارد المستهلكة بدلا ليل من كميات الموارد 
المتاحة ، كما يساعد نظام محاسبة استهلاك الموارد في تبسيط تحليل التكاليف حيث يتم الانتقال من التحليل الإجمالي لتكلفة الموارد إلي إجراء التحليل علي أساس تكلفة كل مورد علي حدة. 3. دراسة (رقية ،2017) :- استهدفت الدراسة بيان مدى إمكانية تحقيق التكامل بين أسلوب التكلفة المستهدفة ومدخل قياس التكلفة على أساس المواصفات، وأثر ذلك على تكلفة المنتج ، وقد تم تصميم قائمة استقصاء تم توجيهها لبعض المنشآت الصناعية في ليبيا بهدف اختيار فروض الدراسة ومن أهم نتائج الدراسة: أن أسلوب التعلفة المستهدفة يهتم بمرحلة التصميم، حيث تعد النقطة الأساسية التي تنطلق منها جهود خفض التكاليف إذ يجب على المهندسين تصميم المنتج بالثكل الأي يمكن إنتاجه في حدود التكلفة المستهدفة ، كما يعد مدخل التكلفة على أساس المواصفات أحد أدوات معالجة القصور والانتقادات الموجهة إلى نظم التكاليف المتعارف عليها من خلال التخطيط للتكلفة، وذلك في ضوء المواصفات التي يتم تحديدها عن طريق تحليل السوق المنافس، واتباع سياسة التوجه للسوق، والتركيز على إنتاج مـا يمكن بيع لا بيع ما تم إنتاجه ـ ويؤدي التكامل بين ABCII وTC إلى تحقيق الههف المنشود، وهو ترشيد القرارات وتوجيهها، ويتضح ذلك من خلال: دراسة السوق ، وتحليل البيئة التنافسية ، والتخطيط والرقابة تحقيق رضا العملاء ، وخفض تكلفة المنتج • 4. (هاني محاريق ، 2017) : هدفت هذه الدراسة إلى إيضاح أثر تحقيق التكامل بين نظام تخطيط موارد المنشأة ونظام محاسبة استهلاك الموارد في تحقيق الميزة التنافسية المستدامة لمنشأة الأعمال الصناعية ودعم قدرتها التنافيية، من خلال تحديد دور كل من نظام تخطيط الموارد والمعلومات الناتجة عنه مع المعلومات الخاصة بنظام محاسبة استهلاك الموارد وأنظمة المعلومات الأخرى ، لتوفير نظرة واقعية وواضحة لإدارة المنشأة عن تكاليف منتجاتها ومدي ارتباطها بكيفية استهلاك مواردها في دعم أدائها وتحقيق الميزة المستدامة وزيادة قدراتها التنافسية، وتوصل البحث من خلال الاراسة الميدانية علي عينـة من المنشآت الصناعية المصرية إلي أن تحقيق التكامل بين نظام تخطيط موارد المنشأة ونظام محاسبة استهلاك الموارد يساهم في تحقيق الميزة التنافسية المستدامة لمنشـآت الأعمال الصناعية ويدعم قدرتها التنافسية ، حيث إن تطبيق نظام تخطيط موارد المنشأة بصورة نظم مثالية يفرض علي إدارة 
المنثآت الانتقال من التقليدية إلي نظم متقدمة قادرة علي التكيف مع التغيرات التي تحدث في بيئة التصنيع الحديثة وهو ما يمكن تحقيقه من خلال محاسبة استهلاك الموارد. 5. دراسة (Maki Yilmaz 2017 و Mehmet Ceran) هدفت الدراسة تناولت أوجه الاختلاف بين مدخلي التكلفة علي أساس الحجم و RCA في الابتكارات والتغيرات التنظيمية ، وتوصلت

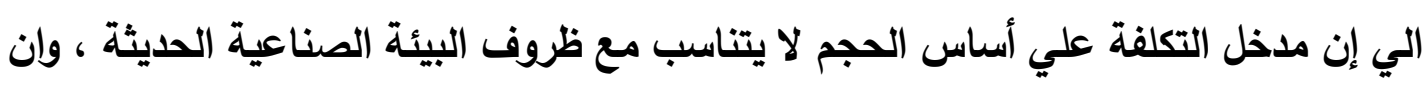
نظام RCA يعد مدخلاً لمحاسبة التكاليف الاستراتيجية ، ويوفر معلومات ملائمة وموثوقة لإني يمكن الاعتماد عليها في اتخاذ القرارات التي تدعم المركز التنافسي للمنشأة. 6. دراسة (Mostafa Al-Qady., \& Said El-Helbawy, 2016) هدفت هذه الاراسة إلى تناول وتحقيق التكامل بين أسلوب التكلفة المستهذفة ومدخل محاسبة استهلاك الموارد

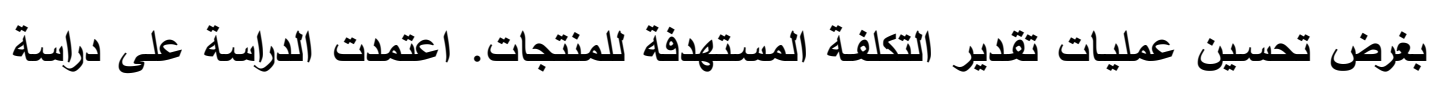
حاله لمصنع العربي للفسالات نصف أوتوماتيك. وقد توصلت الدراسة إلي أن التطبيق الفعال لأسلوب التكلفة المستهدفة يتطلب وجود نظام تكاليفي قادر علي إمداد معلومات ملائمة ودقيقة وفي التوقيت المناسب عن تكلفة المنتجات المستقبلية للشركة، بالإضافة إلي توفير بيانات بخصوص استهلاك الموارد وسلوك التكلفة بهلف تحويل التركيز من متابعة التكلفة إلي متابعة كميات الموارد من خلال نموذج كمي، ويعتبر مدخل محاسبة استهلاك الموارد هو النظام الأفضل القادر علي توفير مثل هذه المعلومات من خلال العمل علي توفير هياكل التكلفة ودئ مدئ لبدائل التصميم المختلفة. 7. دراسة (Hasan Ozyapici, 2016): هدفت هذه الدراسة إلى تناول الفرق بين نظم التكاليف التقليدية ومحاسبة استهلاك الموارد في تخصيص التكاليف، وتوضيح كيف يتم معالجة الطاقة

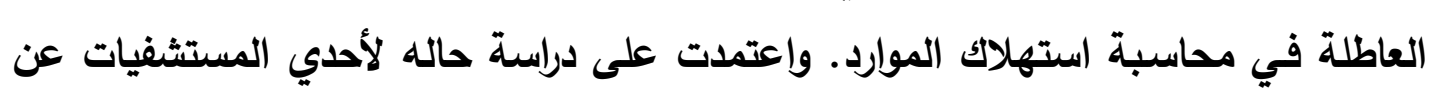

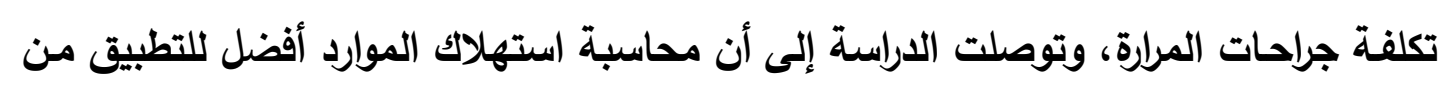

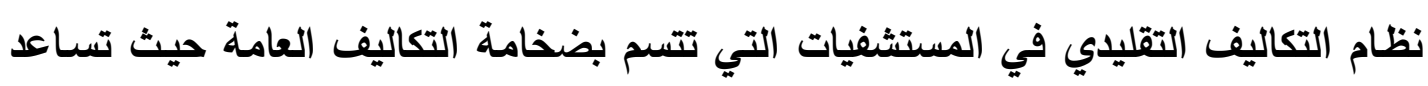
في التخصيص الدقيق للتكاليف العامة من خلال استبعاد تكاليف الطاقة غير المستفلة، وهو ما ظهر من خلال إخفاض تكلفة جراحات المرارة عند استخدام محاسبة استهلاك الموارد مقارنة بالنظام التقليدي حيث تجعل الطاقة غير المستغلة واضحة للمديرين. كما أثشارت النتائج إلى أن تطبيق محاسبة استهلاك الموارد يؤدي إلي التسعير التنافسي للخدمات الصحية، حيث الطئل 
يؤدي فصل التكاليف المتغيرة عن الثابتة إلي مساعدة الإدارة في التسعير، ومن خلال مقارنة

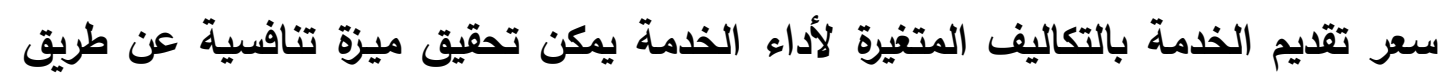
تقديم خدمة بسعر أقل من المنافسين. 8. دراسة (2016, Mohamed Elshahat)، هدفت الدراسة الي التعرف علي إمكانية تبني تطبيق مدخل RCA وإيضاح مفهومة ، ومكوناته ، ومميزاته ، وتحديد مشاكل تطبيقه في بيئة

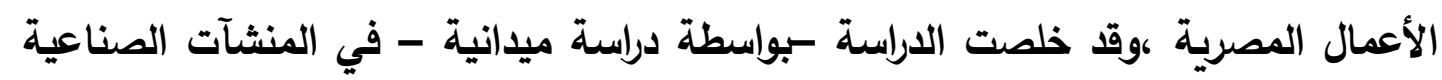

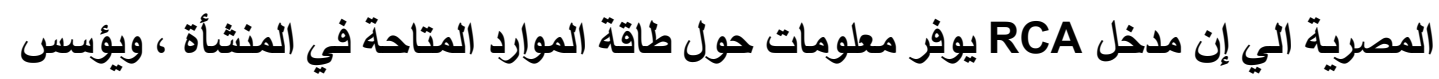
علاقة بين الموارد ومجمعات التكلفة علي أساس كمي ، بما يمكن من توفير نظرة مستقبلية ، ويميز بين الطاقة العاطلة والمستغلة ، وبالتالي تواجه تطبيق مدخل RCA في بيئة الإعمال المصرية منها مقاومة الموظفين بسبب نقص المعلومات عن الأساليب الجديدة ، نقص الخبرة ، القلق من فثل استخدام أساليب المحاسبة الإدارية الحديثة، ندرة الأبحاث العلمية.

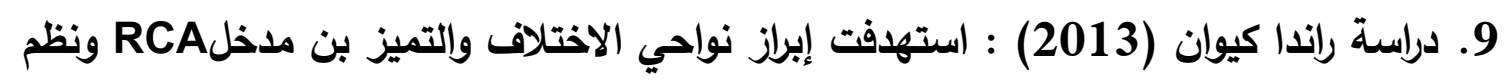
التكاليف المطبقة حاليا في الوحدات الاقتصادية، لتحقيق أهداف نظم إدارة التكلفة في بيئة

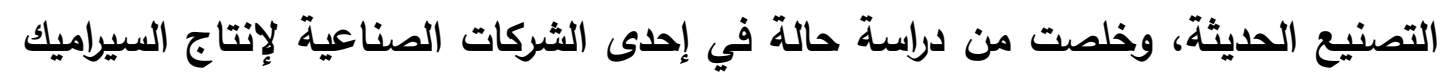

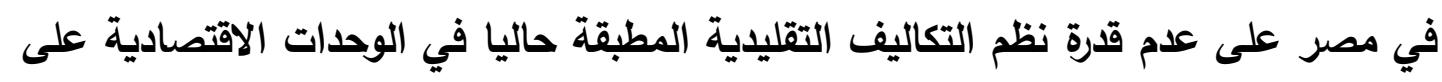
تلبية احتياجات نظم إدارة التكلفة في الظروف الراهنة، وأوضحت قدرة مدخل RCA على التظلب على أوجه القصور الموجودة في نظم التكاليف المطبقة في الوحدات الاقتصادية بواسطة تزويد المديرين بمعلومات أكثر دقة واعتمادية لاتخاذ القرار. 10. أوضحت دراسة فتحي السوفيري وفها النافع (2013) أن تزايد معدلات استخدام هذه الألية في الصناعة من عام لأخر ، أدت إلى تزايد نسبة التكاليف غير المباشرة بنسبة تقترب من ثلثي

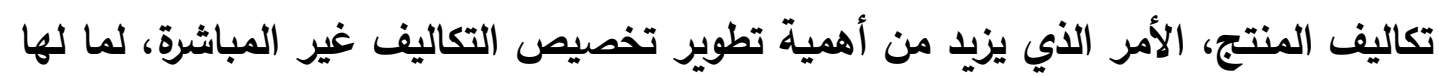
من تأثير كبير على جودة المعلومات التكاليفية التي يجب توافرها لمتخذي القرارات.

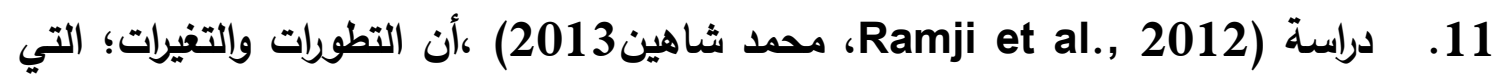
حدثت في البيئة الصناعية الحديثة، وما ترتب عليها من زيادة حدة المنافسة، والتطور

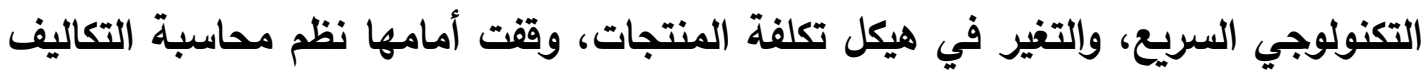
التقليدية عاجزة عن توفير احتياجات تلك التطورات والتغيرات، ولخصت أهم الانتقادات التي ولئي 
استخدام مدخل قياس التكاليف للمحاسبة عن استهلاك الموارد(RCA) ......... د.. ايناس جمعه شكر

وجهت للمدخل التقليدي في مجال تخصيص التكاليف غير المباشرة في علم الدقة في القياس

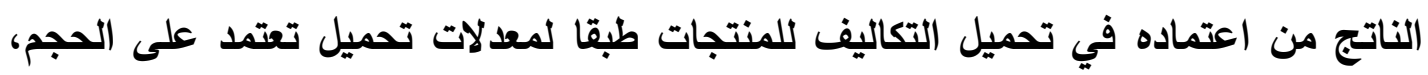
وتجاهل الجزء غير المستغل من طاقات الموارد، وإعتبار جميع تكاليف الموارد تكاليف منتج، وعلدم ملاءمة المعلومات التي يقدمها لاتخاذ القرارات في ظل بيئة التصنيع الحديثة.

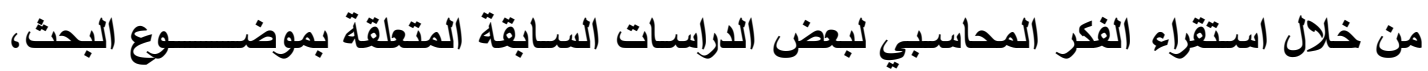

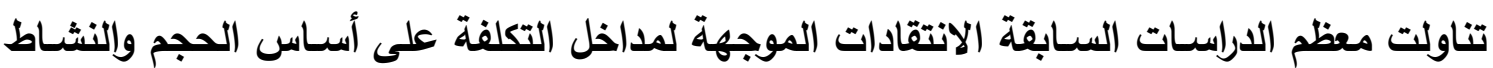
التي كانت الدافع للبحث عن مدخل تكاليفي يعالج تلك الانتقادات، ويعتبر نظام محاسبة استهلاك الموارد هو الجيل القادم لإدارة التكلفة ، حيث يمثل مساهمة ملموسة نحو تحسين مخرجات نظام التكاليف مــن خــلال التخصــيص الدقيق للتكاليف ، وقدرته علي توفير معلومات تثـــيلية واستـراتيجية تسـاعد الإدارة في اتخاذ القرارات علي المدي القصير والبعيد ، بما يسهم في زيـادة

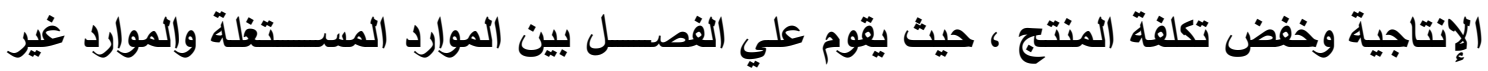

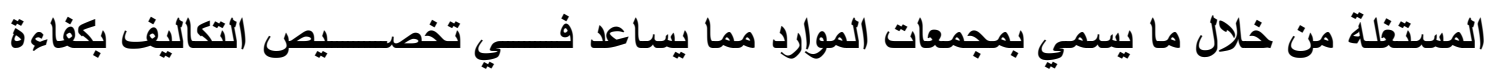
وتخفيض تكلفة المنتجات ، وبالتالي دعم الميزة التنافسـية للوحدات الاقتصــادية ـ ـواســتكمالا

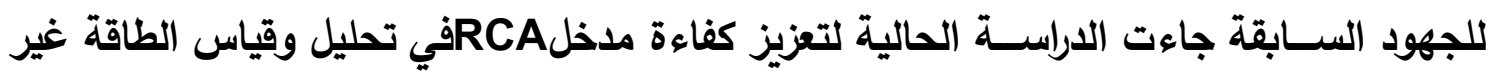
المسـتفلة من أجل تحسين جودة معلومات التكلفة، واختبار آثار تطبيق ذلك في بيئة الصـناعة

المصرية.

ثانياً :- الأسس التي يقوم عليها مدخل محاسبة استهلاك الموارد (RCA): يستند نمزجه التكلفة اعتماداً علي تدفق الموارد بين مجمعات الموارد مع تصنيفها نسبية

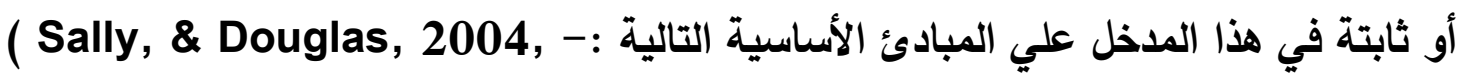
p:22), (Okutmus, 2015, p:47) (Syed\& Moosa , 2011, p.755)

الثكل رقم (6) الي دور محاسبة استهلاك الموارد ، في إدارة الطاقة حيث يتم إدارة الطاقة ، Merwe, 2008 (بواسطة مدخل محاسبة استهلاك الموارد ، وكيفية استهلاك الموارد. (Keys \& 


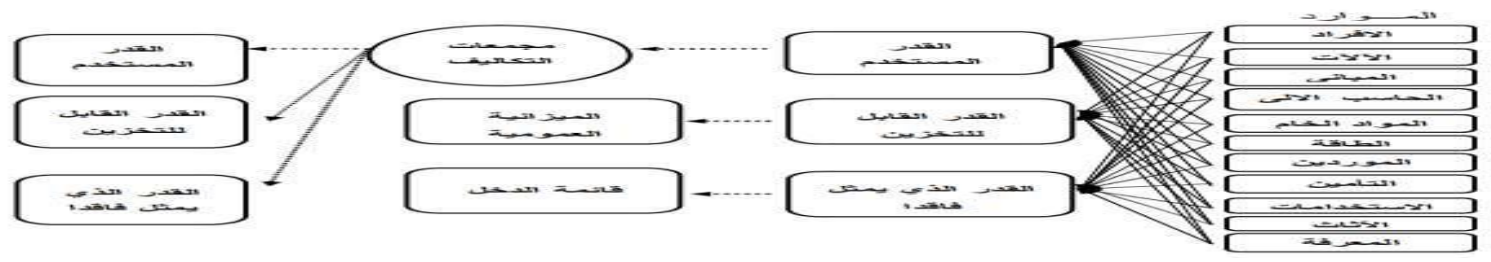

شكل رقم (2) دور محاسبة استهلاك الموارد في إدارة الطاقة

(MC Nair 2007, p.17) : المصدر

1-مسبب (محرك) التكلفة الخاصة بالمواردResources Cost Driver: يتطلب هذا المبدأ إن يكون تدفق الموارد كافة التكاليف المرتبطة بها مستخدمة لتعكس علاقة السبب - الأثر لترادي Cause - Effect علي التخصيص التعفي Arbitrary Allocation للتكاليف بين مجمعات الموارد ، ويستند مبدأ السببية علي مصطلح للصلة Relevant Term وهو المصطلح الذي أوجد مفهوم التكلفة القابلة للتبرير Attributable والتي تعتبر التكلفة السليمة للمحاسبة الإدارية اللازمة لترشيد القرار ، كما يعبر عن حجم الموارد التي يجب أنفاقها داخل مجمع الموارد للوصول الي حجم معين من المخرجات المتوقع من المورد ، مثل (ساعات العمل المباشر، ساعات تثغيل الآلات ... الخ) . معنم من المعات

2-مجمعات الموارد Resources Pools: يركز مدخل المحاسبة عن الاستهلاك بشكل أساسي على الموارد حيث تتمثل مجمعات الموارد في تجميع للموارد المتجانسة داخل مجمع واحد والذي ئي يتمثل في مجموعة من عناصر الموارد مثل (الأفراد، الآلات، والمعدات، الخدمات المختلفة

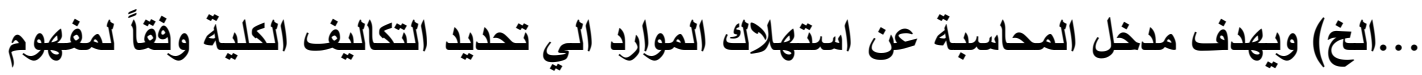
إن وجود التكاليف Costs ترجع الي إنها خدمة الموارد Resources، ومن ثم فان التبع والفهم الجيد لسلوك الموارد يؤدي حتما الي التتبع والفهم الجيد لسلوك التكاليف في الثركة. 3esponsiveness الاستجابة: يحد مبدأ الاستجابة سلوك التكلفة وفقاً لمبدأ السبية، حيث تعتبر الاستجابة بمثابة المكمل والمفسر للسببية، فالاستجابة تحكم علاقات الثبات والنسبية في توقعات الموارد والتي يجب أن تكون كمية، وبالتالي فإن المبدأ يسمح بتوضيح العلاقات التبادلية بين التكلفة الكلية والحجم الثكلي عندما تكون درجة تعقيد الإنتاج عالية. 4-مجمعات تكلفة الأنثطة /العمليات:Activity (Process Pools) تتمثل مجمعات تكلفة الأنثطة أو العمليات في عملية معينة من عمليات دورة الإنتاج، هذا المبدأ مستمد من مدخل

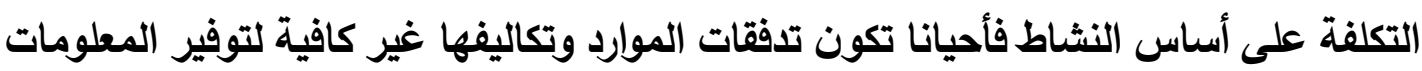


المطلوبة لمتذذ القرار، ولذلك فإن الأنثطة تعرف بثكل دوري أو مستمر لتشرح ما هي الأنثطة التي كان تنفيذها سبباً لاستهلاك الموارد بين مجمعات الموارد.

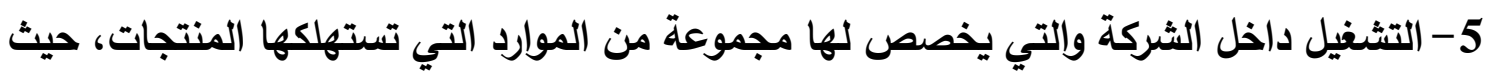
يتوقف استهلاك الموارد على عاملين هما: - - مور الأنثطة في استهلاك الموارد. - - التأكيد على العلاقات التشابكية وإلمتداخلة بين الموارد وبعضها البعض اولهورد بين الموارد والأنثطة (مسببات التكلفة). يتصف نظام محاسبة استهلاك الموارد بمجموعة من الخصائص التي تميزه عن غيره من نظم

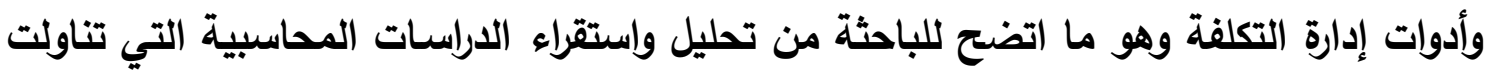
مدخل RCAومن هذه الخصائص (Sally, 2004. pp. 21 - 28): 1- النظرة الثمولية للموارد: - (صفاء عبد الدايم، 2014، صدمدهن (240:243) حيث يركز النظام علي الموارد بمفهومها الثامل ويعمل علي تجميع الموارد في مجمعات موارد، يتضمن كل منها الموارد

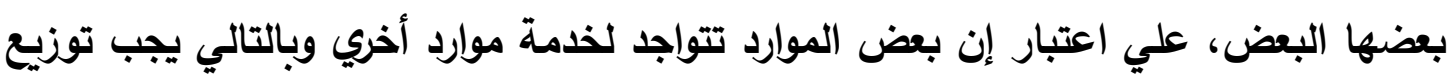

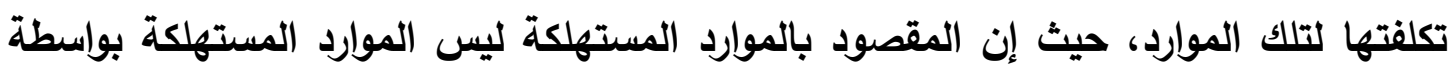
النشاط فقط ولكن أيضاً الموارد المستهلكة بواسطة موارد أخري. 2- مدخل للتخطيط الفعال للموارد : حيث يتميز بإمكانية الاعتماد عليه في عملية التخطيط التثغيلي والاستراتيجي بغرض حساب كل من كميات الموارد وما يرتبط بها من قيم محددة وضرورية لتدعيم تنفيذ المعلومات اللازمة للتخطيط سواء علي المستوي الاستراتيجي أو التكتيكي أو التثغيلي للشركة ، وكذلك توفير المعلومات المالية وغير المالية في ضوء الاتجاهات المستقبلية

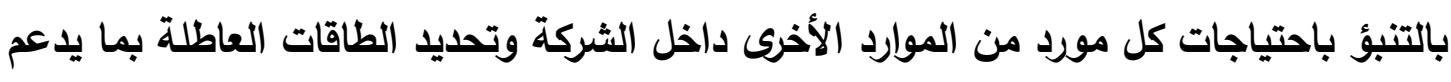

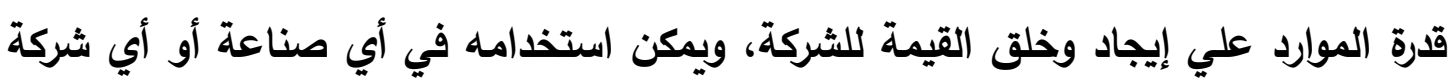

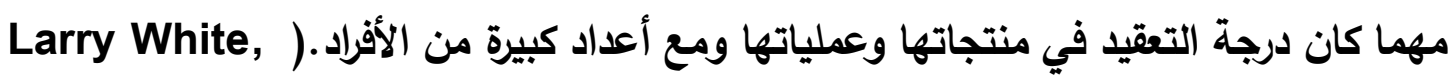
(2009, p. 64 الموارد" Quantity Resource" وإلتكاليف المرتبطة بها. 3- مدخل للرقابة الذاتية علي الموارد : حيث يتميز مدخل المحاسبة عن استهلاك الموارد بالاهتمام بتوفير المعلومات اللازمة في مجال الرقابة الذاتية علي أنثطة الثركة سواء في الآجل القصير 
أو الآجل الطويل حيث أن مسببات حدوث التكاليف والرقابة عليها يحدث علي مستوي الموارد وليس علي مستوي النشاط، مما يساعد علي ترشيد استهلاك الموارد والسيطرة علي الطاقة

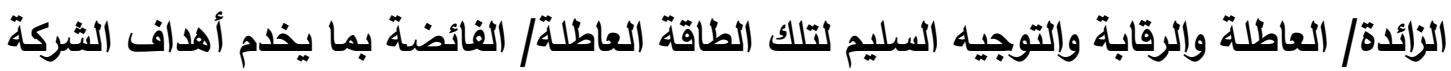
في الرقابة الذاتية علي الموارد، حيث يتعامل المدخل مع التقلبات في حجم المنتج النهائي أو الخدمة النهائية دون تثويه لعملية تخصيص تكلفة المنتج. 4- مدخل لاتخاذ القرارات الملائمة: - حيث يتميز المدخل بالاهتمام بتوفير المعلومات الملائمة في

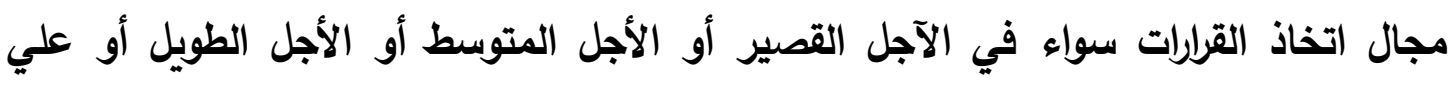
المستويات الاستراتيجية والتكتيكية والتشغيلية للشركة وبما يحقق دقة اكبر في التكاليف التي التي التهل تحقق قيمة مضافة ومنافع مقدمة للعميل، بالإضافة الي يوفر المعلومات اللازمة في جميع المستويات الإدارية، فعلى المستوى الاستراتيجي يساعد على اتخاذ قرارات دخول / خروج من لن لئ

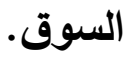

5- مدخل ديناميكي: تتمثل الديناميكية في دراسة تأثير البدائل المختلفة من الأنثطة والعمليات المتوقعة ومدي وجود فاقد أو فائض مما يؤدي الي ترشيد تكاليف الطاقة المستخدمة والتركيز على التكاليف التي تحقق قيمة، يساعد في تحقيق قرارات الثراء والإنتاج، وفهم الطبيعة الأولية للتكلفة، وقرارات تجنب التكاليف الثابتة، والمستوى التشغيلي ويساعد في إدارة الطاقة والأفراد والمعدات من منظور اقتصادي. وكذلك يمكن التظلب على تعقيدات النموذج من خلال التكامل

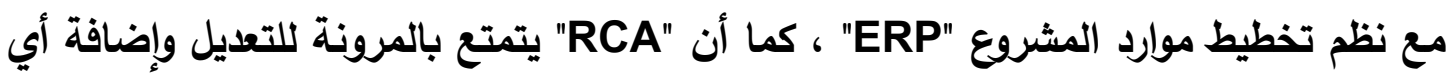
تعديلات عليه. 6- مدخل متكامل وشامل: يتميز مدخل المحاسبة عن استهلاك الموارد بأنه مدخل متكامل مع كل نظم التكاليف الأخرى، كما يتميز في كونه مدخل شامل يركز على الموارد حيث يؤدي الي التحديد الثامل للتكاليف الكلية للموارد والذي يتضمن مجموعة من الأنظمة التكليفية الأخرى مثل (التكلفة

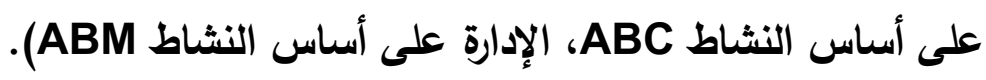
7- مدخل لقياس الأداء: يوفر مقاييس دقيقة للأداء من خلال تحليل الانحرافات وفصل الكمية المستهلكة من الموارد عن القيمة المناظرة لها، وبالتالي يوفر معلومات أكثر مصداقية في تحليل الانحرافات مما يدعم مدخل محاسبة المسئولية على مستوي جميع وظائف الثركة. 
8- مدخل لاعم فلسفة التوجه نحو العميل: وذلك من خلال الإدارة السليمة للموارد المستثمرة وتوجهها نحو الأنثطة ذات القيمة المضافة التي تحقق المنافع للعميل وفق توجهات السوق، وله مع تخفيض الاستثمارات في الأنثطة التي لا تضيف قيمة للعميل والتخلص من الفاقد، مما يترتب عليه تحسين أداء أنشطة الثركة ذات القيم المضافة للعميل، وتحقيق اعلي درجات التوافق بين التكاليف وأنثطة الثركة وتفضيلات القيمة بالنسبة للعملاء.

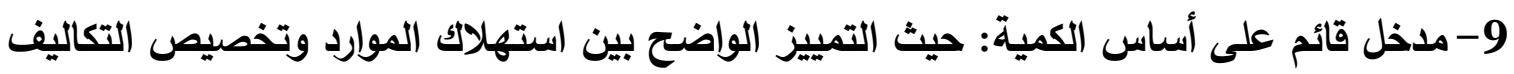
والذي يمكن إن يسهل تحليل الانحرافات من خلال فصل الكمية المستهلكة عن القيمة حيث إن إن التتبع المستمر لبيانات الاستهلاك الفعلي يتطلب فقط المحاسبة عن الكميات المحددة في العلاقة بين الموارد وبعضها البعض، حيث السهولة في تحليل الطاقة طالما إن تكاليف الموارد تخصص عند استخدامها فقط. كما يزودنا المدخل بالمعلومات عن هامش المساهمة وتقارير الربحية عند كافة المستويات داخل المنشأة وضمن مختلف الأبعاد (المنتج - الخدمة - العملاء - قنوات

$$
\text { التوزيع.... الخ). }
$$

على الرغم من المزايا التي يتمتع بها أسلوب محاسبة استهلاك الموارد إلا أن هناك بعض الصعوبات التي تقف عائقا في طريق تطبيقه في منشآت الأعمال ومنها: - - - ارتفاع تكاليف التطبيق. - - يحتاج إلى الكثير من الوقت اللازم للتخطيط المطلوب.

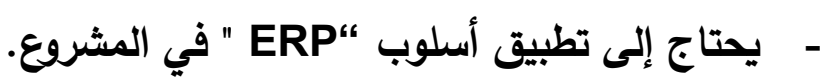
- وجود أمثلة قليلة عن المنشآت التي تطبق أسلوب محاسبة استهلاك الموارد حتى وقتنا الحاضر على الرغم من أن أسلوب محاسبة استهلاك الموارد يوفر تحسينات ملحوظة على العمليات وبيانات الكلفة خاصة في المنشآت ذات العمليات المعقدة إلا أنه يتطلب تدريبا كبيرا وتصميم النماذج والتطبيقات وخبرة متخصصة بخلاف ما هو معروف حول أنظمة التكاليف في الولايات

ثانياً:- دعم القدرة التنافسية باستخدام المحاسبة عن استهلاك الموارد :-

تعتبر المحاسبة عن استهلاك الموارد أحد المداخل الحديثة في إدارة التكلفة ويؤدي استخدام مدخل المحاسبة عن استهلاك الموارد الي إدارة التكلفة بثكل جيد ومن ثم دعم القدرة التنافسية 
للمنشأة من خلال تحقيق المجالات التالية: (محمد الصغير ،2011، ص 100:88)، (على

$$
\text { أ. الثطبي ،2016، صجال تخفيض التكلفة: - }
$$

إن مدخل المحاسبة عن استهلاك الموارد يؤدي الي زيادة قدرة المنشأة على الإدارة الأفضل

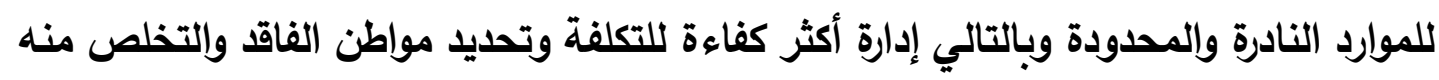
عن طريق تحديد مناطق عدم الكفاءة في استخدام الموارد ومن ثم الوصول الي هدف تخفيض التكاليف. ب. في مجال تحقيق هدف تحسين الجودة: يساهم مدخل المحاسبة عن استهلاك الموارد في تحقيق هدف تحسين الجودة من خلال قدرته

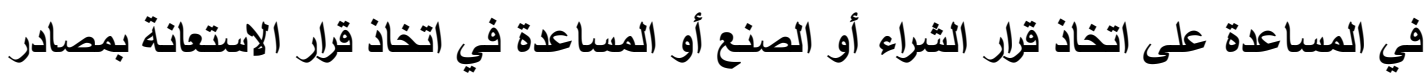
خارجية من خلال تركيزه بصفة أساسية على الموارد من منظور شامل واهتمامه بالعلاقات التبادلية بين الموارد وبعضها البعض مما يدعم إدارة وتنفيذ برنامج الجودة الثاملة. ج. في مجال الاستغلال الأمثل للموارد: يساهم الاستغلال الأمثل للموارد في دعم القدرة التنافسية للمنثاة، حيث يعتبر مؤشر للتأكد

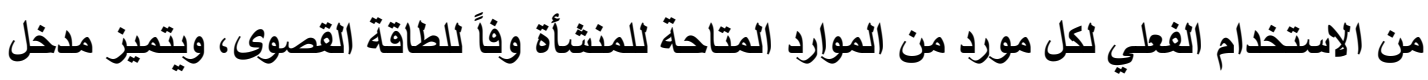

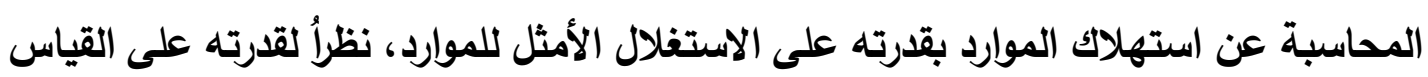
الدقيق للطاقة العاطلة عن طريق التتبع التفصيلي لاستهلاك كل مورد من الموارد المتاحة وتمييز الطاقة العاطلة، ومن ثم توصيل معلومات دقيقة لاتخاذ القرارات المتعلقة بثأنها. د. في مجال دقة قياس التكاليف: يستطيع مدخل المحاسبة عن استهلاك المواد من خلال توفيره للاقة في تبويب عناصر التكاليف الي تكاليف ثابتة ومتغيرة متناسبة مع حجم المخرجات أن يوفر بيانات تكاليفية دقيقة يمكن الاعتماد عليها لأغراض إجراء التحليل التفاضلي في الآجل القصير. هـ في مجال دعم اتخاذ القرارات: يتميز مدخل المحاسبة عن استهلاك الموارد بقدرته على توفير معلومات مالية وغير مالية

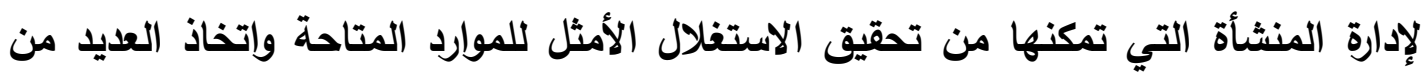


استخدام مدخل قياس التكاليف للمحاسبة عن استهلاك الموارد(RCA) ......... د.. ايناس جمعه شكر

القرارات المتعلقة بتخفيض التكاليف ومعالجة الطاقة غير المستغلة في مجالات أخري، مما يزيد من الزبحية وتحقيق ميزة تنافسية. كما يستطيع مدخل المحاسبة عن استهلاك الموارد أن يدعم اتخاذ العديد من القرارات من خلال توفير بيانات التكلفة الحدية لتركيز هذا النظام على هذا المفهوم حيث إن عملية تخصيص

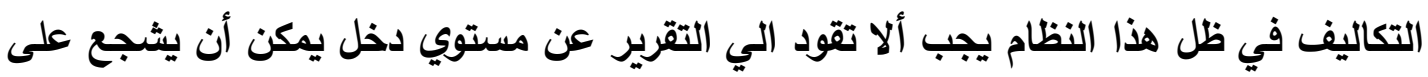
الإفراط في الإنتاج، بل إن نظام محاسبة استهلاك الموارد يؤكد على الإدارة الجيدة للموارد

ومنع الإفراط والثاقد في تلك الموارد. و. في مجال تعظيم قيمة العميل: -

إن مدخل المحاسبة عن استهلاك الموارد يدعم فلسفة التوجه بالعميل من خلال الإدارة السليمة للموارد المستثمرة وتوجيهها نحو الأنثطة الأساسية ذات القيمة للعميل تبعا لتوجهات السوق وتقليل الاستثمار في الأنثطة التي لا تضيف قيمة للعميل وتحقيق أعلي درجات التوافق بين تكاليف وأنثطة المنشأة وتفضيلات القيمة بالنسبة للعملاء، مما يجعل من القول بأن مدخل المحاسبة عن استهلاك الموارد يؤثر بشكل إيجابي على تعظيم قيمة العميل.

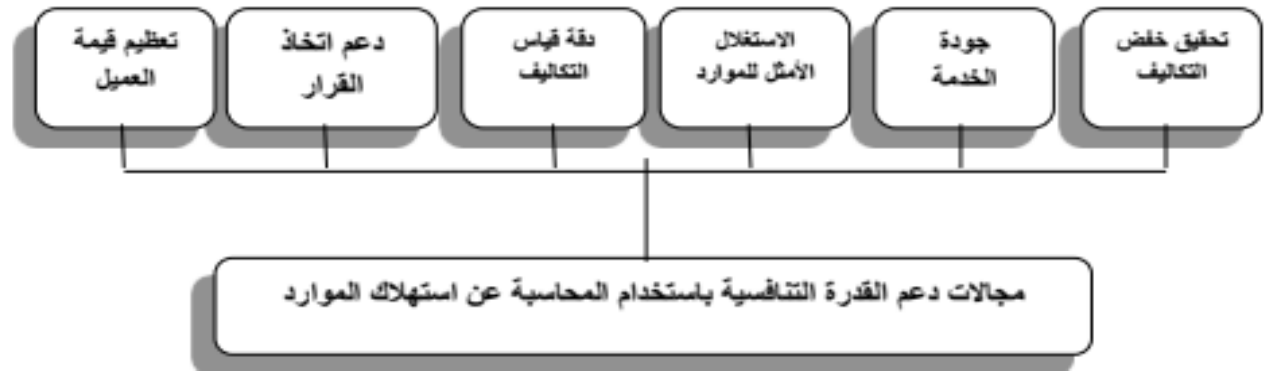

شكل رقم (3) دور مدخل المحاسبة عن استهلاك الموارد في دعم القدرة التنافسية

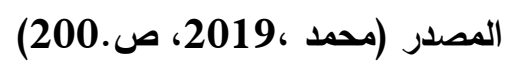

ويتبين مما سبق الدور البارز لمدخل المحاسبة عن استهلاك الموارد في دعم القدرة التنافسية من خلال قدراته وإمكاناته علي إدارة التكلفة بثـكل جيا ومن ثم تحقيق الاستغلال الأمثل للموارد

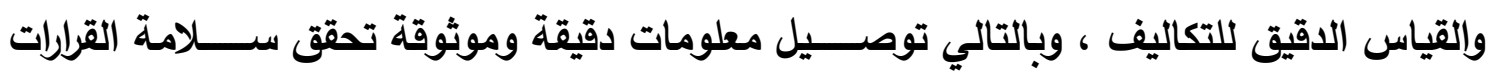
المتعلقة بمجالات تخفيض التكاليف ومعالجة الطاقة العاطلة في مجالات أخري ، كما يؤثر مدخل المحاسـبة عن اسـتهلاك الموارد علي تعظيم قيمة العملاء وتحسـين الجودة وإلتجديد والابتكار

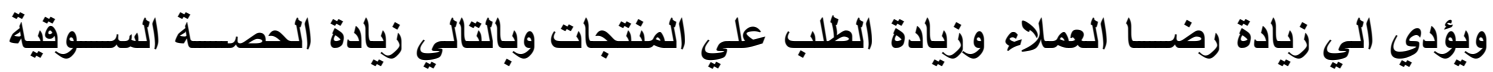
وزيادة الأرباح السنوية ومن ثم تدعيم القدرة التنافسية. 


\section{مجلة البحوث المالية والتجارية ـ المجلد (22) ـ العدد الثاني - إبريل 2021}

ويمكن توضيح دور مدخل المحاسبة عن استهلاك الموارد في دعم القدرة التنافسية من خلال

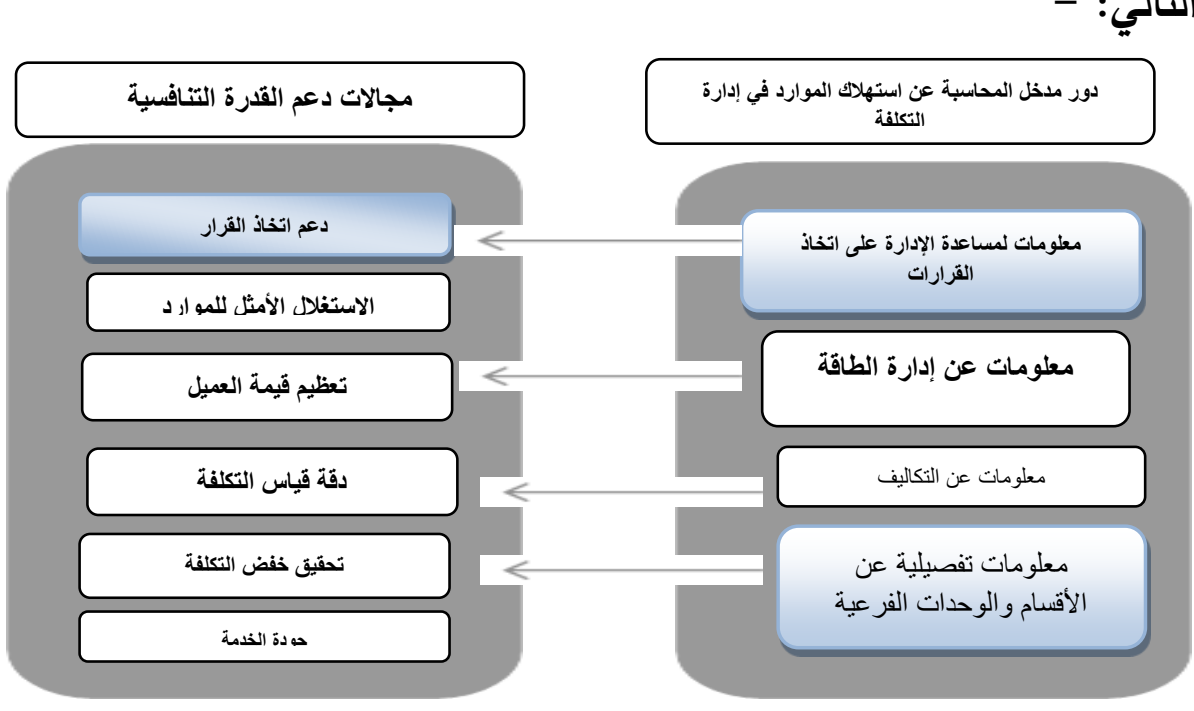

شكل رقم (4) دور الححاسبة عن استهلاك الموارد في إدارة التكلفة ومن ثم الوصول لاعم القدرة التنافسية المصدر (إعداد الباحث) (4) دو المدانة)

\section{القسم الثالث}

ممارسات إدارة سلسلة التوريد ودورها في دعم المركز التنافسي تتناول الباحثة في هذه الجزئية الإطار العام لإدارة سلسلة التوريد وأهم ممارساتها، والذي

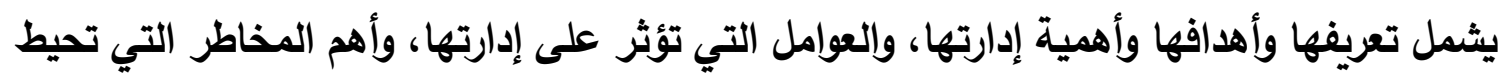

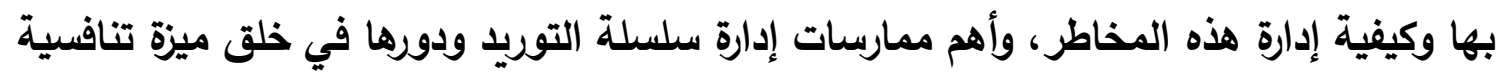


تعددت وتنوعت الدراسـات التي تناولت مجال إدارة سـلسلة التوريد ومجال المخزون، ويسعي هذا القسم الي التعرف على الإطار النظري لممارسات إدارة سلسلة التوريد من خلال تناول كلا من: أولا: مفهوم ممارسات إدارة سلسلة التوريد البيئية. ثانيا: مفهوم المسؤولية الاجتماعية. أولاً: مفهوم ممارسات إدارة سلسلة التوريد البيئية: -

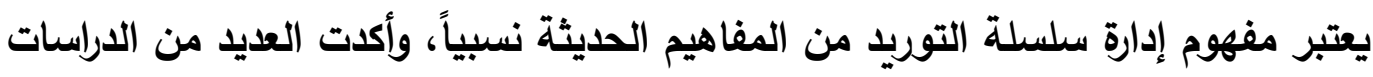
أن إدارة سلسلة التوريد أصبحت أكثر أهمية لمواجهة تحديات المنافسة، حيث تمكن أعضاء سلسلة التهاء

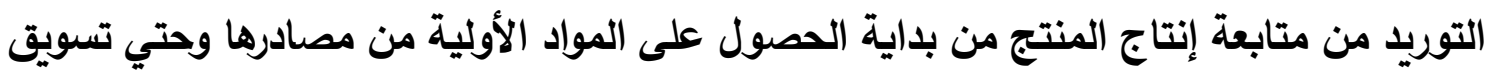


Institute of Management Accounting,(1999); المنتج ووصوله إلي العميل النهائي (2003), Mouritsen et al a ويتحدث مجتمع الأعمال في الوقت الحاضر عن إدارة سلسلة

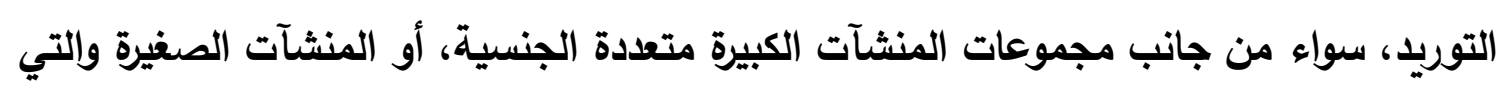

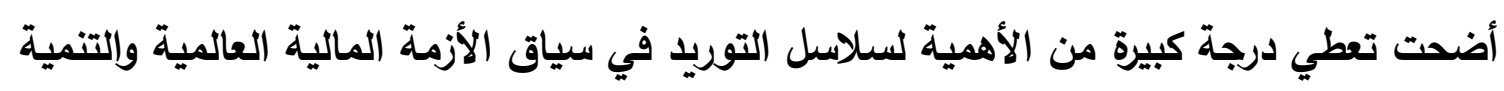
الاقتصادية والتي تحتاج إلي التغيير، فالمنشآت جميعها أعادت تركيزها مرة أخري تجاه سلاسل الاسل التهل التوريد (2013) Wei and Xiag

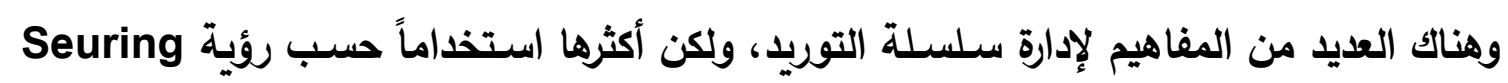

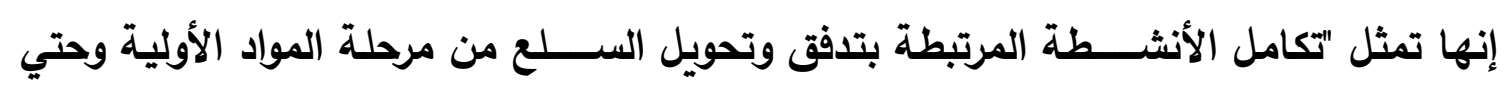

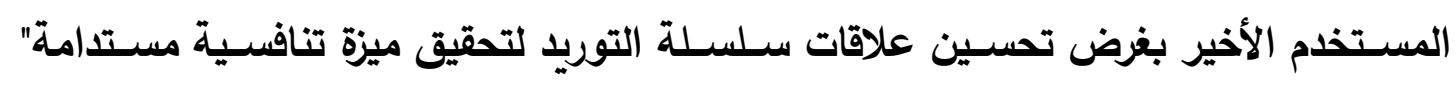
Wei and Xiag ويري (Seuring , 2002) الكامل لسلسلة التوريد والذي يشمل التخطيط, وإلتنسيق والتشغيل والرقابة وتعظيم الاستفادة من

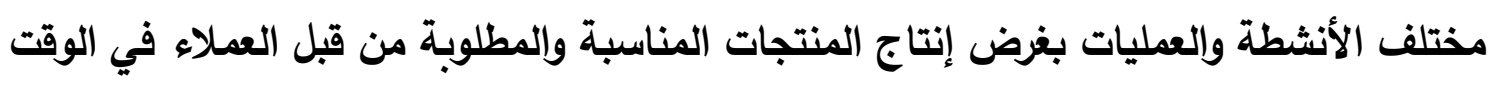

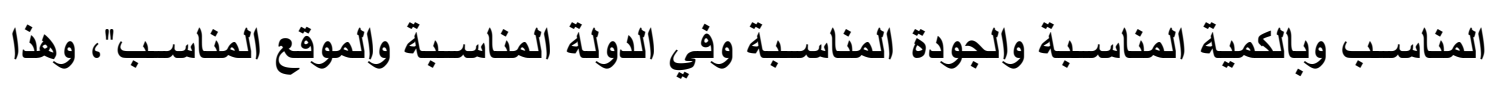
يتطلب رقابة جيدة لجانبين (2013) Wei and Xiag. • ت تدفق المعلومات ورأس المال والخدمات اللوجستية في السلسلة. • الأنثطة الإدارية المستمرة المرتبطة بشراء المواد الخام وتصنيع المنتجات الوسيطة والنهائية والمبيعات، لكل من الموردين والمصنعين والموزعين وتجار التجزئة وحتى العملاء النهائيين

$$
\text { داخل هيكل شامل لسلسلة وظيفية. }
$$

ويرى Kauffman and Crimi أن إدارة سلسلة التوريد تمثل "مدخل متكامل لإدارة شبكات

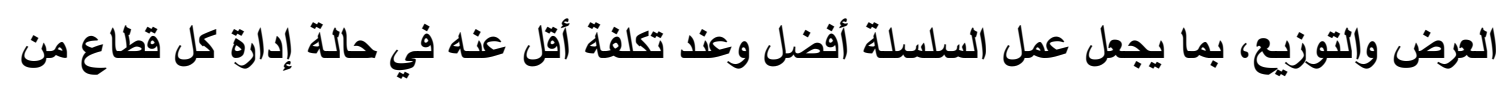

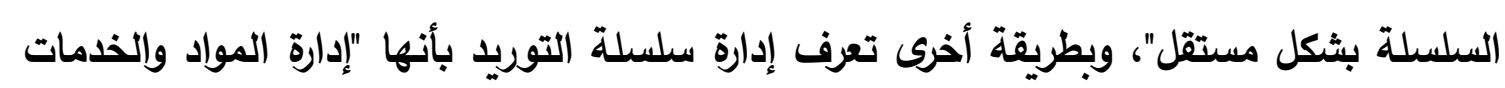

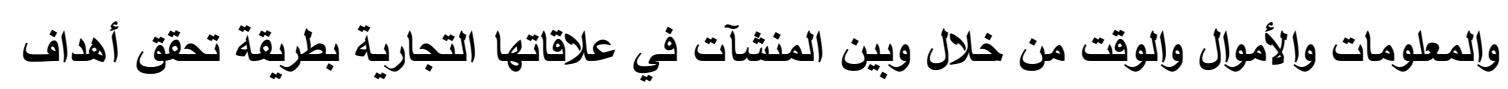
كل منها عند أقل تكلفة" (1998) Kauffman and Crimi ويرى Vokurka وآخرون وآخرون أن إدارة سلسلة التوريد تمثل "جميع الأنثطة المشاركة في تقديم منتج ممثلة في الحصول على المواد الخام وقطع الغيار، والتصنيع والتخزين وتتبع المخزون، مدخلات النظام وإدارة النظام، والتوزيع عبر جميع القنوات، التسليم للعميل، ونظم المعلومات اللازمة لمراقبة جميع هذه الأنثطة" 
(vokurka,et al., 2002) ، وقد أشارت العديد من الدراسات إلي أهمية إدارة سلسلة التوريد، وذلك كما يلي:-

1-دراسة (2004, Sarkis, and Zhu) : التي تستهاف الي تحديد العلاقة بين ممارسات إدارة سلسلة التوريد الخضراء وبين الأداء البيئي والاقتصادي ، كما تهاف الي التعرف علي التئي

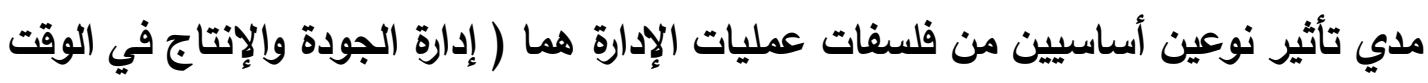
المحدد) علي العلاقة بين ممارسات إدارة سلسلة التوريد الخضراء وكل من الأداء البيئي

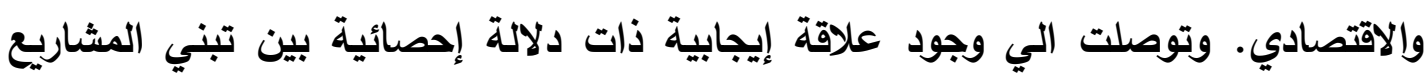

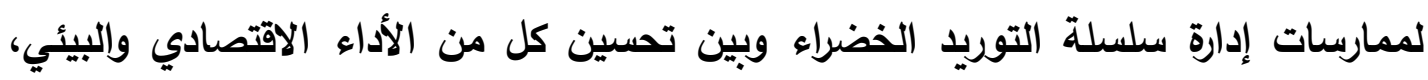
بالإضافة إلي وجود علاقة إيجابية ذات دلالة إحصائية بين ممارسات إدارة الجودة أكثر من المشاريع التي تمتلك مستويات منخفضة من تبني ممارسات إدارة الجودة.

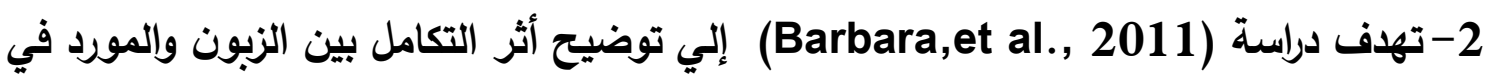

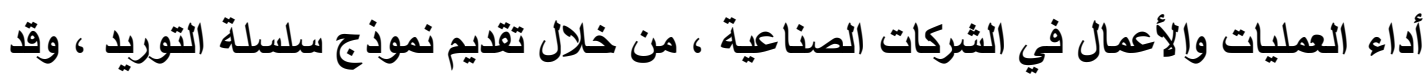
توصلت الدراسة إلي أن هناك علاقة مباشرة وذات دلالة إحصائية بين التكامل الداخلي وأداء العمليات في الثركات الصناعية ، ولم تظهر الدراسة أي أثر ذي دلالة إحصائية لتكامل المورد

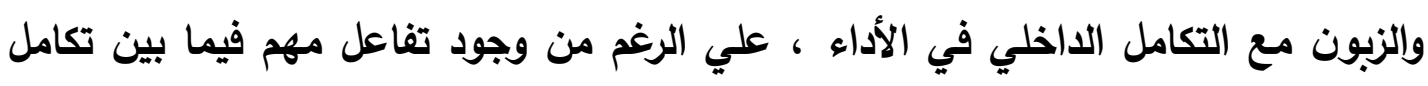
الزبون مع المورد ، كما توجد علاقة إيجابية بين التكامل الداخلي وأداء الأعمال. 3-3 دراسة (2013) Wei and Xiang استهدفت الدراسة تبيان أهمية ممارسات إدارة سلسلة التوريد سواء من جانب المنشآت كبيرة الحجم ومتعددة الجنسية أو المنشآت صغيرة الحجم في سياق الأزمة المالية العالمية. وركزت الاراسة على بعض ممارسات إدارة سلسلة التوريد وهي:

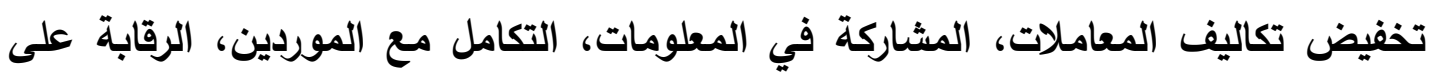

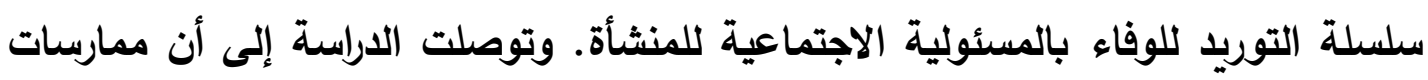
إدارة سلسلة التوريد تُكن المنثآت من الفهم الكامل لطلبات العملاء والسوق وألماعه وأن المشاركة بين أعضاء السلسلة والتكامل مع الموردين يحسن من تنافسية سلسلة التوريد ويقوي حساسيتها تجاه مخاطر السوق وتلبية احتياجات العملاء بثكل فعال ويحقق التنمية المستدامة للمنشآت في الأجل الطويل. 
4- أما دراسة ( Che-Fu Hsueh 2014 تهذف إلي التعرف علي الآثار الاجتماعية والبيئية للأنشطة الصناعية في سلاسل التوريد، حيث تناول مدي إمكانية تحسين المسئولية الاجتماعية للشركات (CSR) من منظور التعاون بينها وبين سلسلة التوريد ، وأثارت إلي انه يمكن

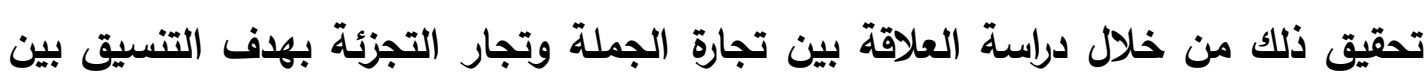
أعضاء سلسلة التوريد في حالة تذبذب كمية الطلب وارتفاع الحصة السوقية لتاجر التجزئة وتقاسم الأرباح بينهم.

وهناك أهداف عديدة لإدارة سلسلة التوريد، وتثمل الأهداف المشتركة: تقليل الفاقد والأنثطة غير المضيفة للقيمة، وسهولة الوصول للمخزون، وسرعة الاستجابة لطلبات العملاء (مما يؤدى

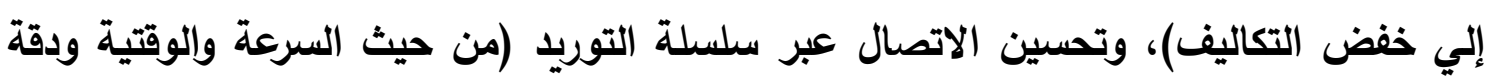

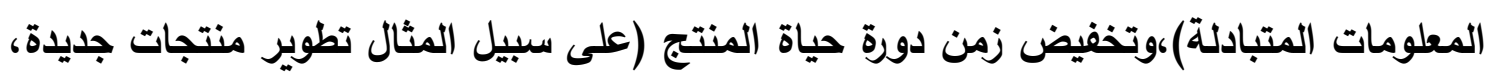

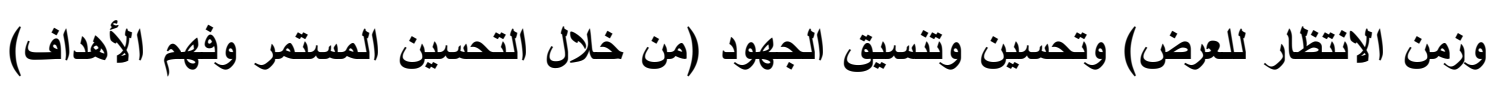

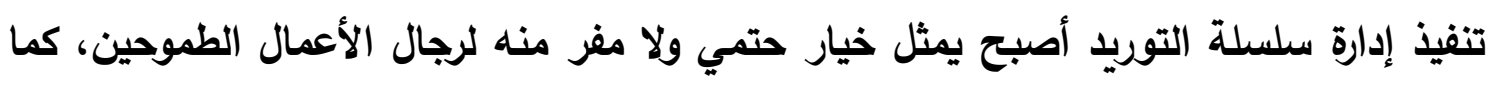
تهدف إدارة سلسلة التوريد على تخفيض التكاليف خاصة تكاليف الصفقات ، وكذلك تنفيذ إدارة

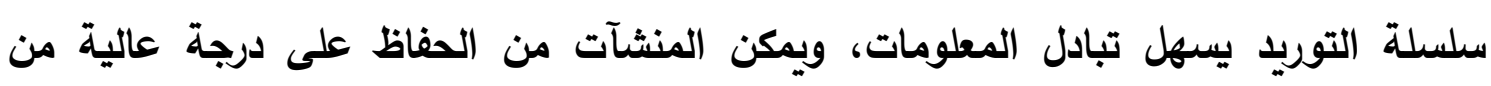

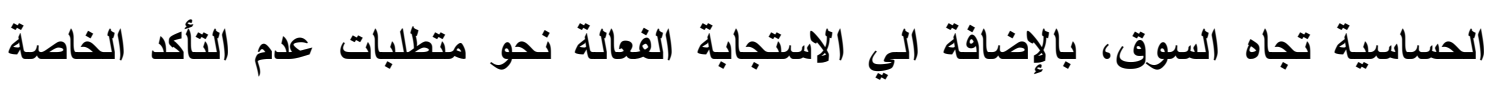
بالسوق.- توفير المعرفة من خلال تنوع الطرق والعمليات والتقنيات والأنظمة التي يمكن الأبنابه استخذامها في إدارة سلسلة التوريد مما يساعد على تحسين أداء سلسلة التوريد. ويرى Ellram أن أهداف إدارة سلسلة التوريد تثمل الحصول على التدفقات المستمرة للمواد Ellram حياة المنتج، تخفيض المخاطر وعدم التأكد وتحسين رضا العملاء، وأوضع أن الأهداف السابقة

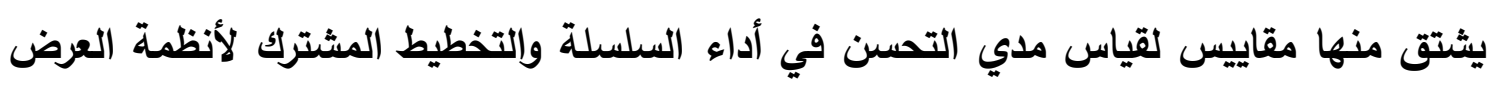
والمبادرات، وتخفيض عدد الموردين وشركات النقل وتخفيض تكاليف الاستثمار في المخزون.

(Ellrm 2002)

ثانياً: أبعاد ممارسات إدارة سلسلة التوريد البيئية ودورها في دعم المركز التنافسي: أهتمت العديد من البحوث والدارات العلمية بدراسة وتحليل أبعاد ممارسات إدارة سلسلة التوريد البيئية، هذا ومن خلال الاراسة المتأنية والمتعقة من الباحثين لمعظم التراث الفكري الذي تناول 
مجلة البحوث المالية والتجارية ـ المجلد (22) - العدد الثاني - إبريل 2021

أبعاد هذه الممارسات ، ويمكن توضيحها فيما يلي : البحوث التي ركزت علي دراسة وتحليل أربعة أبعاد لممارسات إدارة سلسلة التوريد البيئية: دراسة Sarkis, and Zhu ,2004 (الإدارة البيئية الداخلية - الإدارة البيئية الخارجية (الموردين ، العملاء)- التصميم الصديق للبيئة - استرداد الاستثمار)، ودراسة Ninlawan (الإدارة البيئية الاخلية - الثراء الأخضر - التصميم الصديق للبيئة - التعاون مع العملاء - استرداد الاستثمار)، ودراسة (Li et al., 2009) (الإدارة البيئة الاخلية - الثراء الأخضر - التعاون مع العملاء - التصميم الصديق للبيئة- استرداد الاستثمار). أ- ممارسيات إدارة سلسلة التوريد: -

عرف Hamister ممارسات إدارة سلسلة التوربا على أنها "مجموعة من الإجراءات أو Hamister(2012)"التصرفات الإدارية التي يتم إجراء ها لتحسين أداء سلسلة التوريد المتكاملة , وعرفها Moslem Ghatebi وآخرون بأنها "سلسلة من الأنشطة ينبغي القيام بها للتشجيع على الإدارة الفعالة لتكاليف سلسلة التوريد بالمنشأة" (2013) Moslem Ghatebi et al. وعرفها Talib للمنشأة وربطها مع العمليات الخارجية للموردين والعملاء والأعضاء الأخرين في سلسلة التوريد"

Talib ,et al .,2011

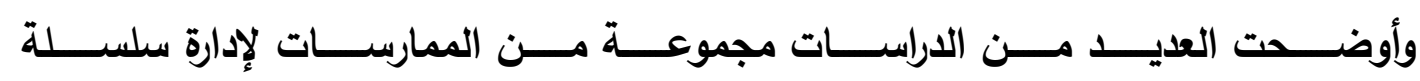
التوريد لتعزيز الميزة التنافسية لمنثآت الأعمال وأهمها: -

Strategic Partnerships and الثراكات والتحالفات الاستراتيجية مع الموردين -: Alliances with Suppliers

تعرف الثراكة الاستراتيجية مع الموردين بأنها "العلاقة طويلة الأجل بين المنشأة ومورديها والمصممة للاستفادة من القدرات الاستراتيجية والتشغيلية للمنشآت الفردية المشاركة في سلسلة التوريد لمساعدتها على تحقيق منافع كثيرة ومستمرة" Li S,et al.,2006 .وتبين في الوقت الحاضر أن المنشآت تحقق منافع أكثر إذا عملت مع بعضها عن الوضع الأي تعمل فيه بثكل مستقل، وتنظم الشراكات الاستراتيجية مع الموردين الجهود وتخلق شبكة من الموردين المؤهلين، وتثمل هذه الجهود جميع الأنشطة اللازمة لتحسين الأداء الحالي والمستقبلي للموردين، وتصمم الثراكات الاستراتيجية معهم لتحقيق التكامل بين القدرات التشغيلية والاستراتيجية للمنشآت والموردين للمساعدة على تحقيق منافع أكثر(Swink, and C., Wang (2007) وتعد الشراكة 
الاستراتيجية مع الموردين شراكة طويلة الأجل تشجع على تنسيق الجهود من أجل حل المشاكل

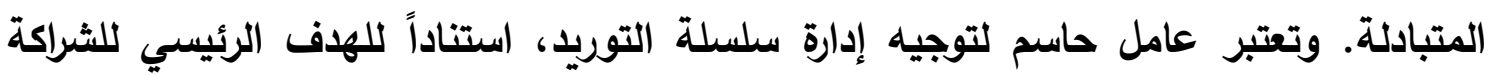

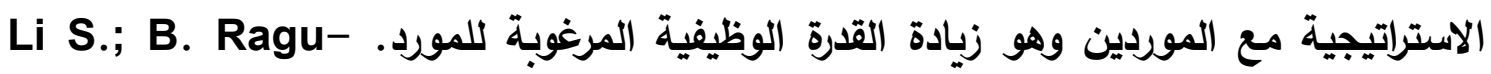
Nathan; T. Ragu-Nathan and S. Rao,(2006) الموردين أساس لتحديد مصادر التوريد الأساسية في سلسلة التوريد، كما يعتبر اختيار المورد

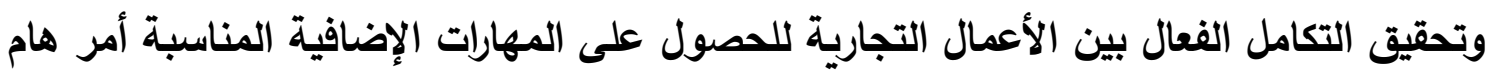
فamister,(2012). في هذا الإطار مما يحسن أداء سلسلة التوريد ويخفض تكاليفها

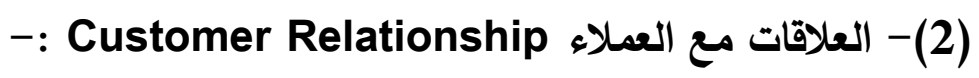
تعرف العلاقة مع العملاء بأنها "مجموعة كاملة من الممارسات والتي تستخدم لغرض إدارة

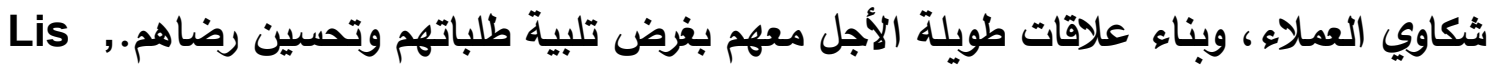

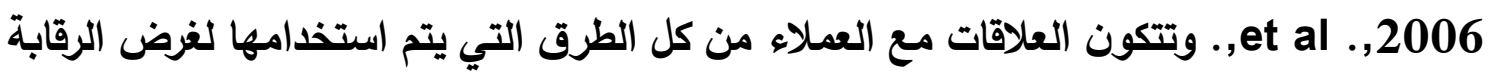
وإدارة شكاوي العملاء، وخلق علاقات طويلة الأجل معهم وتحسين رضاهم. وتعد إدارة علاقات العملاء عنصر هام لإجراء الإدارة الاستراتيجية للتكلفة وتحقق منافع جيدة. ويعد تطوير توقعات

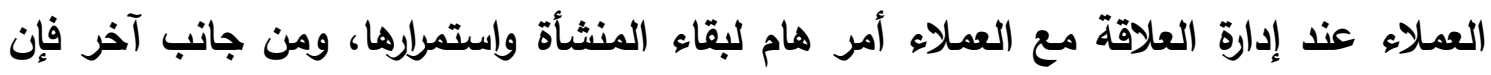
العلاقات الجيدة مع أعضاء سلسلة التوريد بما فيهم العملاء يعد أمر هام لإدارة التكلفة الاستراتيجية بنجاح، وهذا يثير إلى تميز المنتجات المقدمة لهم بالمقارنة بالمنافسين مما يخلق ميزة تنافسية، ، Li S.; B. Ragu-Nathan; T. Ragu-Nathan and S.Rao.(2006). أهداف تحسين العلاقات مع العملاء فيما يلى(2007):Niknia:• تحديد الفرص التجارية الجديدة وتقليل الفرص الضائعة. • • زيادة ولاء العملاء والحد من فقدهم. • تحسين خدمة العملاء وتحسين صورة المنشأة أمامهم. • • تخفيض التكاليف وزيادة الإيرادات.

(3)- مستوى مشاركة (تبادل) المعلومات: Level of Information Sharing) يشير تبادل المعلومات إلى المدي الذى يتم خلاله تبادل ونقل المعلومات على امتداد سلسلة التوريد. ويقلل التبادل الفعال المعلومات من سوء الفهم، ويحسن من اتخاذ القرارات ويحقق المرونة وسرعة الاستجابة.Hamister , (2012 ، ويوضح مستوي تبادل المعلومات قدرة المنشأة على سونى 
تبادل المعرفة والمعلومات مع الشركاء في سلسلة التوريد بفاعلية وكفاءة. ويعد تبادل المعلومات

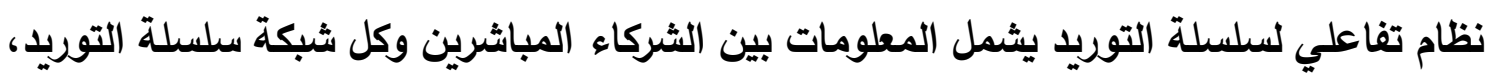
ويرتبط مستوى تبادل المعلومات بثكل وثيق بجودة النظام المحاسبي، والثركاء في سلسلة التوريد

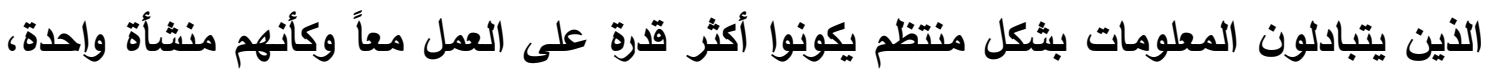

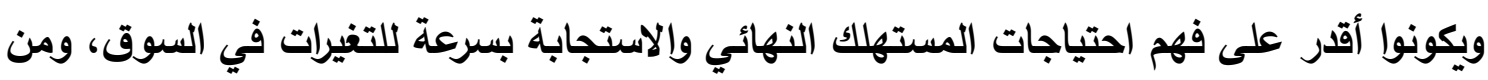
جانب أخر فإن الاستخدام الفعال للمعلومات المناسبة وفي الوقت المناسب من جاتب جميع الثركاء

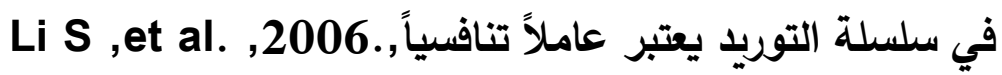
جودة المعلومات المتبادلة:Quality of Information Sharing :-

تثير جودة المعلومات إلي دقة ومصداقية المعلومات المشتركة بين الشركاء التجاريين. كما يعد تبادل المعلومات الدقيقة وفي الوقت المناسب من العوامل الهامة لتحسين الأداء على امتداد

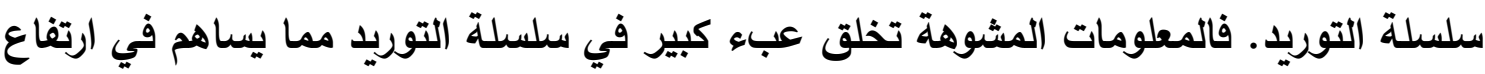
التكلفة Li S.; et al., 2006 رقابة المخزون، التخزين، توزيع المنتجات، وإدارة المعلومات هي أنثطة هامة في سلسلة التوريد. وبالتالي ينبغي أن تكون المنثأة قادرة على النظر في طلب المخزون وفقاً لعدد المنتجات، والقيام بتخطيط الإنتاج ووضع جداول الإنتاج قبل طلب المواد الخام وهذا يعتمد على جودة المعلومات المتبادلة بين أعضاء سلسلة التوريد( (Chin o. et al. , 2010)

\section{:Outsourcing التعهيد:- (5) - (5 )}

يعد التعهيد أحد المصطحات الجديدة التي أضيفت إلي المصطلحات المستخدمة في مجال تكنولوجيا المعلومات في ظل ما تثهره من تطور متسارع ومتنامي وأيضاً عابر للحدود، ويعرف التعهيد بأنه إسناد العمل الأي كان يتم أدائه سابقاً داخل المنشأة لمنشأة خارجية لتقوم بأدائه،

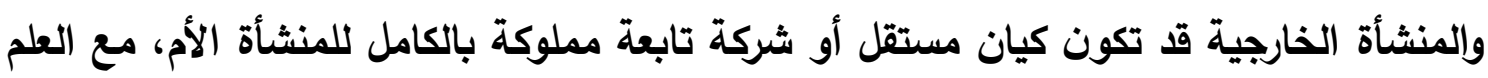

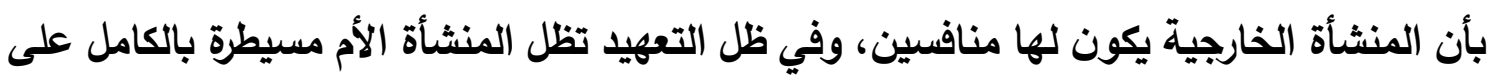
العملية من حيث تحديدها بدقة وتحديد ما يتعين القيام به. وفي الآونة الأخيرة اتسع مجال خدمات

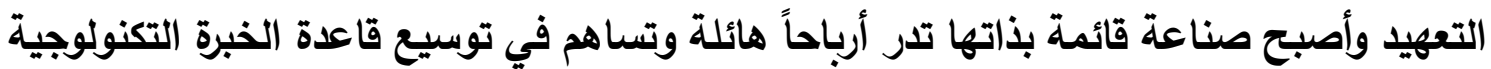

للقائمين بها. Nicholas and Amrik,(2004) 
ويوجد العديد من الأنثطة التي تقوم الثركات الصناعية بتعهيدها لعل من أهمها الثلاثة

$$
\text { Kenyon and Meixell,(2011) - أنثطة الآتية: }
$$

• النقل والتخزين: تنطوي عملية النقل علي نقل المواد الخام من المورد إلي المصـــع، وأيضـــا

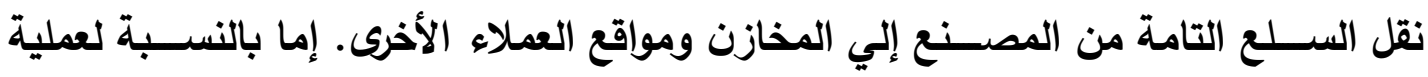
التخزين في الثــركات الصــناعية فهي تنظوي علي تخزين المكونات والمواد الخام واللســـع المصنعة. • التوزيع والتجهيز : تنطوي عملية التوزيع على إدارة الســلـع في المســار الفعلي بين الإنتاج والاستهلاك.

• التعبئة والتغليف: تنظوي عملية التعبئة والتغليف على تظليف المنتجات النهائية لحمايتها أثناء التعامل معها في المخازن ومركبات النقل.

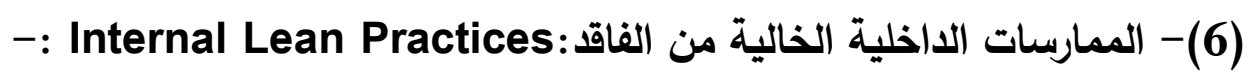
يعد استخدام الممارسات الداخلية الخالية من الفاقد(†) ممارسة أخري من ممارسات إدارة

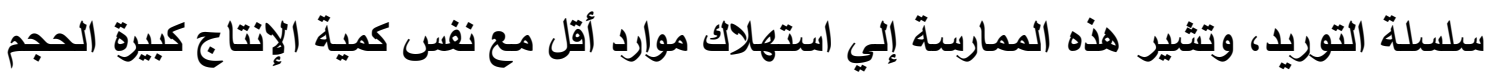
وعروض أكثر تنوعاً للعملاء. ولعل أحد الأفكار الأساسية في الممارسات الداخلية الخالية من الفاقد هو التخلص من الفائض (الإنتاج الزائد عن الحاجة)، فالإنتاج بدون فاقد وفي الوقت المناسب الونب


(Chin 0.,et al.,2010)190.

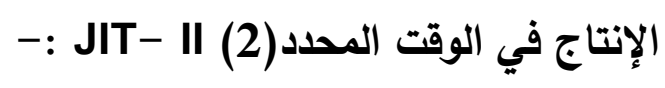

يعد الإنتاج في الوقت المحدد (2) مفروم الابتكرته شركة Bose - IIT الأمريكية وتم

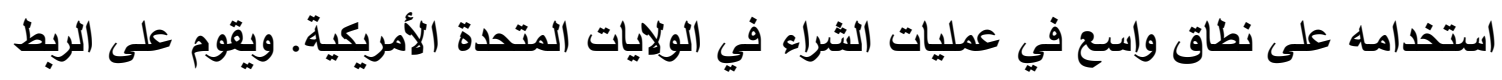

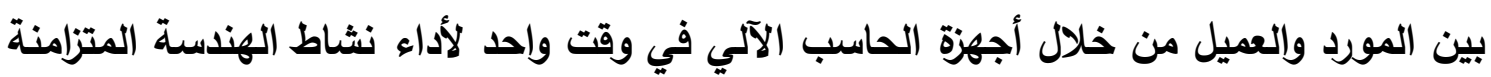
مع قسم هندة العملاء داخل شركة العميل لإدارة المخزون والتجديد التلقائي للمواد المطلوبة. ويستخدم هذا الأسلوب عندما يستخدم العميل عدد كبير من المواد وهنا يتطلب الأمر التعاون

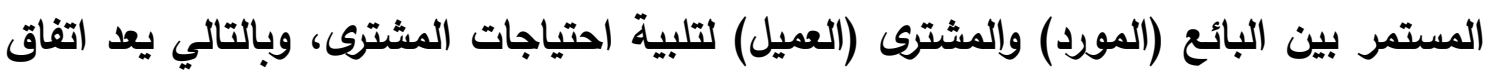
شراكة طويل الأجل مع العميل ينفذ في موقعه (1998) Kauffman, and Crimi. ب- إدارة سلسلة التوريد ودورها في خلق ميزة تنافسية:- 


\section{مجلة البحوث المالية والتجارية ـ المجلد (22) - العدد الثاني - إبريل 2021}

يتم تحسين أداء سلسلة التوريد من خلال تطوير خمسة أولويات تنافسية في تسلسل محدد

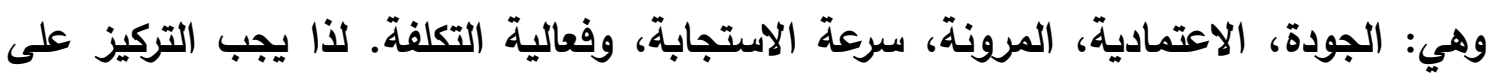
الجودة كأساس للشراكة في سلسلة التوريد، والاعتماد على المصادر الخارجية (التعهيد). ويجب الإديه أن يتبع الجودة تركيز الجهود على تحسين موثوقية تسليم المنتجات والخدمات. ويعد تحسين التكلفة النتيجة النهائية للجهود المستمرة في تحسين كل من الجودة، والاعتمادية، والمرونة،

وسرعة الاستجابة.

\section{القسم الرابع}

دور عمليات المصادر الخارجية(BPO) في دعم المركز التنافسي أصبحت ممارسة عمليات المصادر الخارجية (BPO) ظاهرة عالمية حيث بدأ استخدام عمليات المصادر الخارجية بقوة منذ بداية التسعينات كوسيلة لتخفيض التكاليف ثم تحولت بعد ذلك إلى وسيلة لتخفيض المخاطر أيضاً ولتحقيق العديد من المزايا الأخرى.، ويمكن تناول هذه الجزئية البحثية في العنصرين التاليين:-

أولاً: مفاهيم خاصة بعمليات المصادر الخارجية BPO ثانياً: عمليات المصادر الخارجية واثره في دعم المركز التنافسي. أولاً : مفاهيم خاصة بعمليات المصادر الخارجية BPO:-

تعددت التعاريف الخاصة بعمليات المصادر الخارجية BPO وبالرغم من تثابهها من حيث المضمون، عرفها (2011) Forough Karimi, et al., "إسناد بعض أو كل الأنثطة الخاصة بتكنولوجيا المعلومات بالمنشأة لطرف أو أطراف خارجية لأدائها"، ولكن هذا التعريف يخص عمليات

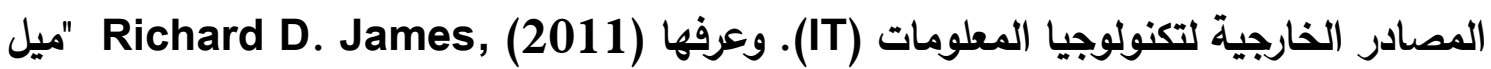
بعض الثركات الكبرى في مجالها إلى إسناد أنشطة نظم المعلومات للشركة إلى مورد خارجي ليقوم بها وهذا له الأثر في تخفيض التكاليف". دراسـة (2005) (ستهدفت الاراسة بحث التغيرات التي تطرأ على المنثأة نتيجة استخدامها عمليات المصادر الخارجية (BPO) وتأثير ذلك على المحاسبة الإدارية وطبقت على ثلاث حالات هم شركات القطاع الخاص (Private Sector)

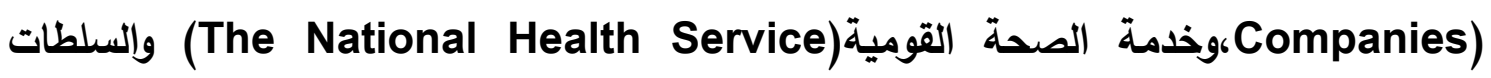
المحلية (Local Authorities). وتوصلت الدراسة إلى ان عمليات المصادر الخارجية تعمل على إحداث تغيرات داخل المنشأة، و تحسين مرونة المنثأة في تقديم خدمات ومنتجات جديدة 
وتخفيض التكاليف ويتيح للمنشأة التركيز على الأنشطة الأساسية بها لتدعم مركزها التنافسي. وإحداث تغيرات في ممارسات وأساليب المحاسبة الإدارية. دراسة (2007) Jonathan William Whitaker : استهافت الاراسة بحث تأثير عمليات المصادر الخارجية المحلية والدولية على المنشأة والعملاء. وتوصلت إلى إن الثركات ذات البنية الأساسية القوية لتكنولوجيا المعلومات هي التي تهتم باستخدام عمليات المصادر الخارجية المحلية

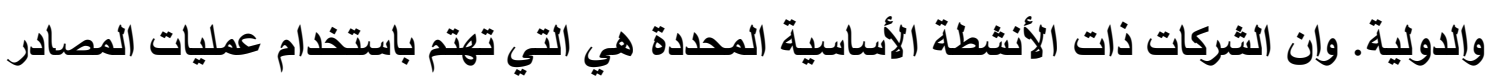
الخارجية المحلية والدولية. الثركات التي تهاف إلى سياسة تخفيض التكلفة وسياسة نمو الإيرادات هي التي تهتم باستخدام عمليات المصادر الخارجية المحلية والدولية. دراسة Gayathri Sundar (2008) استهدفت الدراسة التعرف على العوامل التي تؤدي إلى نجاح عمليات المصادر الخارجية حيث رصدت الدراسة أن "معظم الثركات الأمريكية أصبحت

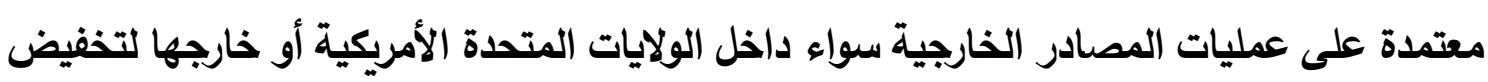
التكاليف وزيادة القدرة التنافسية للشركات. وتوصلت الاراسة إلى توجد علاقة طردية بين احتفاظ

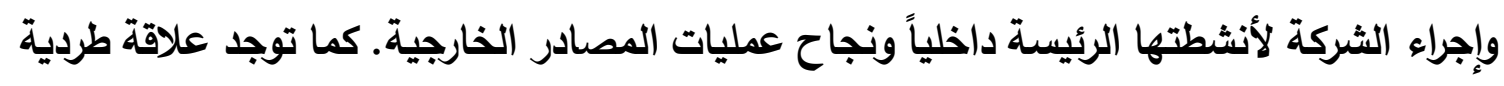
بين قدرة الثركة على التعرف والحصول على أنثطة معينة - تكون مؤثرة على الموقف التنافسي

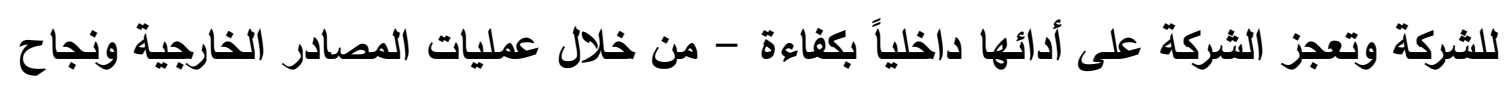
عمليات المصادر الخارجية. دراسة (2010) Yodong Luo and others: استهافت الاراسة وضع إطار لإدارة عمليات المصادر الخارجية لضمان نجاحها. وتوصلت الدراسة إلى أن معظم الثركات الرائدة في نشاطها مثل: AT \& T corporation, Boing Co., Citibank, General Electric Co., Morgan Stanley Dean Witter \& Co., Sony Corp, Swissair and تستخدم عمليات المصادر الخارجية بنجاح لتتفرغ لأنثطتها الأساسية والرئيسة Wall- Stores". ولذلك فإن تركيزها على عاملين هامين في إدارة عمليات المصادر الذارجية وهي:1- التكامل بين

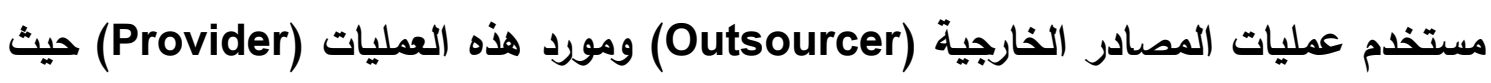
هذا التكامل يضمن نجاح عمليات المصادر الخارجية ويحمي من بعض الأخطار الملازمة لعمليات

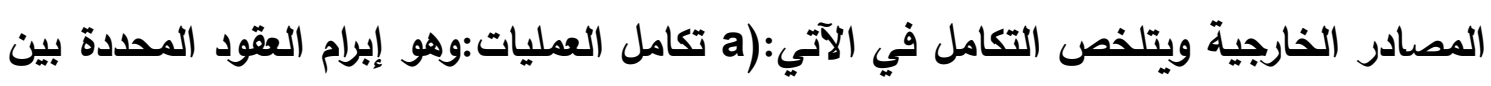

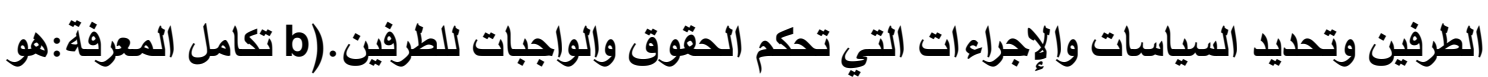


مجلة البحوث المالية والتجارية ـ المجلد (22) - العدد الثاني - إبريل 2021

أن يتم تبادل المعلومات والمعرفة بين الطرفين ويكون بينهما درجة عالية من الاستجابة والتفاهم

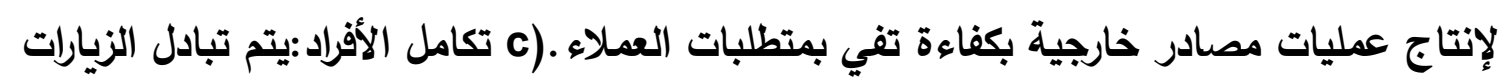

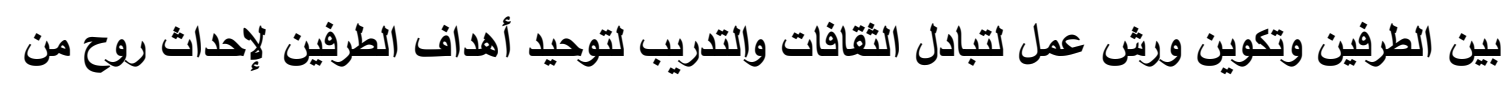
التعاون طويل الأجل. 2-التكامل بين أقسام ووظائف داخل شركات موردي عمليات المصادر

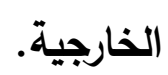

وعرفها (2009) Ragishekhar, G and Others, وأن عمليات المصادر الخارجية تنقسم إلى ثلاثة أنواع، وهم:

1- عمليات المصادر الخارجية (BPO) خارج حدود البلد: Offshore outsourcing

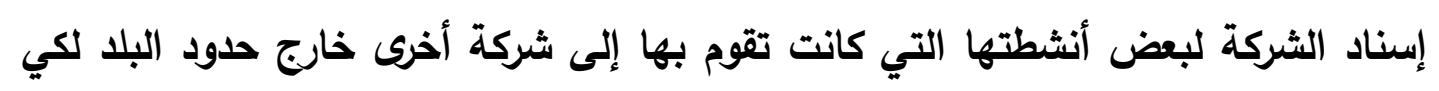

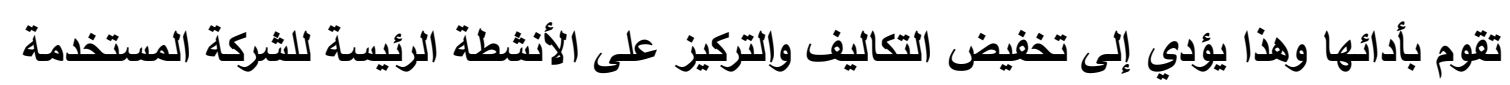

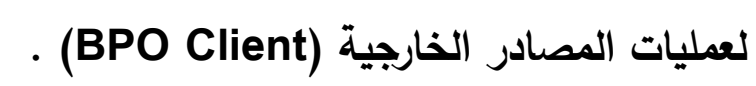

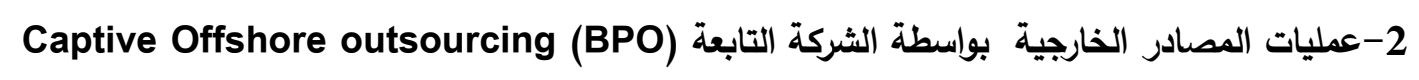
ويقصد بها أن الثركة تنتج منتجاً أو خدمة عن طريق الثركة الثركات الثرات التابعة الموجودة خارج حدود بلا الثركة القابضة نفسها وبهذه الطريقة تستطيع (Own Subsidiary) الثركة أن تفرض كامل رقابتها على الأنثطة وتستفيد من المزايا الموجودة في بلد الثركات التابعة لئل

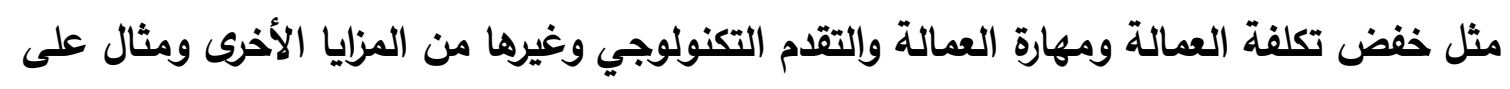

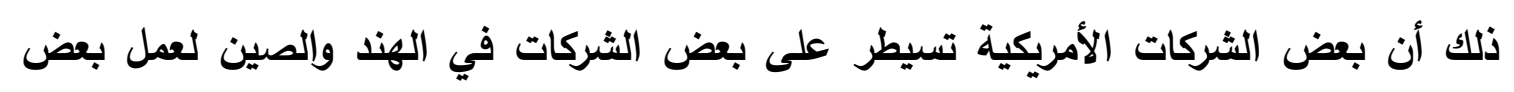
الأنثطة الخاصة بها في الثركة القابضة الموجودة في أمريكا.

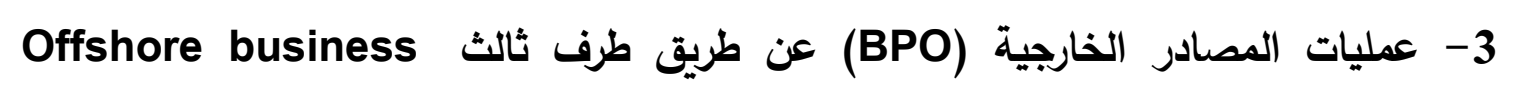

\section{Development Centers}

وهو يقصد به أن الثركة القابضة تعطي بعض أنثطتها الموجودة في الثركة التابعة خارج

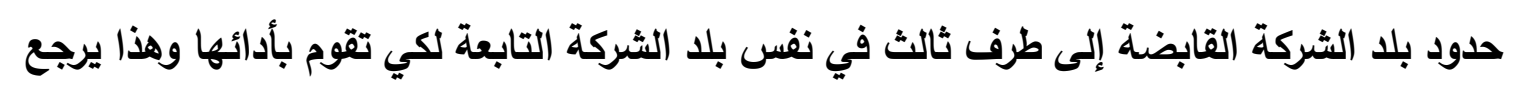
إلى تخفيض التكاليف وإلحصول على جودة أعلى.

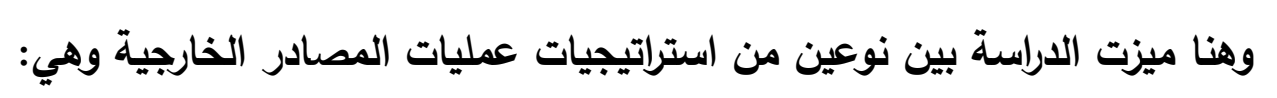
"Horizontal outsourcing Model" عمليات المصادر الخارجية الأفقية. 
حيث تثير هذه الاستراتيجية إلى أن الثركة ومورديها سيتعاونون أثناء دورة حياة المنتج، حيث تكون الثركة مسئولة عن مكونات معينة للمنتج منذ مرحلة البحوث وإلتطوير وحتى مرحلة

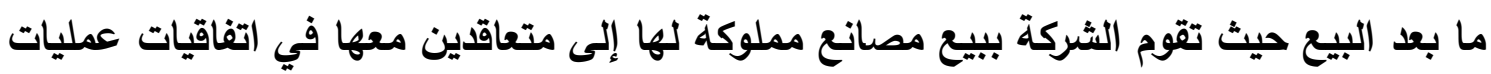

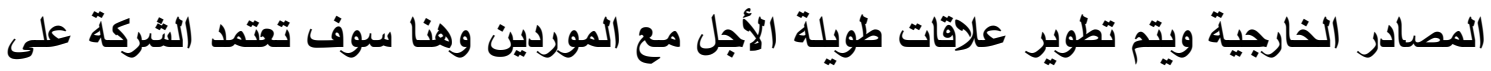
إسناد تصنيع مكونات غير رئيسة للمنتج إلى هذه الثركات المباعة ولكن المكونات الرئيسة للمنتج تظل تُصنع داخل الثركة.

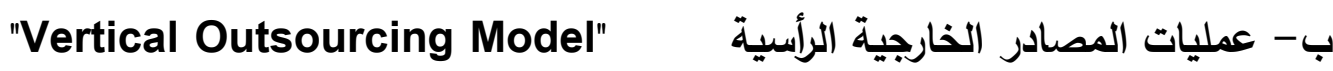
حيث تثير هذه الاستراتيجية إلى أن الثركة: صاحبة المنتج الرئيس تقوم بعملية تصميم وتصنيع المنتجات الجديدة ويتولى المتعاقدون في توريد عمليات المصادر الخارجية مسئولية إنتاج المنتجات التقليدية ولتحقيق عمليات المصادر الخارجية الرأسية يتم جعل مركز التطوير والتصميم المنتجات الجديدة في دولة معينة أما مركز إنتاج المنتجات التقليدية في دولة أخرى. أهداف ومنافع عمليات المصادر الخارحية: "استخدام عمليات المصادر الخارجية تؤدي إلى تحقيق مرونة الثركة. وتخفيض التكاليف

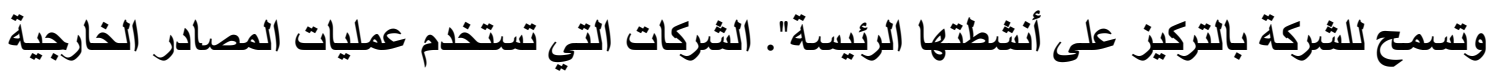
(BPO) هدف عملي (فني): الهلف الفني هو أن مستخدم عمليات المصادر الخارجية (BPO Client)

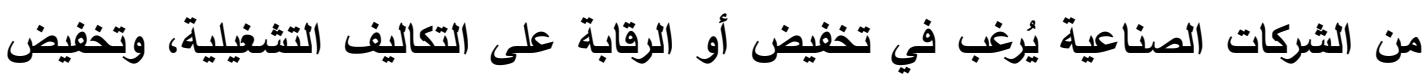
وإحكام الرقابة على الإنفاق الرأسمالي على الوظائف والأنشطة غير الرئيسة وتأمين الموارد المادية والفنية والجغرافية المحدودة للثركة وتوجيهها نحو تنمية الأنثطة الرئيسة. • هاف استراتيجي: وهو إعادة هيكلة الثركة من ناحية التركيز على مهام الثركة الرئيسة والعلاقات الخارجية مع الثركات الأخرى، حيث عمليات المصادر الخارجية تعمل على إصلاح

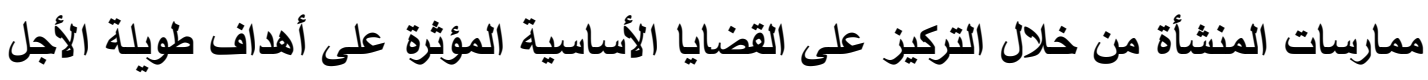
للشركة، وهي أيضا تساعد الثركة على التركيز على الأنشطة الرئيسة للشركة وتستطيع

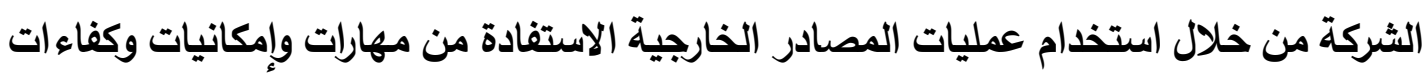
منفذو عمليات المصادر الخارجية. ثانياً: عمليات المصادر الخارجية وايثره في دعم المركز التنافسي :- 
في الآونة الأخيرة تحول اتجاه العالم من أسواق البائع Seller's Markets إلى أسواق المشتري Buyer's Markets، فأدى ذلك إلى زيادة اهتمام إدارة الشركات تجاه العملاء حيث التركيز على التى الإيفاء بمتطلباتهم عن طريق تقديم منتجات متنوعة ذات جودة عالية مع سعر منخفض يناسب

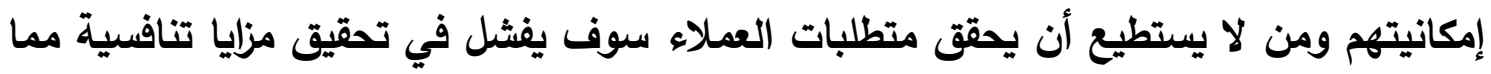
يؤثر على المركز التنافسي للشركة، وأيضاً بسبب ظهور العديد من التكتلات الاقتصادية والاتفاقيات الدولية.

حيث إن تحقيق القدرة التنافسية عن طريق ما سبق يُساعد الثركات على اكتساب حصص سوقية كبيرة ودفع العملاء إلى تفضيل منتجاتهم بخلاف المنافسين، لذلك بعض الثركات تحاول أن تبني البرامج الخاصة لزيادة القدرة التنافسية لها. وهنا تلقي الباحثة الضوء على دور عمليات المصادر الخارجية BPO في تدعيم أبعاد المركز التنافسي، وإتأثير على الاستراتيجيات التنافسية، من خلال الآتي: أولاً: عمليات المصادر الخارجية (BPO) واستراتيجية ريادة التكلفة: إذا استطاعت الثركة إسناد بعض مهام (أنشطة) الثركة إلى مورد خارجي يقوم بأدائها بكفاءة وفاعلية فتستطيع المنشاة من خلال تحليل الأنثطة الخاصة بها معرفة الأنثطة غير المضيقة للقيمة فتقوم باستبعادها، وبالتالي تتفوق المنشأة بتقديم المنتج

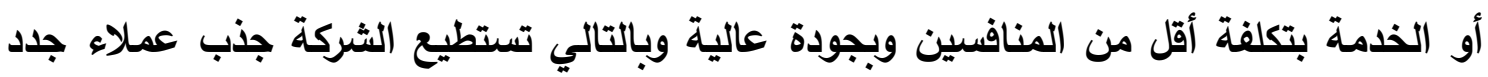
والاستحواذ على حصة سوقية أكبر من مثيلاتها.

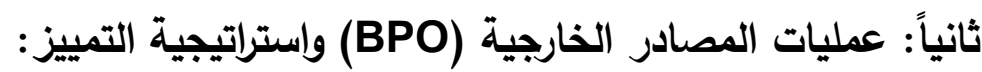
إذا استطاعت الشركة إسناد بعض مهام (أنشطة) الثركة إلى مورد خارجي يقوم بأدائه بكفاءة وفاعلية، فتستطيع المنشأة أن تتميز في بعض الأنثطة الأخرى والتي تستطيع أن تقوم بأدائه بأقل التكاليف وبالجودة العالية وفي الوقت المناسب ومواكبة التطور والابتكار إذا لزم الأمر. ثالثاً: عمليات المصادر الخارجية واستراتيجية التركيز : إذا استطاعت الثركة إسناد بعض مهام (أنشطة) الثركة إلى مورد خارجي يقوم بأدائه بكفاءة وفاعلية، فتستطيع المنشأة التركيز على منتجات أو خدمات جديدة تخص فئة معينة من العملاء وتقوم على تقديمها بجودة عالية وسعر مناسب، وبالتالي تستطيع أن تجذب شريحة معينة من 
استخدام مدخل قياس التكاليف للمحاسبة عن استهلاك الموارد(RCA) ......... د.. ايناس جمعه شكر

العملاء الجدد بالإضافة إلى عملائها الحاليين، وبالتالي تزيد الحصة السوقية للشركة مقارنة

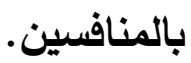
رابعاً: عمليات المصادر الخارجية (BPO) وسياسة الاتحاد: إذا استطاعت الشركة إسناد بعض مهام (أنثطة) الشركة إلى مورد خارجي يقوم بأدائه بكفاءة

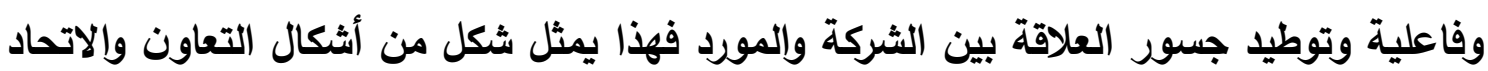

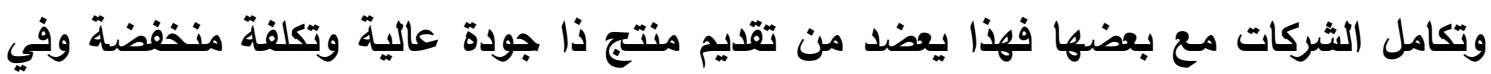
الوقت المناسب. القسم الخامس

الإطار المقترح لاعم المركز التنافسي للشركات الصناعية

يعتمد الاطار المقترح لتطوير نظم إدارة التكلفة علي التكامل والترابط بين مدخل المحاسبة عن استهلاك الموارد (RCA) وسلسلة التوريد البيئية مع عمليات المصادر الخارجية (BPO) وكيفية الاستفادة من مزايا هذا التكامل والترابط في تدعيم القدرة التنافسية لمنثآت الأعمال الصناعية في بيئة التصنيع الحديثة، مما يتطلب تحقيق الاستغلال الأمثل لموارد الثركة من خلال

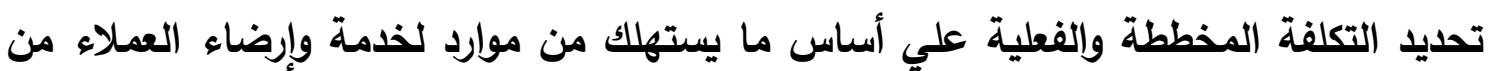
خلال التركيز علي الموارد، كيفية استهلاك المخرجات للموارد بما يعظم من القدرات والإمكانيات الاقتصادية للشركة من حيث تعظيم الربحية وتحسين جودة منتجاتها وتخفيض تكلفة الإنتاج والتحسين المستمر للموارد واستغلال الطاقة الفائضة/ العاطلة بما يحقق رغبات وطموحات العملاء ويضيف قيمة ومساهمة حقيقية سواء علي مستوي الثركة أو علي مستوي المنتجات أو علي مستوي العملاء.

وتتمثل مراحل الإطار المقترح في تحليل أثار التكامل وذلك علي النحو التالي: - مـراحل تحليل خطوات القيود والاختناقات: يُراعى عند تطبيق الإطار المقترح تتبع المراحل الآتية: 
Planning:المرحلة الأولى: التخطيـط حيث يتم تثخيص وتصنيف القيود أو الاختناقات التي تحد من العمليات الإنتاجية وكذلك مجموعة الموارد النادرة والتي تمثل قيد أو نقطة اختناق على الثركة تحد من أنثطتها التثغيلية وتتمثل مجالات تثخيص وتصنيف القيود أو الاختناقات التي تحد من العمليات الإنتاجية فيما يلي: التخطيط لموارد الشركة المتاحة وغير المتاحة، التخطيط لإدارة الطاقة العاطلة. • التخطيط للفصل بين الموارد بالقدر المتاح، والموارد بالقدر المستخدم. • تحديد الموارد على شكل كمي والعلاقات المتداخلة والمتثابكة بين الموارد وبعضها البعض. • تحديد نوعية القيود والاختناقات. • تحديد الأنثطة الرئيسية وتصنيفها وتكلفة تلك الأنثطة وفق ما يلي: • • أنثطة تضيف قيمة للشركة ويتم استغلالها استغلال أمثل. • أنثطة لا تضيف قيمة للشركة وقابلة للتحسين في حالة استغلالها استغلال أمثل والسيطرة علي الفاقد منها. Implementing::المرحلة الثانية: التنفيذ الفهيذ وفيه يتم التعرف على نقاط القيود والاختناقات التي تواجه الاستغلال الأمثل للموارد وإدارة

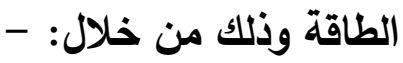
• تدعيم الاستغلال الأمثل للموارد بما يساعد على تحقيق أقصى فاعلة وإنتاجية ممكنة للقيود زيادة طاقة تؤدي الي زيادة في التكاليف.

• تدعيم إدارة طاقة الموارد العاطلة/ الفائضة بالاستغلال الأمثل للموارد وتعظيم الربحية.

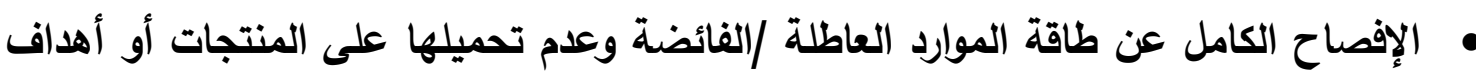
التكلفة الأخرى بثكل تقديري. • تدعيم حسن إدارة الموارد والاستغلال الأمثل لها والسيطرة على مناطق الفاقد والتخلص من الأنثطة الزائدة التي لا يمكن استغلالها. • تحليل الطاقة وتخصيص التكاليف الموارد وقت حدوثها وبالتالي تحديد حجم الطاقة العاطلة. حيث يتم التنفيذ الفعلي للإطار المقترح ويتم ذلك من خلال الخطوات الآتية: 
• الخطوة الأولى: تحديد معايير لتقييم أداء تطبيق الإطار المقترح، وهنا تبأ الإدارة العليا بتدشين

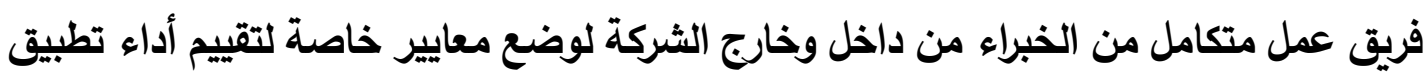

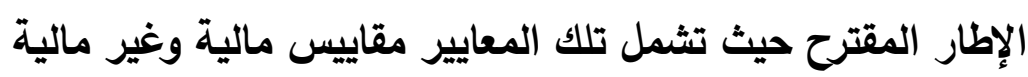

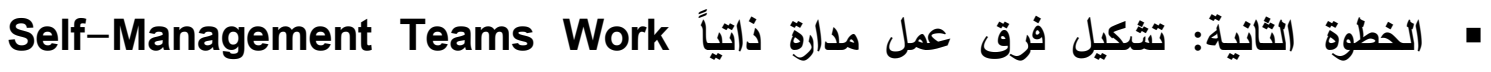
(اللامركزية)، وهنا تبدأ الإدارة العليا بتثكيل فرق عمل مدارة ذاتياً وأن تكون لها صلاحيات واسعة لإدارة العمل بكفاءة على أن تكون بين تلك الفرق تفاهم وترابط لتدارك أي أخطاء يمكن أن تحدث في تطبيق الإطار المقترح. • الخطوة الثالثة: الرقابة على أداء فرق العمل، وهنا تبدأ الإدارة العليا بمراقبة أداء فرق العمل المختلفة ومطابقة أدائهم بالأهداف المحددة مسبقاً. • الخطوة الرابعة: تحليل وتقييم الأداء، وهنا تبدأ الإدارة العليا بمقارنة النتائج الفعلية لتطبيق الإطار المقترح والمعايير المحدد مسبقاً كما توجد في الخطوة الأولى وتبدأ عملية التقييم لأداء تطبيق الإطار المقترح ويتم الوقوف على مناطق الضعف في الأداء إذا وجلت. • الخطوة الخامسة: المراجعة المستمرة وتصحيح الإجراءات لتطبيق الإطار المقترح، وهنا تبدأ الإدارة العليا بالمراجعة المستمرة لمعايير تقييم أداء تطبيق الإطار المقترح وتعديلها مما يلائم البيئة المحيطة المرحلة الثالثة: التحسين المستمر والتوسع::Continuous Improvements \& Expansion حيث يتم في هذه المرحلة تطوير الخطط والأداء وفقاً لنتائج التقييم وصولاً إلى أفضل مستوى لتطبيق الإطار المقترح ثم يتم التوسع في تطبيق الإطار المقترح على مستوى فروع الثركة بأكملها. المرحلة الرابعة: التكامل::Integration يتم من خلال التكامل بين مدخل المحاسبة عن استهلاك الموارد وسلسلة التوريد البيئية مع عمليات المصادر الخارجية التعرف على ما يلي: • العلاقة بين الموارد بالقدر المتاح والقدر المستخدم بغرض تحديد القيود أو الاختناقات. • كيفية التوافق في تدفق المنتجات وتخفيض المخزون تحت التشغيل وزيادة معدل الإنجاز . • التركيز علي تحسين أنثطة الاختناقات لزيادة الطاقة المتاحة بالثركة.

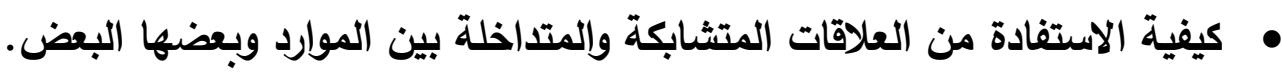




\section{مجلة البحوث المالية والتجارية ـ المجلا (22) - العدد الثاني - إبريل 2021}

• كيفية إيجاد قيمة مضافة على مستوي الثركة أو عملائها من خلال التوظيف الأمثل

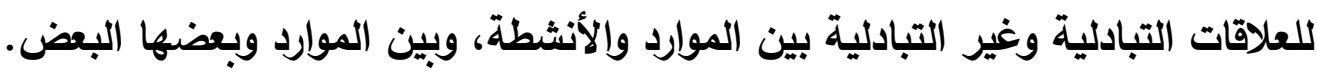
وهنا يتم تكامل الإطار المقترح مع أساليب المحاسبة الإدارية الحديثة والتي منها:

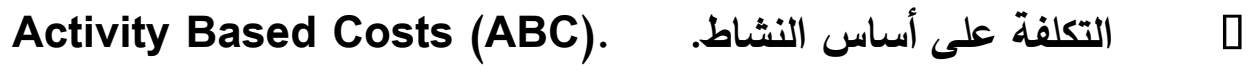
Target Costing (TC). الت التكلفة المستهدفة.

Continuous Improvements (Cl).

Balanced Scorecard (BSC).

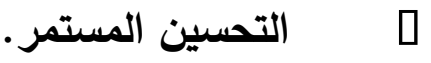

Benchmarking (BM).

Value Chain Analysis (VCA).

Lean Production (LP).

Value Engineering (VE).

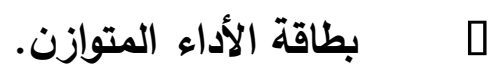
[ الاقتداء بأفضل الممارسات. ب الإنتاج الانسيابي.

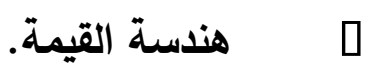

- أثار التكامل بين نظام التكلفة على أساس علي لنظام التكلفة على أساس النشاط ABC للأنظمة الثلاث (مدخل المحاسبة عن استهلاك الموارد (RCA) وسلسلة التوريد البيئية مع عمليات المصادر الخارجية (BPO). يوفر نظام قياس التكلفة على أساس النشاط ABC آلية محاسبية تبسط من عملية تتبع التكاليف وتصنيفها على أساس الأنثطة الموجودة بالثركة، لذلك يعتبر نظام قياس التكلفة على أساس النثاط مصدر أساسي للبيانات والمعلومات التي تحتاجها الثركة عند أخذ قرار تطبيق الأنظمة الثلاثة (RCA ) وسلسلة التوريد البيئية مع (BPO). - الدور التكاملي لأسلوب إدارة الوقت (تحسين دورة الزمن) للأنظمة الثلاثة (مدخل المحاسبة عن استهلاك الموارد (RCA) وسلسلة التوريد البيئية مع عمليات المصادر الخارجية (BPO) تظهر أثار التكامل في تدعيم وتحسين إدارة الوقت والزمن لتصبح داعمة لمنتجات الثركة

$$
\text { وعملائها بالتركيز علي ما يلي :- }
$$

أ. تحديد وتصنيف أنثطة الثركة في مجموعات ترتبط بدورة الزمن هي (الإعداد، الانتظار،

التثغيل، التفتيش، التفريغ، التحريك).

ب. أن تحسين إدارة الوقت يساعد علي زيادة الإنتاجية من خلال: م تقليل وتخفيض دورة زمن التثغيل دون إضافة طاقة.

م التمكين من جدولة التشغيل والتسليم زمنياً سواء على مستوي المنتجات أو العملاء. م التمكين من حذف الوقت الضائع للأنثطة ذات الاختناق والقيود. 
استخدام مدخل قياس التكاليف للمحاسبة عن استهلاك الموارد(RCA) ......... د.. ايناس جمعه شكر

م تخفيض وقت إعداد وتثغيل العمليات ذات الاختناق من خلال تبسيط تصميم المنتج، تخفيض عدد مكونات أجزاء المنتج، تخفيض وقت صيانة الآلات وإلمعدات. - الدور التكاملي لمدخل تكلفة المواصفات للأنظمة الثلاثة ( مدخل المحاسبة عن استهلاك الموارد وسلسلة التوريد البيئية مع عمليات المصادر الخارجية (RCA) فيما يلي :أ. تحديد خصائص ومواصفات المنتج من خلال (تحديد المواصفات والخصائص ذات القبول والرغبة الثديدة في المنتجات من قبل العملاء-تحليل مستويات إنجاز وتنقية وتصفية المواصفات والخصائص ذات القيمة التنافسية - تعديد المواصفات والخصائص التي تضيف قيمة للمنتج- تحديد المواصفات وإلخصائص ومستويات الإنجاز التي لا تضيف قيمة للمنتج - تحديد الأنثطة اللازمة لتحقيق المواصفات وتصنيفها الي أنثطة تضيف ولا تضيف للقيمةإن تعكس المواصفات وقدرة المنتج علي الاستجابة لتوقعات العملاء بصفة مستمرة.

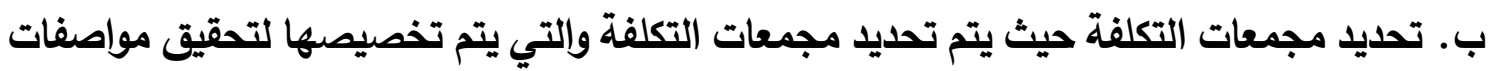
وخصائص المنتجات التي تقابل رغبات وتوقعات العملاء والأزمة لإنجاز مهام المنتج، وتثمل

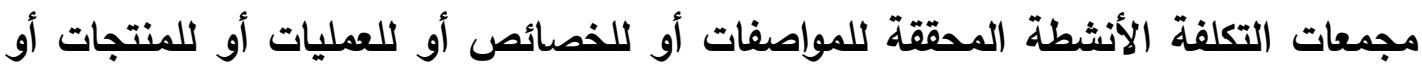
للعملاء أو قنوات البيع. ج. تحديد العلاقات التشابكية بين مجمعات الموارد، يتم تحديد العلاقات التبادلية بين مجمعات الموارد بعضها البعض بغرض التعرف على استفادة كل مورد من الموارد الأخرى، وربط الموارد

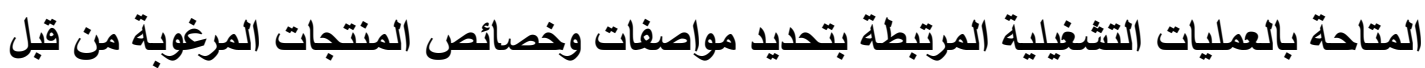
العملاء عن طريق مسبيات الموارد. د. تحديد مسببات استخدام الموارد، تعتبر موضوعات القياس التكليفي والتي تثمل (مواصفات المنتجات، العملاء، قنوات التوزيع) والتي تثمل الدقة في تصديد مسببات استخدام الموارد بما

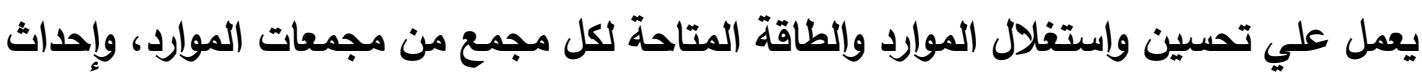
حالة من التجانس الكبير في عناصر التكاليف داخل مجمعات الموارد - إمكانية استخدام مسبيات الموارد في تدعيم الكثير من القرارات مثل " إدارة الموارد، كفاءة استغلال الموارد، إحلال الموارد، الاستثمار في تكنولوجيا المعلومات. 
هـ تحديد الأنثطة المحقة والمنجزة للمواصفات: يمكن تحديد الأنثطة المحققة والمنجزة لمواصفات المنتج وتستهلك الموارد من خلال تحديد الأنثطة التي تضيف قيمة لمواصفات المنتج - تحديد الأنثطة التي لا تضيف قيمة لمواصفات المنتج - توزيع التكاليف الخاصة بمجمعات الموارد على الأنثطة الإنتاجية وذلك بغرض (تحديد دقيق التكاليف مواصفات التهات وخصائص الأنشطة الإنتاجية وتحديد تكلفة الطاقة العاطلة على مستوي الموارد - اتخاذ القرارات والتصرفات للتخلص من الطاقة العاطلة أو تخفيضها قدر الإمكان). و. تحديد موضوعات القياس التكاليفي - وهي تلك التي تتمثل في المنتجات النهائية ذات التهان المواصفات والخصائص المختلفة والتي تحقق إثباع رغبات العملاء حيث أن التعرف على لتى

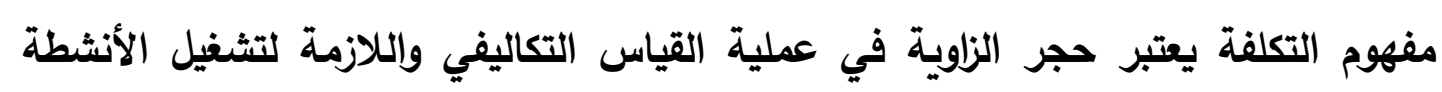
وتحقيق الإنتاجية وإضافة قيمة للعملاء. - الدور التكاملي لأسلوب التكلفة المستهدفة TC للأنظمة الثلاثة (مدخل المحاسبة عن استهلاك الموارد (RCA) وسلسلة التوريد البيئية مع عمليات المصادر الخارجية (BPO).

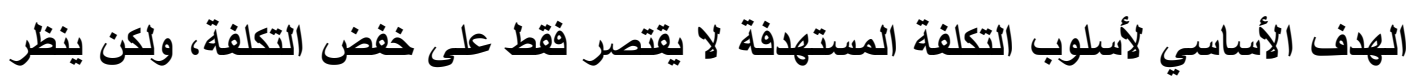

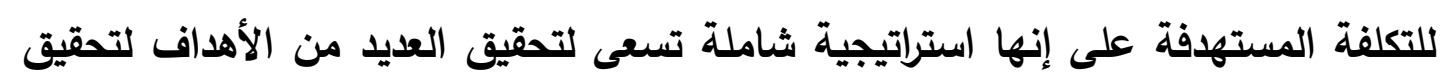

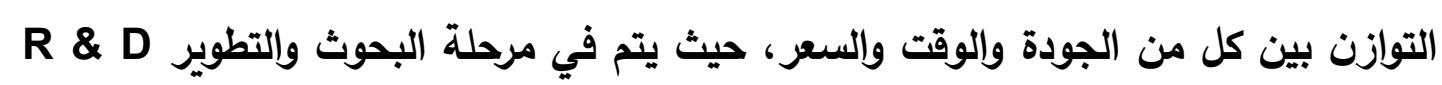

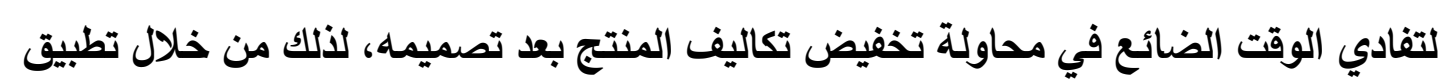
أسلوب التكلفة المستهدفة يمكن التعرف على فاعلية التكاليف المصاحبة لتطبيق النظم الثلاثة

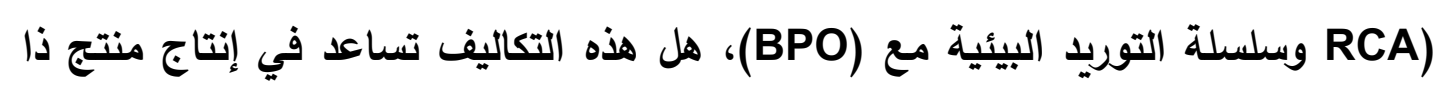
جودة عالية وبتكاليف أقلّل من أفضل الصناع لنفس المنتج، لذائك فتطبيق أسلوب التكلفة المستهدفة يدعم من تطبيق النظم الثلاثة (RCA) وسلسلة التوريد البيئية مع (BPO). - الدور التكاملي لأسلوب التحسين المستمر Kazzin للأنظمة الثلاثة (مدخل المحاسبة عن لئل

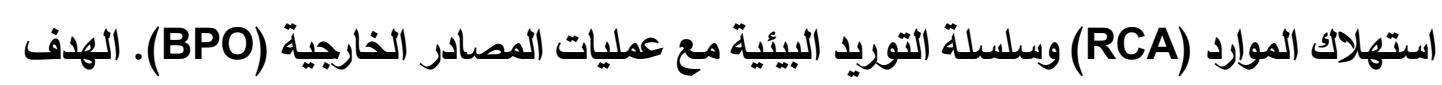
الأساسي لأسلوب التحسين المستمر هو التحسين المستمر لأساليب الإنتاج وتحسين جودة

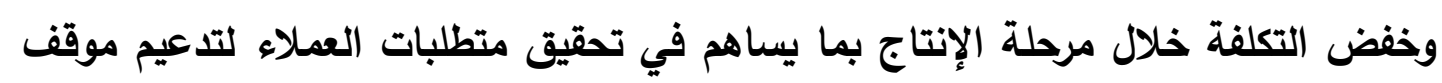

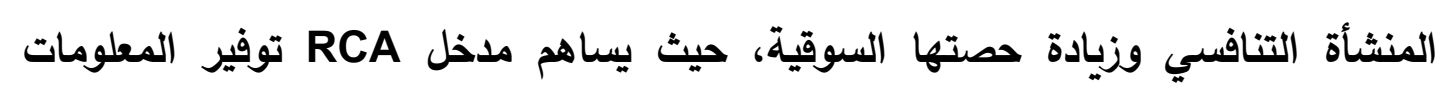


المناسبة عن كيفية الاستغلال الأمثل لموارد الأنثطة بالثركة واستخدام تلك المعلومات في التحسين المستمر لعمليات الأداء التشغيلي والمالي لتدفقات القيمة من خلال: أ. تعظيم القيمة علي مستوي الثركة او علي مستوي العملاء. ب. التخلص من المعلومات المتولدة من نمط الإنتاج القائم علي أساس الدفعة الإنتاجية التملية التصميم التظيمي الكفء لمسارات تدفق القيمة يخلق نوعاً من التركيز علي استهلاك الإتكاج الموارد لكل مجموعة من المنتجات (عائلة المنتجات). ج. التصميم القائم على مسارات تدفق القيمة للمنتج يبحث عن الامثليه من خلال التركيز علي أداء مسار تدفق القيمة ككل.

- لذلك فالتحسين المستمر يدعم من تطبيق الأنظمة الثلاثة (مدخل المحاسبة عن استهلاك

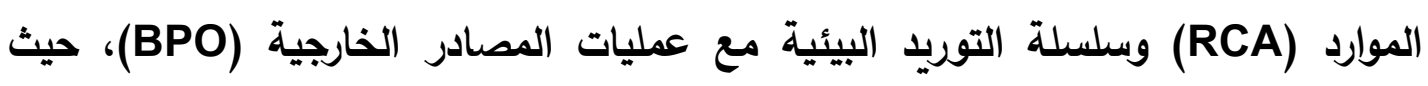

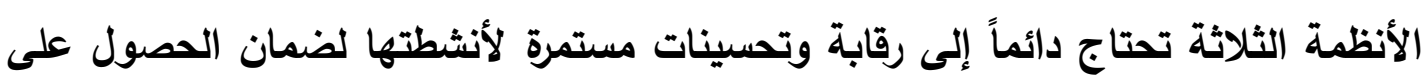
الهدف والمنافع من تطبيقها. - الدور التكاملي لبطاقة الأداء المتوازن BSC للأنظمة الثلاثة (BPO مذلطعل المحاسبة عن

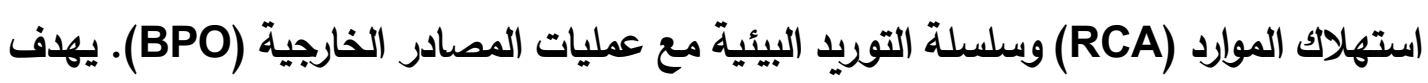
أسلوب بطاقة الأداء المتوازن إلى خلق علاقة توازنيه بين الأداء المالي وغير المالي، وذلكاتك


ومقاييس الأداء غير المالية التي تستهاف قياس مسببات الأداء المالي في الأجل الطويل،

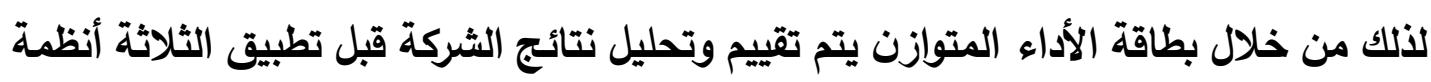
المقترحة ( مدخل المحاسبة عن استهلاك الموارد (RCA) وسلسلة التوريد البيئية مع عمليات المصادر الخارجية (BPO) ، وبعد تطبيقها وإعطاء الإدارة العليا للشركة البيانات والمعلومات اللازمة لاتخاذ القرار الخاص بتطبيق الإطار المقترح.

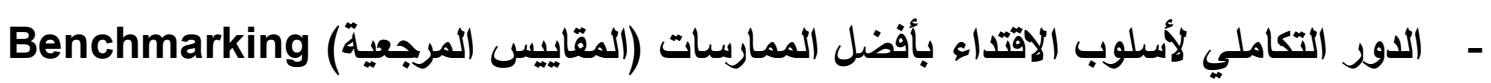

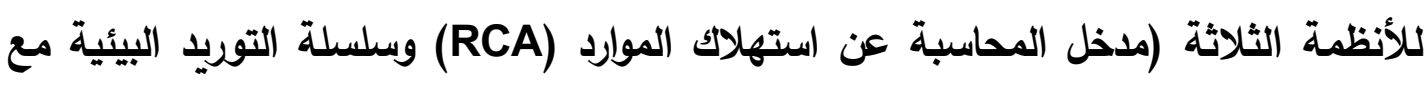

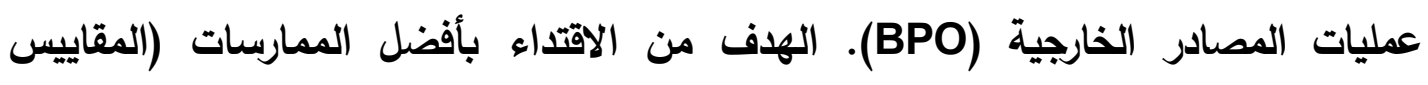
المرجعية) تمثل في تحديد أعلى المقاييس أو المعايير للتفوق في كل من المنتجات والخدمات التهات

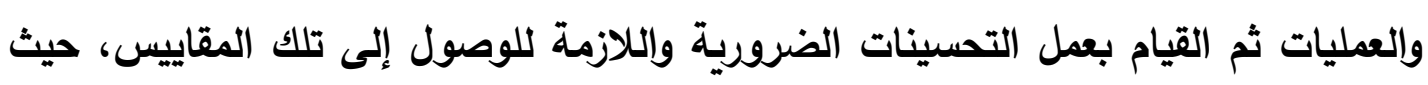


يطلق عليها أفضل الممارسات، وتقوم فكرة الاقتداء بأفضل الممارسات على أساس أن تكون الثركة قادرة على إدراك وفهم أوجه القصور لايها والاعتراف بأن هناك بعض الثركات يمكنها القيام بأداء أفضل منها وأن تتعلم الثركة أفضل الأداء ثم تتولى تنفيذه داخل الثركة، لذألك

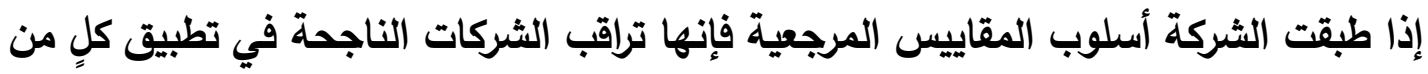
الأنظمة الثلاثة ( مدخل المحاسبة عن استهلاك الموارد (RCA) وسلسلة التوريد البيئية مع عمليات المصادر الخارجية (BPO)) وتحاول أن تتعلم منهم وتتفوق عليهم، وهذا يؤثر على النى

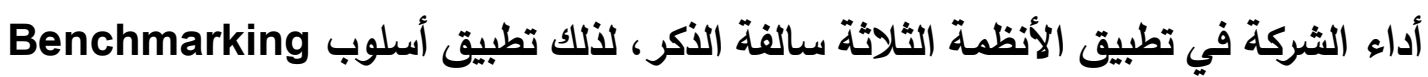
يدعم من تطبيق الإطار المقترح. - الدور التكاملي لتحليل سلسلة القيمة Value Chain Analysis للأنظمة الإنة الثلاثة (ملخل المحاسبة عن استهلاك الموارد (RCA) وسلسلة التوريد البيئية مع عمليات المصادر الخارجية (BPO). يُعتبر تحليل سلسلة القيمة من أحد الدعائم الأساسية لتطبيق

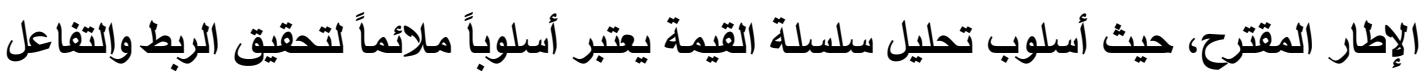

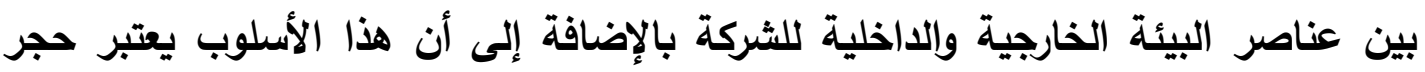

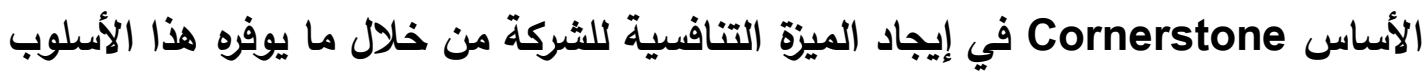
من معلومات مالية وغير مالية من كافة أنثطة وعمليات الثركة بداية من مرحلة البحوث

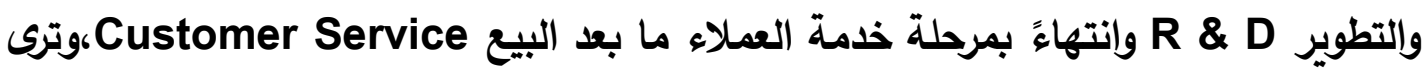
الباحثة أن الدراسة التفصيلية لأنثطة سلسلة القيمة يدعم من تطبيق الأنظمة الثلاثة(مدخل

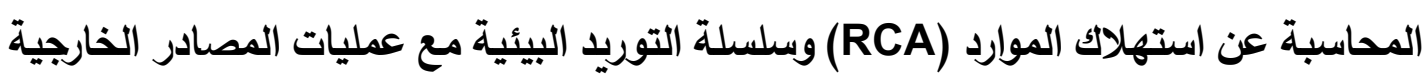

(BPO)

- الدور التكاملي لأسلوب هندة القيمة Value Engineering للأنظمة الثلاثة (ملخل المحاسبة عن استهلاك الموارد (RCA) وسلسلة التوريد البيئية مع عمليات المصادر الخارجية (BPO). يهدف هذا الأسلوب إلى تحليل الوظائف التي تؤديها المكونات المختلفة للمنتج بهدف تحقيق تلك الوظائف بأقل تكلفة ممكنة، وبشرط ألا يؤثر ذلك على جودة المنتج، حيث تعتمد هندسة القيمة على مقارنة الأهمية النسبية لأجزاء المنتج بتكلفة تلك الأجزاء، فقد يتضح أن ما تنفقه الثركة على بعض الأجزاء أقل من أهيتها النسبية للعملاء، وفي هذه الحالة تخضع هذه الأجزاء لعمليات التحسين والتطوير ، أما تلك الأجزاء التي يتبين أن ما تنفقه التهاء التهاء 
استخدام مدخل قياس التكاليف للمحاسبة عن استهلاك الموارد(RCA) ......... د.. ايناس جمعه شكر

عليها الثركة أكبر من أهميتها النسبية للعملاء، ففي هذه الحالة يتم إجراء عمليات هندسة

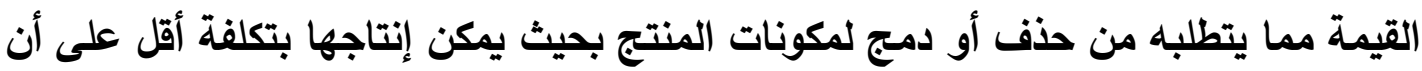
تؤدي نفس الوظائف، وبنفس الكفاءة، لذلك ترى الباحثة أن أسلوب هندسة القيمة يلزم أن تطبق على الثلاثة أنظمة ( مدخل المحاسبة عن استهلاك الموارد (RCA) وسلسلة التوريد البيئية مع عمليات المصادر الخارجية (BPO)، ومعرفة أي الأنثطة داخل الثلاثة أنظمة

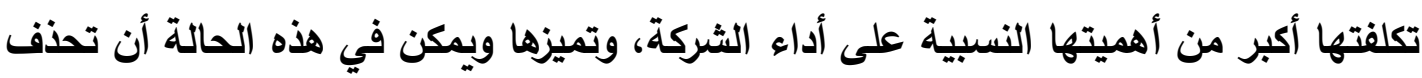
إذا لم تؤثر على أداء الثركة أو يعاد تصميمها وإعادة هندستها لكي تكون أهميتها النسبية أكبر من تكلفتها، لذلك فإن أسلوب هندسة القيمة يدعم من تطبيق النظم الثلاثة (مدخل

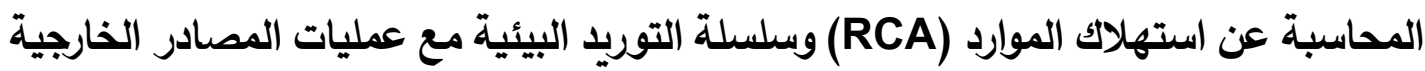

((BPO) - المرحلة الخامسة: تحديد مسببات استخدام الموارد: - من خلال التعرف على الموارد التي يمكن زيادتها أو تخفيضها وفق القيود أو الاختناقات التي تعوق تحديد مسببات استخدام الموارد وذلك كما يلي: ت تديد الموارد بعد التعرف على إزلالة كافة القيود أو الاختناقات. • استبعاد الطاقة التي لا تضيف قيمة في منتجات أو عملاء الثركة وتعظيم قدرتها التنافسية. • التعرف علي الموارد التي يمكن زيادتها اكثر من اللازم والتي لن يؤدي تخفيضها الي حدوث أي قيود أو اختناقات تعوق استخدام الموارد.

• التمييز بين الموارد وبعضها البعض وكيفية استغلال الموارد وبيانات الطاقة غير المستغلة.

Stability \& Continuous Evaluation: المرحلة السادة: الاستقرار والتقييم المستمر بالتعرف علي مجالات وأوجه التحسين المستمر من خلال الاستغلال الأمثل للموارد المتاحة التي تعتمد علي قدرات وإمكانيات الثركة في توظيف واستغلال الطاقات المختلفة بها افضل استغلال وذلك علي النحو التالي: • التعرف على مجالات إزالة وإتبعاد الطاقة التي لا تضيف قيمة أو مساهمة سواء على مستوي الثركة أو علي مستوي العملاء. • التوصل الي إن هناك طاقة أخري تستوجب إجراء عمليات التحسين المستمر عليها. 


\section{مجلة البحوث المالية والتجارية ـ المجلا (22) - العدد الثاني - إبريل 2021}

• العودة الي الخطوة الأولي للتعرف على تثخيص وتصنيف القيود أو الاختناقات التي تحد من الاستغلال الأمثل للطاقة حتى تضيف قيمة مضافة ومساهمة إنتاجية للشركة وعملائها. حيث يتم الاستقرار في تطبيق الإطار ويتم حفظونشر نتائج التطبيق وتقييم استقرار التطبيق دورياً، وبمكن توضيح المرحلة الخامسة من خلال الخطوات التالية:

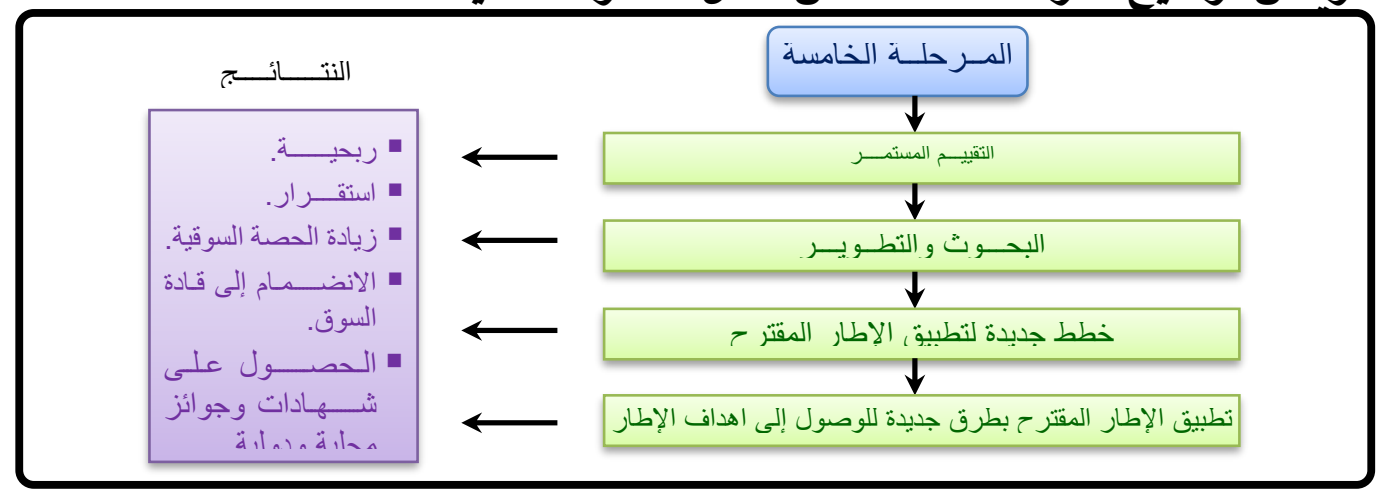

\section{شكل رقم (5): يوضح خطوات المرحلة الخامسة (الاستقرار والتثييم المستمر)}

المصدر (إعداد الباحثة)

طبقاً للشكل السـابق يمكن توضيح المرحلة السـادسـة من مراحل تطبيق الإطار المقترح من خلال أربع خطوات يمكن توضيحها فيما يلي: • الخطوة الأولى: التقييم المســتمر، وهنا تبدأ الثـــركة بتقييم المســـمر لأداء تطبيق الإطار المقترح على مســـتوى الفروع كلها بعد الاطمئنـان من نتائج تطبيق الإطار في المراحل السابقة.

• المرحلة الثانية: البحوث والتطوير، وهنا تبأ الثــركة من مواصـلة البحوث والتطوير لتطبيق

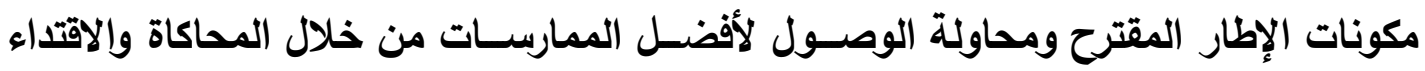
بأفضل المنافسين المطبقين نفس الإطار.

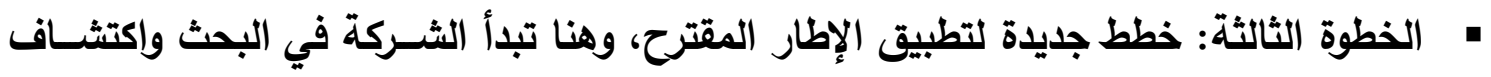
خطط جديدة لتطبيق الإطار المقترح ليتناســـب مع المســـتجدات الحديثة في بنية الأعمال

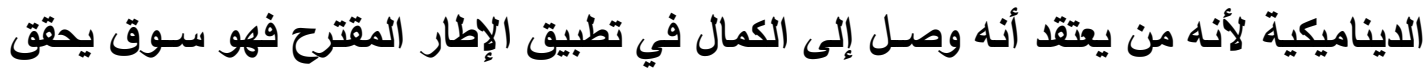
تراجع كبير في التنافسية بين الأخرين. • الخطوة الرابعة: تطبيق الإطار المقترح، بطرق جديدة للوصول إلى أهداف الإطار وهي:

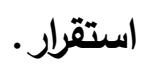
• ربحية. • الانضمام إلى قادة السوق. • زيادة الحصة السوقية. 


\section{• • الحصول على شهادات وجوائز محلية ودولية. \\ وكل ما سبق يصب في دعم المركز التنافسي للشركة.}

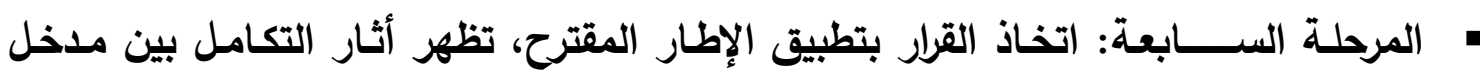

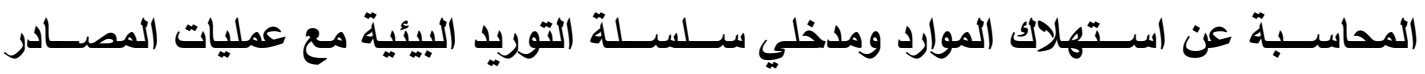
الخارجية في مســاعدة الإدارة في اتخاذ القرارات قصـيرة الأجل والقرارات طويلة الآجل، وذلك علكي على النحو التالي: أ. علي المستوي المدي القصير : تظهر نتائج التكامل في تحسين ربحية الثركة من خلال زيادة المخرجات والتركيز على الفعالية حيث يركز مدخل RCA على الإدارة الجيدة لموارد الثـــركة

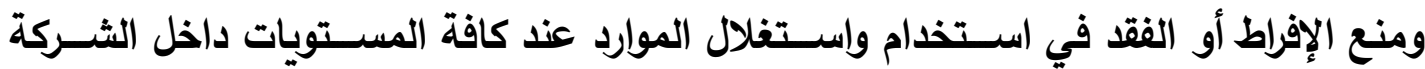
ويشمل مختلف الأبعاد (المنتج، الخدمة، العملاء، فنوات التوزيع.... الخ). ب. علي مستوي المدي الطويل: ويعتمد على التوسـع أو ربط الطاقة داخل التسـهيلات الإنتاجية في اســـذام واســـفلال كافة الكفاءات والقدرات والطاقات وتســـــيل عملية التنبؤ بالموارد بالثكل الأي يمكن الثركة من وضع موازناتها التخطيطية على أسساس كمية الموارد المتوقع الطلب عليها في المدي الطويل. ج. علي مسـتويات الثـركة (التثـيلية، التكتيكية، الاستراتيجية): يوفر إطار التكامل المعلومات اللازمة في تحسين اتخاذ القرارات، وذلك على النحو التالي: • علي المستوي التشغيلي يساعد في تدعيم قرارات الطاقة والعاملين والآلات بشكل اقتصادي.

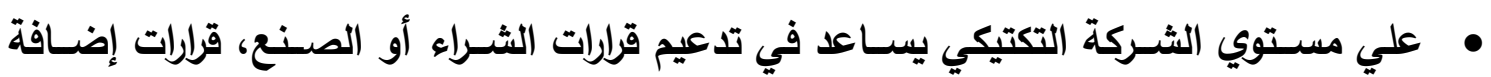
منتج، قرارات استكمال أو عدم استكمال التصنيع، قرارات فهم الطبيعة الأولية للتكاليف. • علي مستوي الثركة الاستراتيجي يساعد في تدعيم قرارات الدخول في السوق التنافسي. وهنا تتبنى الإدارة العليا فكرة التطبيق الفعلي المقترح ومحاولة إقناع جميع العاملين بالثــركة بأهمية تطبيق هذا الإطار وإلمزايا التي سوف تعود عليهم وعلى الثركة ككل. 
مجلة البحوث المالية والتجارية ـ المجلد (22) - العدد الثاني - إبريل 2021

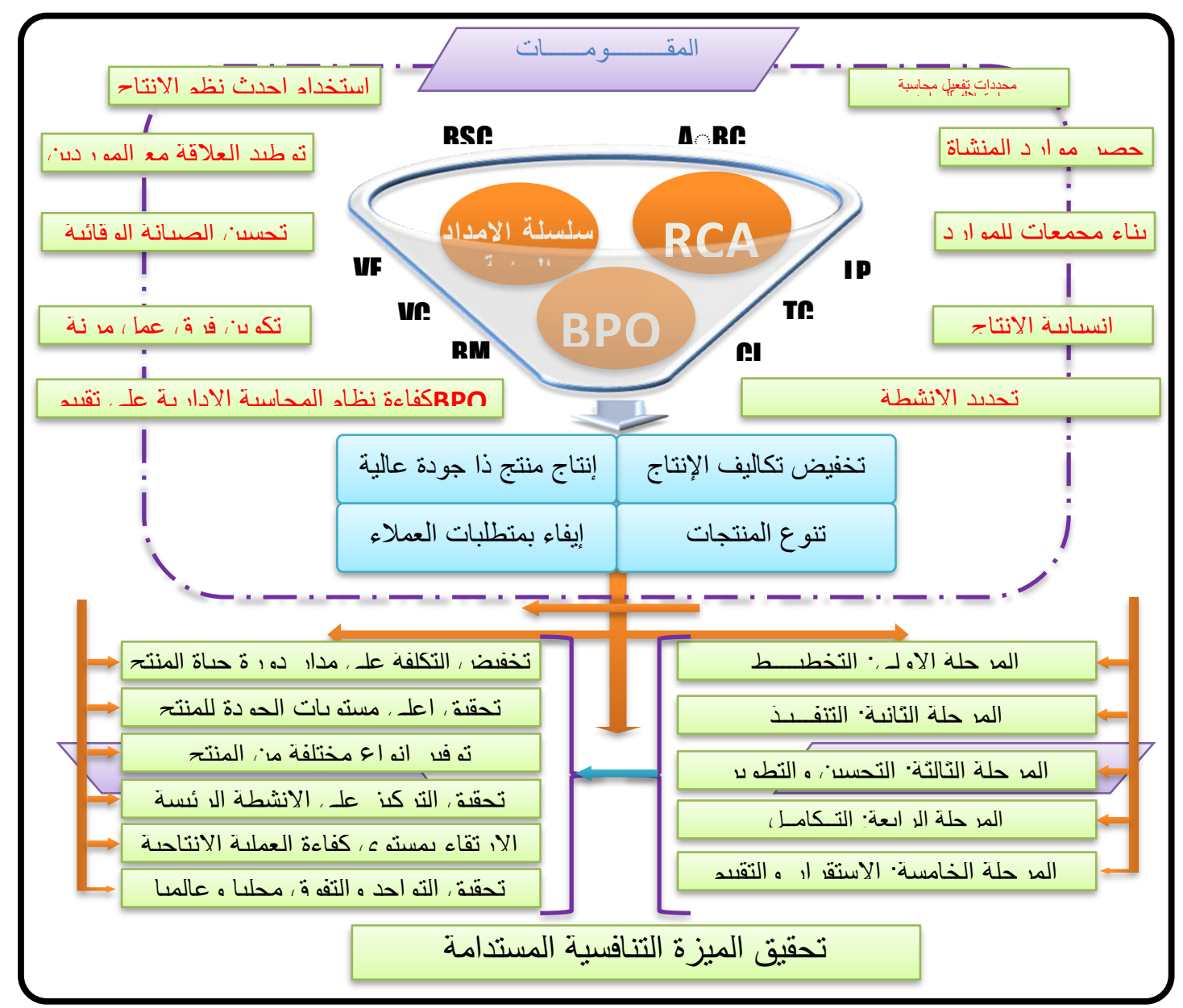

شكل رقم (6)يوضح الإطار المقترح لتكامل مدخل المحاسبة عن استهلاك الموارد (RCA) مع سلسلة التوريد مع عمليات المصادر

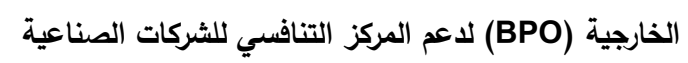

$$
\text { - الدراسة المداد الباحثة) }
$$

تستهاف الدراسة الميدانية اختبار فروض البحث، وذلك من خلال استطلاع أراء عينة البحث

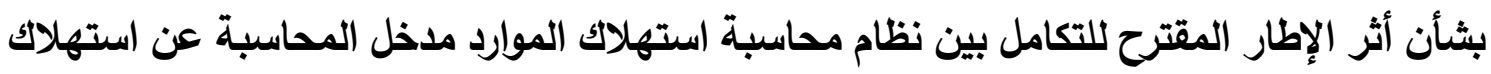
الموارد (RCA) وسلسلة التوريد البيئية مع عمليات المصادر الخارجية (BPO) في تدعيم القدرة التنافسية لمنشآت الأعمال. وقد تم الاعتماد في تجميع البيانات الميدانية على استمارة استقصاء

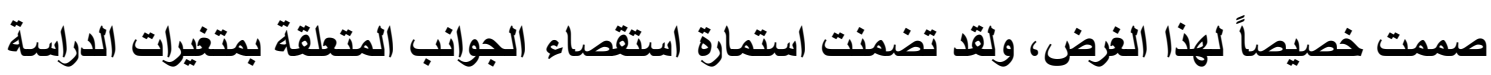
بغرض تجميع البيانات تمهيدا لتحليلها إحصائيا لاختبار فروض البحث. 
استخدام مدخل قياس التكاليف للمحاسبة عن استهلاك الموارد(RCA) ......... د.. ايناس جمعه شكر

$$
\text { - مجتمع الدراسة وحجم العينة: }
$$

يتمثل مجتمع الدراسة في مجموعة من الثركات الصناعية الموجودة في القاهرة الكبرى (المنطقة الصناعية في السادس من أكتوبر والعاثر من رمضان ومدينة بدر وقو يسنا) في 170 شركة وفق تقرير اتحاد الصناعات لعام 2019، وقد حددت الباحثة عينة الدراسة باستخدام أسلوب العينة العشوائية البسيطة، وتم تحديد حجم العينة العشوائية للمجتمع المددود طبقا للمعادلة التالية:-

حجم العينة العشوائية

$$
n_{1}=\frac{170 *(0.5(1-0.5))}{170 *\left(\frac{0.05}{1.96}\right)^{2}+(0.5(1-0.5))}=117 \cong 120
$$

ونظراً لأنه لا يمكن إجراء المسح الثامل لمجتمع الدراسة فقد تم الاقتصار على عينة ممثلة لهذا المجتمع. ومن ثم فقد تم توزيع عدد 120 استمارة استقصاء على العاملين في منظمات

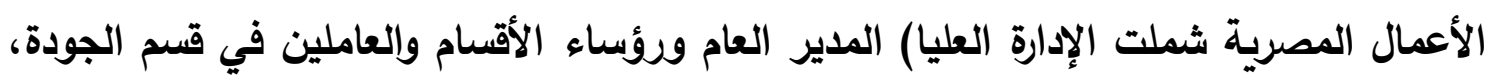
والمتوسطة باعتبارهم الفئة المنوط بها البحث، وركزت الباحثة في الاختيار علي تلك المناطق

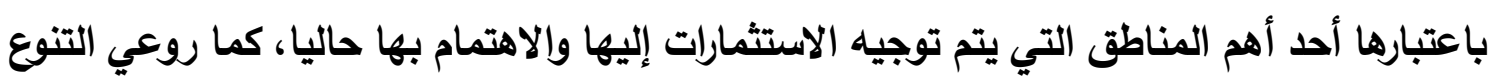
في الأنشطة التي تمارسها تلك المنشآت والتي تمثل صناعات هامة ينبغي التركيز عليها، ويوضح الجدول التالي القوائم الموزعة والمستلمة لفئات الدراسة.

\begin{tabular}{|c|c|c|c|c|c|}
\hline نسبة القالحة للتحليل المستردة & الإلتصنتردة & المستردة والميرة اللتحير & المسترّرة & الموزعة القو & ــــان \\
\hline 78\% تقريبا & 43 & 3 & 9 & 55 & شركات صناعيةٌ بمدينة السادس من اكتوبر \\
\hline ا 77\% تقريباً & 27 & - & 8 & 35 & شركات صناعية بمدينة العاشر من رمضان \\
\hline$\% 80$ & 12 & 3 & - & 15 & شركات صناعية بمدينة بلر \\
\hline $\mathbf{\% 8 0}$ & 12 & 2 & $\overline{1}$ & 15 & شركات صناعية بقويسنا \\
\hline$\% 78.3$ & 94 & 8 & 18 & 120 & الإجمالي \\
\hline
\end{tabular}

جدول رقم (1) يوضح عدد القوائم الموزعة، والمستردة والصالحة للتحليل الإحصائي

وفى ضوء الجدول السابق يتضح أن نسبة القوائم الصالحة للتحليل الإحصائي لكل فئة من

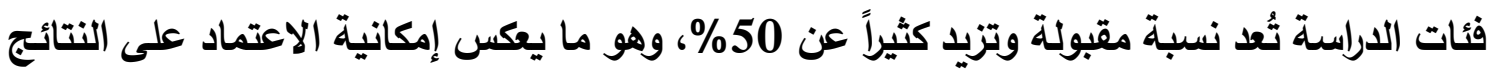

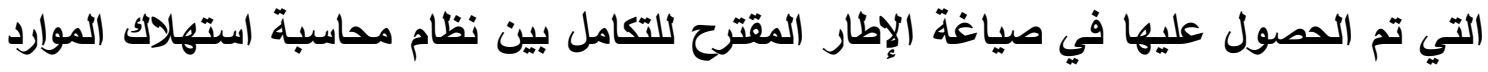




\section{مجلة البحوث المالية والتجارية ـ المجلد (22) ـ العدد الثاني - إبريل 2021}

مدخل المحاسبة عن استهلاك الموارد (RCA) وسلسلة التوريد البيئية مع عمليات المصادر الخارجية (BPO) في تدعيم القدرة التنافسية لمنشآت الأعمال.

\section{- م - ميم أداة الدراسة:}

تم إعداد أسئلة قائمة الاستقصاء بحيث تثمل على ما يلي:

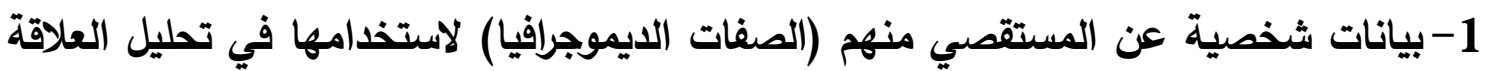

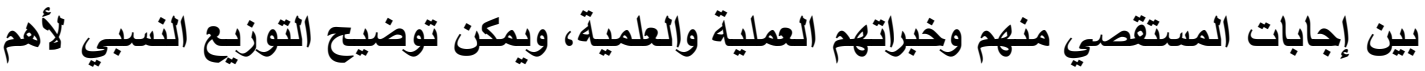

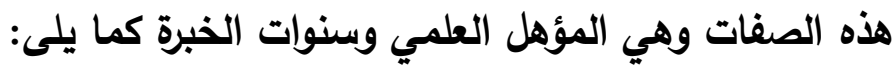

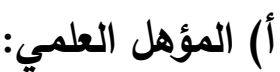

\begin{tabular}{|c|c|c|}
\hline النسبة \% & التكرار & المؤهل العلمي \\
\hline 0.119 & 18 & ماجستير \\
\hline 78.7 & 74 & بكالوريوس \\
\hline 2.1 & 2 & دبلوم متوسط \\
\hline 100 & 94 & الإجمالي \\
\hline
\end{tabular}

ب) مدة الخـبرة جدول رقم (3) يوضح التكرار والنسبة لعدد سنوات الخبرة للمستقصي منهم

\begin{tabular}{|c|c|c|}
\hline 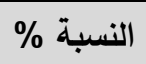 & التكرار & مدة الخبرة \\
\hline 2.1 & 2 & أقل من خمس سنوات \\
\hline 51.1 & 48 & خمس سنوات وأقل من عشرة \\
\hline 46.8 & 44 & أكثر من 10 سنوات \\
\hline $100.0 \%$ & 94 & الإجمالي \\
\hline
\end{tabular}

2-إما القسم الثاني من استمارة الاستقصاء : أسئلة تم صياغتها حسب مقياس ليكرت الخماسي،

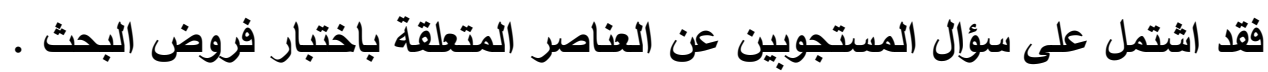

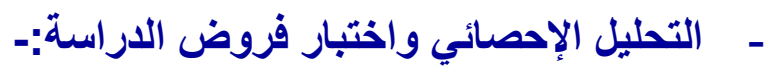

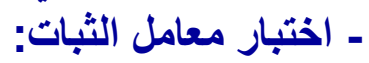

- - ل أغراض هذه الدراسة تم استخدام برنامج الحزمة الإحصائية للعلوم الاجتماعية ، كtatistical Package for Social Sciences (SPSS) Version 16 الإحصائي و ذلك لاختبار الفروض الإحصائية لهذه الدراسة، ولقد قامت الباحثة بإجراء التحليل الوصفي Descriptive Analysis (مثل معدل التكرارات والنسب) للبيانات التي تم تجميعها

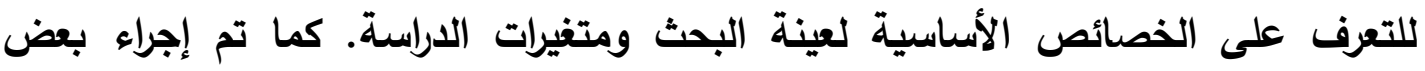


استخدام مدخل قياس التكاليف للمحاسبة عن استهلاك الموارد(RCA) ......... د.. ايناس جمعه شكر

الاختبارات اللامعلمية Non-Parametric Tests لاختبار فروض البحث والتعرف على أثر الإطار المقترح للتكامل بين نظام محاسبة استهلاك الموارد للتكامل بين نظام محاسبة استهلاك الموارد مدخل المحاسبة عن استهلاك الموارد (RCA) وسلسلة التوريد البيئية مع عمليات المصادر الخارجية (BPO) في تدعيم القدرة التنافسية لمنشآت الأعمال كما تم استخدام مستوى معنوية P=0.05 الذي يعد مستوى مقبولاً في العلوم الاجتماعية بصفة عامة ويقابله مستوى ثقة يساوي 09 \% مع لتفسير نتائج الاراسة. - يتناول البحث في الأقسام التالية التحليل الوصفي لخصائص عينة الاراسة، ونتائج الاختبارات الإحصائية لفروض الدراسةDescriptive. Analysis لخصائص عينة الاراسة، ونتائج الاختبارات الإحصائية لفروض الإراسة. - - (ختبار معامل الثبات: تم حساب معامل الثبات (Alpha) للأسئلة المتضمنة في قائمة الاستقصاء حتى يمكن تحديد مدى أمكانية الاعتماد على مخرجات الدراسة الاستطلاعية في تعميم المخرجات وعدم وجود تحيز لهيل أو تحريف في النتائج. ويوضح الجدول التالي نتائج هذا الاختبار لأقسام الدراسة الثلاثة: -

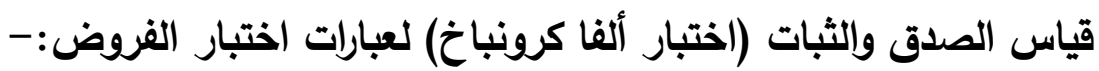

\begin{tabular}{|c|c|c|c|}
\hline معامل الصدق & معامل الثبات (الفا) & عدد العبارات & فروض الدراسة \\
\hline 0.972 & 0.944 & 10 & الفرض الأول \\
\hline 0.939 & 0.881 & 7 & الفرض الثاني \\
\hline 0.944 & 0.891 & 10 & الفرض الثالث \\
\hline
\end{tabular}

يتضح من الجدول السابق أن معاملات الثبات ومعاملات الصدق عالية جدا مما يثير إلى أن التناست الداخلي لعناصر استمارة الاستقصاء يعد قوياً ومقبولاً بدرجة كبيرة. 1- المقاييس الإحصائية الوصفية: فيما يلي عرض التحليل الوصفي لأقسام الدراسة (يمثل كل قسم فرض من فروض الدراسة) حيث قامت الباحثة بحساب المقاييس الإحصائية الوصفية لكل قسم على حده ، بلغ حجم العينة

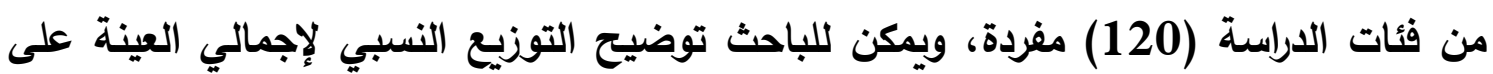

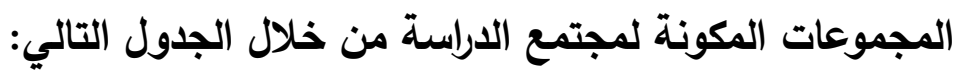
- المقاييس الإحصائية لبيانات الفرض الأول: 
مجلة البحوث المالية والتجارية ـ المجلد (22) - العدد الثاني - إبريل 2021

يهدف اختبار الفرض الأول إلى التعرف على مدى إدراك المستقصي منهم حول أهمية مدخل المحاسبة عن استهلاك الموارد (RCA) وسلسلة التوريد البيئية مع عمليات المصادر الخارجية

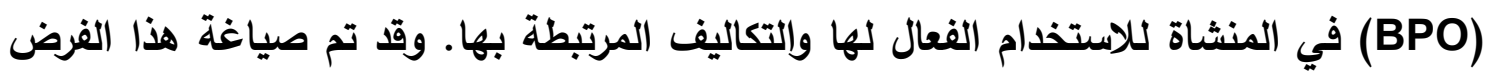
كالتالي: "لا يوجد اختلافا معنويا حول دور مدخل المحاسبة عن استهلاك الموارد (RCA) وسلسلة فئل التوريد البيئية مع عمليات المصادر الخارجية (BPO) إلى تحقيق وفورات في تكاليف الثركات

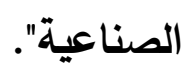

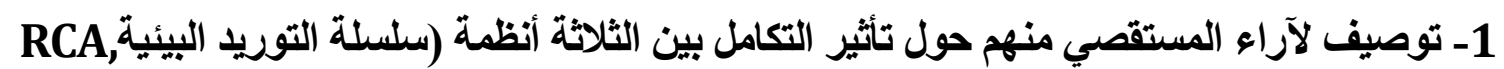

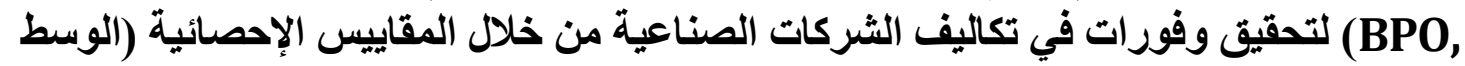

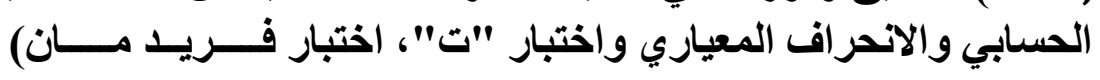
جدول رقم (4) توصيف الآراء من خلال المقاييس الإحصائية للسؤال الرابع للقسم الثاني

\begin{tabular}{|c|c|c|c|c|c|c|}
\hline المغتوية & متوسط & T-test & 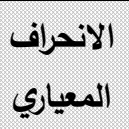 & 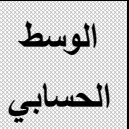 & العدد & الســـــــال \\
\hline \multirow{5}{*}{$* 0.027$} & 2.29 & ***0.000 & 0.79 & 4.17 & 94 & 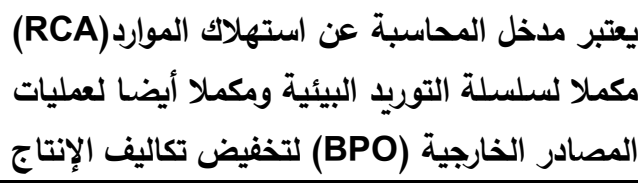 \\
\hline & 2.55 & $* * 0.000$ & 0.54 & 4.49 & 94 & بدورة حياة المنتجـة التوريد البيئية يؤدي إلى الاهتمام \\
\hline & 2.43 & $* * 0.000$ & 0.73 & 4.39 & 94 & 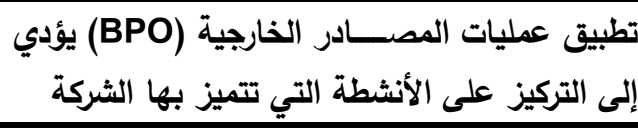 \\
\hline & 2.72 & $* * 0.000$ & 0.62 & 4.54 & 94 & 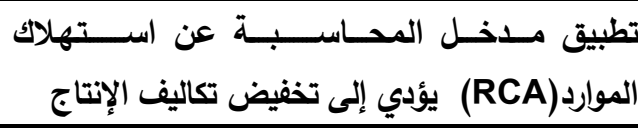 \\
\hline & & $* * 0.000$ & 0.67 & 4.40 & 94 & الوسط الحسابي العام \\
\hline
\end{tabular}

0.05

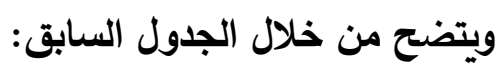

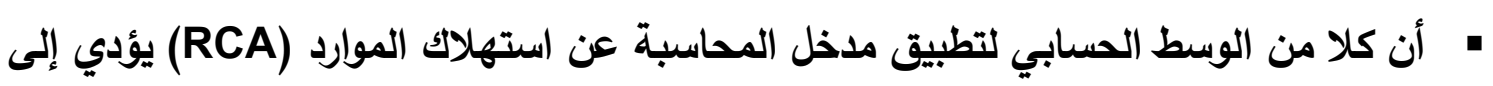

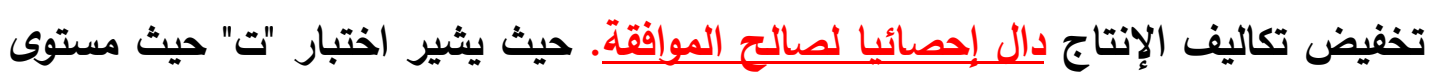
المعنوية p-value أقل من 0.01 إلى أن هناك علاقة ذات دلالة إحصائية أي أن هناك اختلاف أو فروق معنوية. • وبالمثل الوسط الحسابي لتطبيق سلسلة التوريد البيئية يؤدي إلى الاهتمام بدورة حياة المنتج

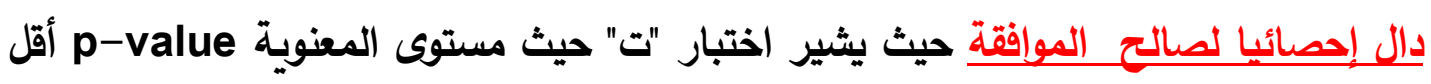


من 0.01 إلى أن هناك علاقة ذات دلالة إحصائية أي أن هناك اختلاف أو فروق معنوية،

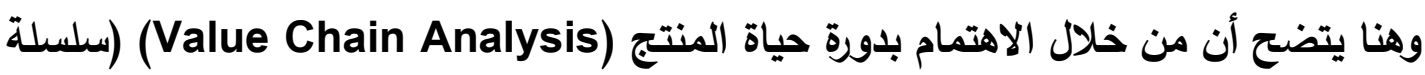

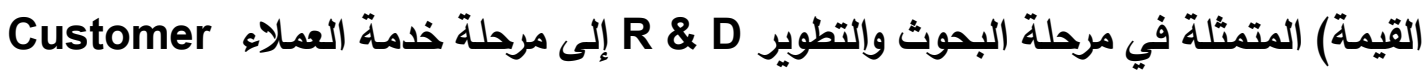
يؤدي إلى التحكم في تكاليف المنتج قبل إنتاجه بما لا يؤثر على جودته، وهذا يصب في تحقيق وفورات في تكاليف الشركات الصناعية الكبرى. - وبالمثل الوسط الحسابي لتطبيق عمليات المصادر الخارجية (BPO) يؤدي إلى التركيز على

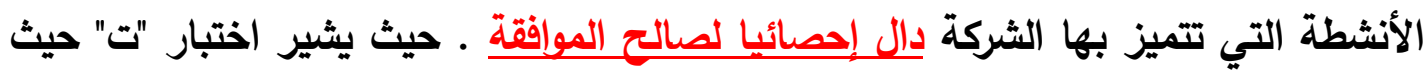
مستوى المعنوية p-value أقل من 0.01 إلى أن هناك علاقة ذات دلالة إحصائية أي أن هناك اختلاف أو فروق معنوية، وهنا يتضح من خلال التركيز على الأنثطة التي تتميز بها الثركة (التركيز على الأنثطة التي تستطيع الثركة أداءها بأعلى جودة وأقل تكلفة) وإسناد

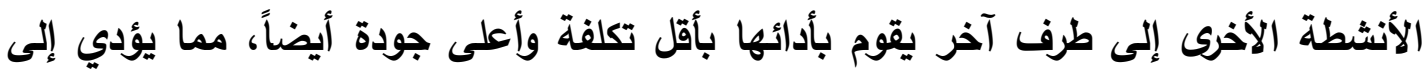
وفورات في تكاليف الثركات الصناعية .وأيضاً الوسط الحسابي اعتبار استهلاك الموارد (BPO) مكملا لسلسلة التوريد البيئية ومكملا أيضا لعمليات المصادر الخارجية التيطية (RCA) لتخفيض تكاليف الإنتاج دال إحصائيا لصالح الموافقة. حيث يثير اختبار "ت" حيث مستوى المعنوية p-value أقل من 0.01 إلى أن هناك علاقة ذات دلالة إحصائية أي أن هناك اختلاف أو فروق معنوية. • ويشير الانحراف المعياري إلى مدى تثتت الآراء حول الوسط الحسابي. ويتضح من الجدول

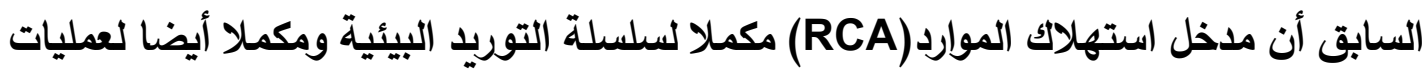
المصادر الخارجية (BPO) لتخفيض تكاليف الإنتاج صغيرة مما يدل على شبه اتفاق مفردات العينة على أن تكامل الأنظمة الثلاثة (green supply chain ,RCA, BPO) يؤدى إلى الثى

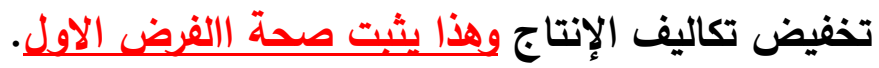
2- توصيف لآراء المستقصي منهم حول أسباب عدم تطبيق التكامل بين الأنظمة الثلاثة) سلسلة التوريد البيئية RCA \& PBO\&). من خلا المقاييس الإحصائية (الوسط الحسابي والآنحراف المعياري

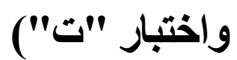
جلول رقم (5) توصيف الآراء من خلال المقاييس الإحصائية للسؤال الخامس القسم الثاني 
مجلة البحوث المالية والتجارية ـ المجلد (22) - العدد الثاني - إبريل 2021

\begin{tabular}{|c|c|c|c|c|c|c|}
\hline المعنوية & متوسط الرتب & T-test & المعياري & الحسابي & العدد & الســــــــــؤال \\
\hline \multirow{6}{*}{$000.0 * *$} & 4.42 & $* * \mathbf{0 . 0 0 0}$ & 0.61 & 4.56 & 70 & مدخم معرفة أهمية الترابط بين سلسلة التوريد البيئيةو \\
\hline & 3.96 & $* * \mathbf{0 . 0 0 0}$ & 1.10 & 3.94 & 70 & و صعوبة تطبيق الأنظمة الثلاثة سلسلة التوريد البيئية \\
\hline & 3.53 & $* * \mathbf{0 . 0 0 0}$ & 1.25 & 4.00 & 70 & جديدة وجود القابلية لاى الإدارة العليا لتبنى تطبيق نظم \\
\hline & 2.97 & $* * \mathbf{0 . 0 0 0}$ & 1.45 & 2.19 & 70 & 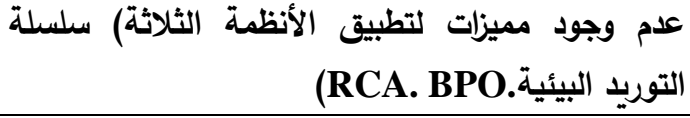 \\
\hline & 2.96 & $* * \mathbf{0 . 0 0 0}$ & 1.02 & 2.33 & 70 & 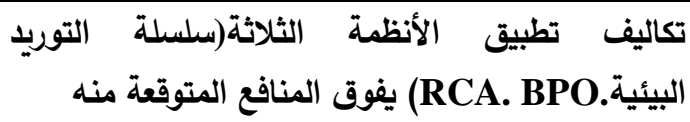 \\
\hline & 2.95 & $* * \mathbf{0 . 0 0 0}$ & 1.08 & 2.21 & 70 & 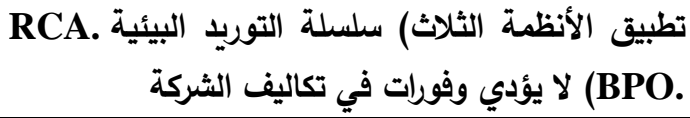 \\
\hline
\end{tabular}

• أن كل من الوسط الحسابي لعدم معرفة أهية الترابط بين نظام سلسلة التوريد البيئية و مدخل استهلاك الموارد (RCA) وعمليات المصادر الخارجية BPO. دال إحصائيا لصالح الموافقة. ويثير اختبار "ت" حيث مستوى المعنوية P-value أقل من.01 إلى أن هناك علاقة ذات دلالة إحصائية أي أن هناك اختلاف وفروق معنوية

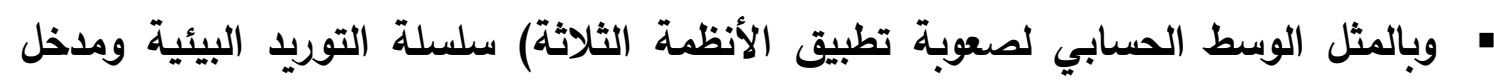
استهلاك الموارد (RCA) وعمليات المصادر الخارجية BPO بسبب عدم وجود الخبرة الكافية لاى العاملين والإدارة العليا دال إحصائيا لصالح الموافقة. ويشير اختبار "ت" حيث مستوى المعنوية P-value أقل من 0.01 إلى أن هناك علاقة ذات دلالة إحصائية أي أن هناك اختلاف أو فروق معنوية • وأيضاً الوسط الحسابي لعدم وجود القابلية لاى الإدارة العليا لتبنى تطبيق نظم جديدة دال

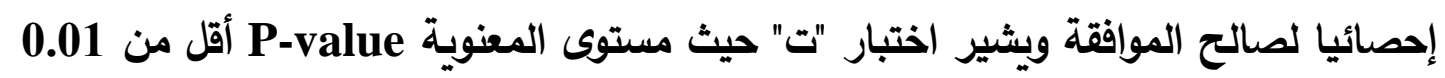
إلى أن هناك علاقة ذات دلالة إحصائية أي أن هناك اختلاف أو فروق معنوية. 
• وبالمثل الوسط الحسابي عدم وجود مميزات لتطبيق الأنظمة الثلاثة سلسلة التوريد البيئية

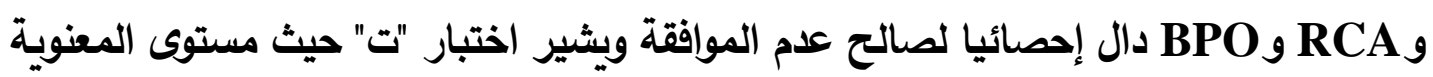
P-value فروق معنوية.

• وأيضاً الوسط الحسابي أن تكاليف تطبيق الأنظمة الثلاثة( سلسلة التوريد البيئية وRCA وBPO يفوق المنافع المتوقعة منه دال إحصائيا لصالح عدم الموافقة ويشير اختبار "ت" حيث مستوى المعنوية P-value أقل من 0.01 إلى أن هناك علاقة ذات دلالة إحصائية أي أن هناك اختلاف أو فروق معنوية

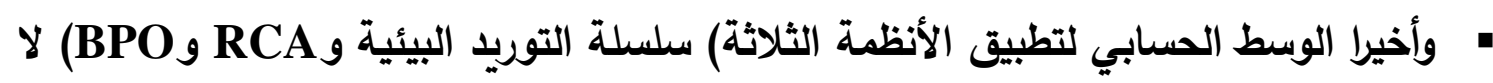
يؤدي وفورات في تكاليف الثركة دال إحصائيا لصالح عدم الموافقة ويشير اختبار "ت" حيث التهابل

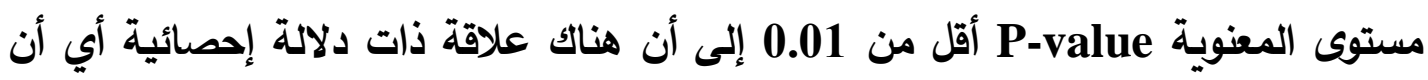

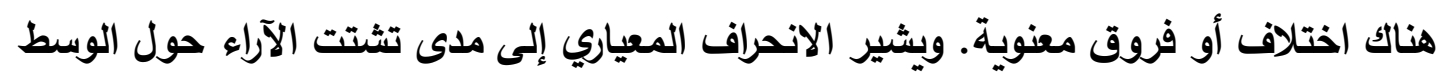
الحسابي. ويتضح من الجدول السابق أيضاً أن الانحراف المعياري صغير مما يدل على شبديه اتفاق بين مفردات العينة على عدم تطبيق الأنظمة الثلاث( سلسلة التوريد البيئية ومدخل استهلاك المواردRCA وBPO يرجع إلى عدم معرفة أهمية الترابط بين هذه الأنظمة الثلاث وهذا يفسر عدم وجود الخبرة الكافية من الإدارة العليا لتبنى النظم الحديثة وهذا له الأثر السلبي على المركز التنافسي للشركات الصناعية المصرية • إن هناك توافق بين آراء العينة حول عدم معرفة أهمية الترابط بين نظام سلسلة التوريد البيئية

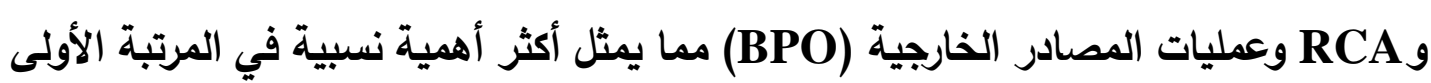
من أسباب عدم تطبيق التكامل بين الأنظمة الثلاث حيث يأخذ أعلى متوسط للرتب: • في المرتبة الثانية عدم وجود القابلية لدى الإدارة العليا لتبنى تطبيق نظم جديدة. • في المرتبة الثالثة صعوبة تطبيق الأنظمة الثلاث (سلسلة التوريد البيئية و وRCA و و بسبب عدم وجود الخبرة الكافية لاى العاملين والإدارية العليا، وفى المرتبة الرابعة عدم وجود الطبه

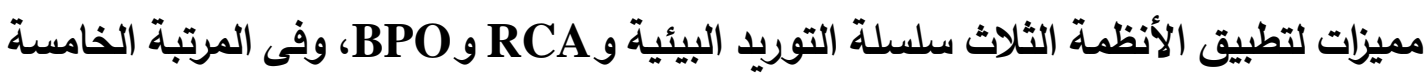

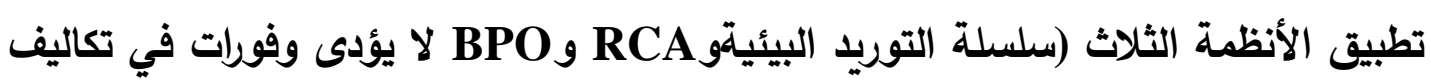

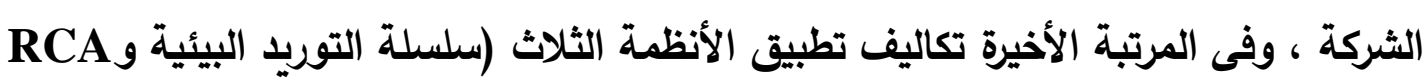


مجلة البحوث المالية والتجارية ـ المجلد (22) - العدد الثاني - إبريل 2021

وBPO يفوق المنافع المتوقعة منه حيث مستوى المعنوية (P-value) أقل من 0.05، مما يال على وجود اختلاف معنوي في الأهمية النسبية لآراء المستقصي منهم حول أسباب عدم تطبيق التكامل بين الأنظمة الثلاث (سلسلة التوريد البيئية و وRCA و وBPO) وبالتالي وفى الاهي ضوء التحليل السابق فقد ثبت صحة الفرض الأول. - المقاييس الإحصائية لبيانات الفرض الثاني: - ويقوم هذا الفرض على أن هناك مجموعة من العناصر والدعائم التي يقوم عليها نظام المحاسبة السيطرة الإحصائية على الجودة في تحقيق دقة قياس تكلفة المنتج. - وقد تم صياغة الفرض كالتالي: - "لا يوجد اختلافا معنويا حول دور تطبيق المحاسبة عن استهلاك الموارد(RCA) وسلسلة التوريد البيئية مع عمليات المصادر الخارجية (BPO) إلى إعطاء الثركة القدرة على إنتاج منتجات متعددة تفي بمتطلبات العملاء". ويعرض الجدول التالي الإحصاء الوصفي لآراء عينه البحث حول الافتراضات والدعائم التي يرتكز عليها نظام السيطرة الإحصائية على الجودة. - جدول رقم (6) توصيف الآراء من خلال المقاييس الإحصائية للسؤال السادس القسم الثاني

\begin{tabular}{|c|c|c|c|c|c|c|}
\hline 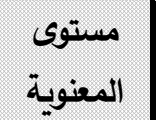 & 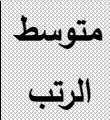 & T-test & 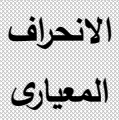 & 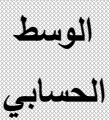 & العدد & الســـــؤال \\
\hline \multirow{5}{*}{ ***0.003 } & 4.02 & ***0.00 & 0.84 & 4.21 & 94 & 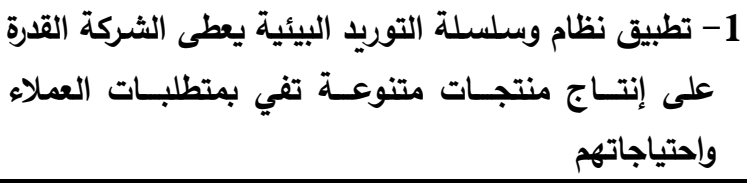 \\
\hline & 3.32 & ***0.00 & 0.80 & 4.03 & 94 & 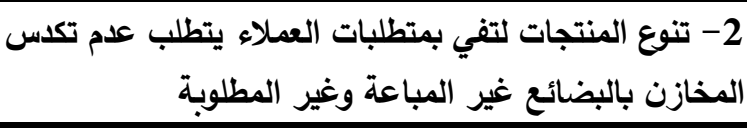 \\
\hline & 4.15 & $* * 0.00$ & 0.71 & 4.43 & 94 &  \\
\hline & 4.17 & $* * 0.00$ & 0.62 & 4.45 & 94 & 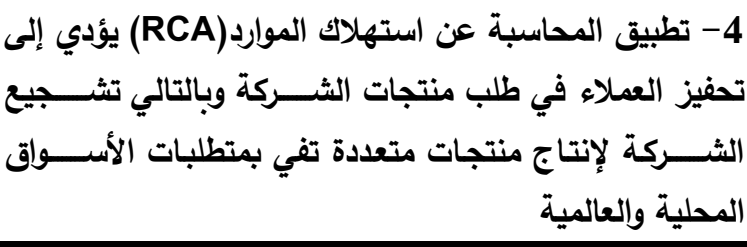 \\
\hline & 4.31 & ***0.00 & 0.68 & 4.48 & 94 &  \\
\hline
\end{tabular}




\begin{tabular}{|c|c|c|c|c|c|c|}
\hline مستوى المعنوية & متوسط الرتب & T-test & الانحراف & الحسابي & العدد & الســـــؤال \\
\hline & 4.02 & $* * 0.00$ & 0.70 & 4.35 & 94 & 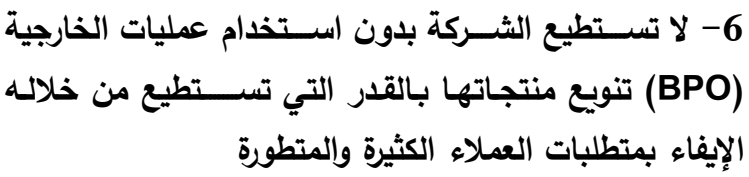 \\
\hline & 40.01 & $* * 0.00$ & 0.86 & 4.32 & 94 & 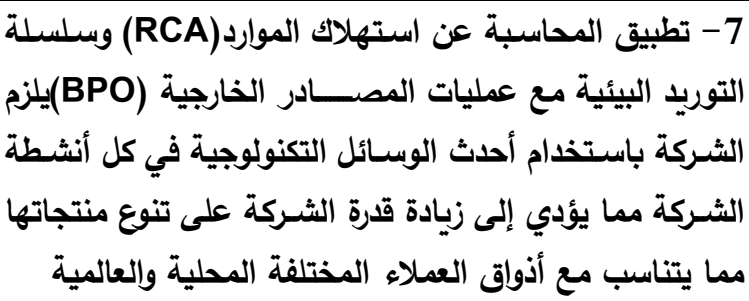 \\
\hline & & $* * 0.00$ & 0.74 & 4.32 & 94 & الوسط الحسابي العام \\
\hline
\end{tabular}

0.05

ويتضح من خلال الجدول السابق: أن كلاً من الوسط الحسابي:

• تطبيق نظام وسلسلة التوريد البيئية يعطى الثركة القدرة على إنتاج منتجات متنوعة تفي

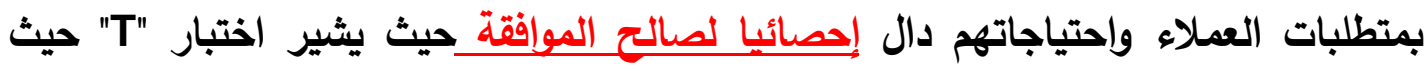
مستوى المعنوية P-value أقل من 0.01 إلى أن هناك علاقة ذات دلالة إحصائية أي أن هناك اختلاف أو فروق معنوية . وبالمثل الوسط الحسابي لتنوع المنتجات لتفى بمتطلبات العملاء يتطلب عدم تكلس المخازن

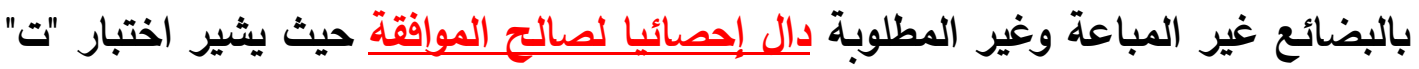
حيث مستوى المعنوية P- value أقل من 0.01 إلى أن هناك علاقة ذات دلالة إحصائية أي أن هناك اختلاف أو فروق معنوية ، وأيضاً الوسط الحسابي تطبيق المحاسبة عن استهلاك الموارد(RCA) يؤدي إلى إحكام الرقابة على موارد الثركة لتمكنها من الاستفادة بكل مواردها

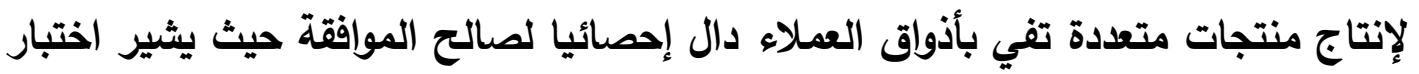
"ت" حيث مستوى المعنوية P-value أقل من 0.01 إلى أن هناك علاقة ذات دلالة إحصائية أي أن هناك اختلاف أو فروق معنوية. • وأيضاً الوسط الحسابي لتطبيق المحاسبة عن استهلاك الموارد(RCA) يؤدي إلى تحفيز العملاء في طلب منتجات الثركة وبالتالي تثجيع الثركة لإنتاج منتجات متعددة تفي لئي

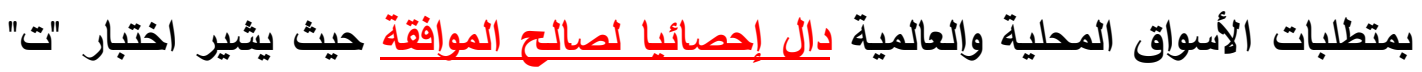
حيث مستوى المعنوية P-value أقل من 0.01 إلى أن هناك علاقة ذات دلالة إحصائية أي أن هناك اختلاف أو فروق معنوية. 
• وبالمثل الوسط الحسابي تطبيق عمليات المصادر الخارجية (BPO) يؤدي إلى إعطاء الثركة القدرة على الاستعانة بالغير لإنتاج المنتجات التقليدية وتتفرغ الثركة ذاتها لإنتاج منتجات مبتكرة وهذا يمكن الثركة من تنويع منتجاتها وإنتشارها على المستوى المحلي والدولي دال إحصائيا لصالح الموافقة حيث يثير اختبار "ت" حيث مستوى المعنوية P-value أقل من 0.01 إلى أن هناك علاقة ذات دلالة إحصائية أي أن هناك اختلاف أو فروق معنوية

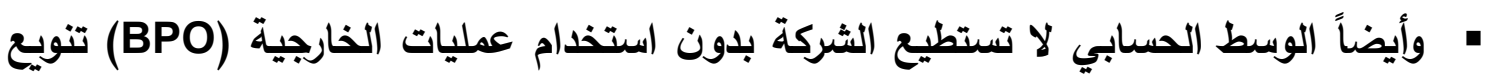
منتجاتها بالقدر الذي تستطيع من خلاله الإيفاء بمتطلبات العملاء الكثيرة والمتطورة دال لإل

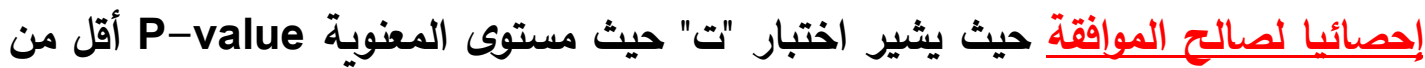
0.01 إلى أن هناك علاقة ذات دلالة إحصائية أي أن هناك اختلاف أو فروق معنوية. • وأخيراً الوسط الحسابي لتطبيق تطبيق المحاسبة عن استهلاك الموارد(RCA) وسلسلة التوريد البيئية مع عمليات المصادر الخارجية (BPO) يلزم الثركة باستخدام أحلث الوسائل

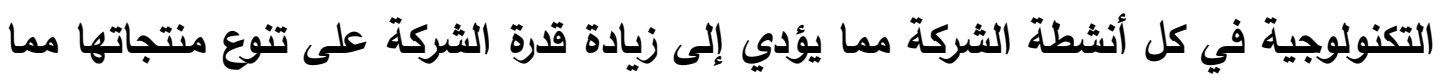

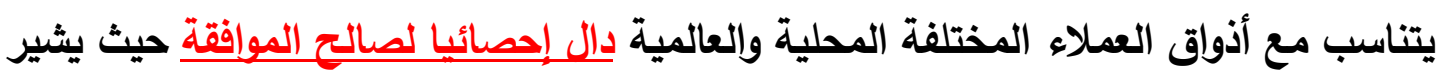
اختبار "ت" حيث مستوى المعنوية P-value أقل من 0.01 إلى أن هناك علاقة ذات دلالة إحصائية أي أن هناك اختلاف أو فروق معنوية. • أن هناك توافق بين آراء العينة حول تطبيق عمليات المصادر الخارجية (BPO) يؤدي إلى إنى إعطاء الثركة القدرة على الاستعانة بالغير لإنتاج المنتجات التقليدية وتتفرغ الثركة ذاتهات التهات

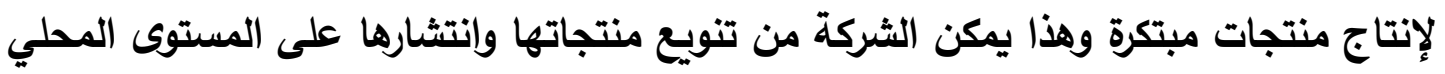
والدولي مما يمثل أكثر أهمية نسبية حيث يأخذ اعلى متوسط للرتب. ويتضح أيضاً من الجدول السابق أن الانحراف المعياري صغيرة لجميع العبارات مما يدل على شبه

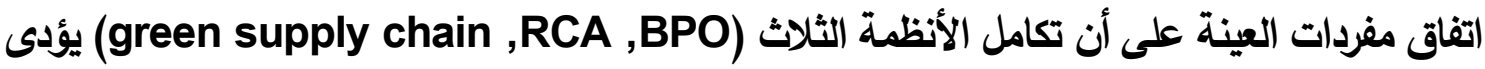
إلى زيادة تنوع منتجات الثركات لتفي بالمتطلبات المتعددة للعملاء وهذا شثبت صحة الفرض الثاني - المقاييس الإحصائية لبيانات الفرض الثالث: والذى ينص على " لا توجد علاقة ذات دلالة إحصائية بين تكامل نظام المحاسبة عن استهلاك الموارد(RCA) وسلسلة التوريد البيئية مع عمليات المصادر الخارجية (BPO) إلى زيادة الحصة 
1- توصيف لآراء المستقصي منهم حول تأثير التكامل بين الأظمة الثلاث RCA وسلسلة التوريد البيئية مع

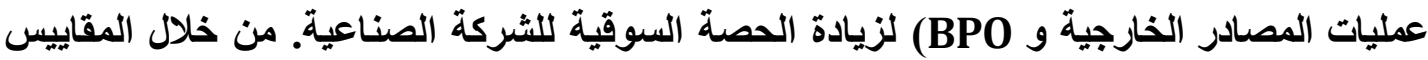

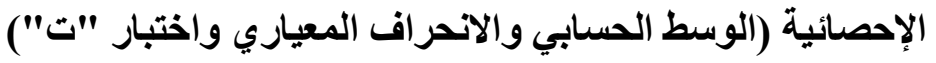

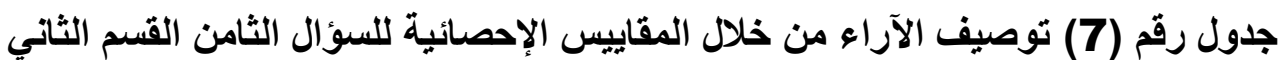

\begin{tabular}{|c|c|c|c|c|c|c|}
\hline المعنوية & متوسط & T-test & المعيارى & الحسابى & 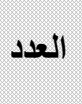 & الســـــــــؤال \\
\hline \multirow{5}{*}{$030.0^{* *}$} & 2.67 & * *0.000 & 0.72 & 4.04 & 94 & 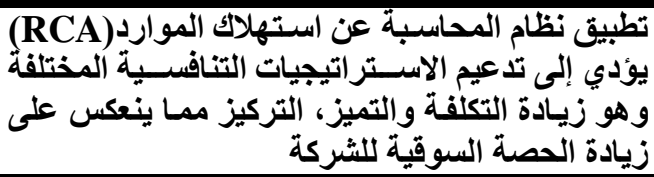 \\
\hline & 2.56 & * *0.000 & 0.62 & 4.47 & 94 & 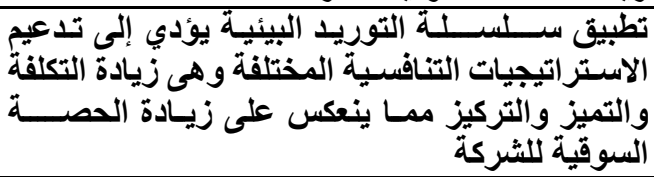 \\
\hline & 2.55 & * *0.000 & 0.64 & 4.38 & 94 & 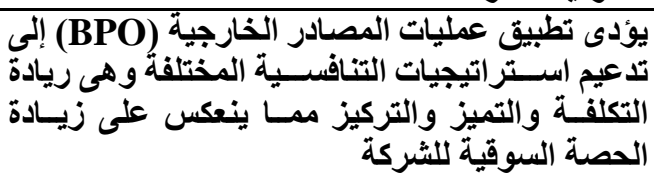 \\
\hline & 2.21 & * *0.000 & 0.58 & 4.43 & 94 & 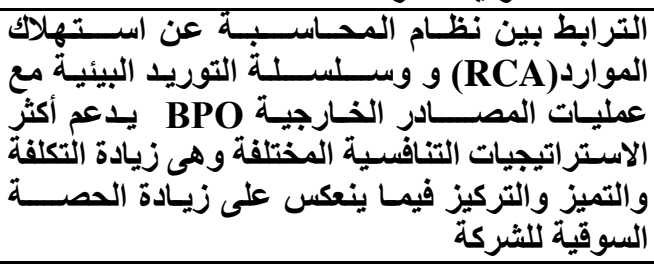 \\
\hline & & **0.000 & 0.64 & 4.33 & 94 & الوسط الحسابي العام \\
\hline
\end{tabular}

• أن كلاً من الوسط الحسابي "وتطبيق نظام المحاسبة عن استهلاك الموارد(RCA) يؤدي إلى . تدعيم الاستراتيجيات التنافسية المختلفة وهو ريادة التكلفة والتميز، التركيز فيما ينعكس على زيادة الحصة السوقية للشركة دال إحصائيا لصالح_الموافقة. ويشير اختبار "ت" حيث مستوى المعنوية P-value أقل من 0.01 إلى أن هناك علاقة ذات دلالة إحصائية أي هناك فروق معنوية ، وبالمثل الوسط الحسابي تطبيق سلسلة التوريا البيئية يؤدي إلى تدعيم الاستراتيجيات التنافسية المختلفة وهى ريادة التكلفة والتميز والتركيز فيما ينعكس على زيادة الحصة السوقية P-value للشركة دال إحصائيا لصالح الموافقة. ويشير اختبار "ت" حيث مستوى المعنوية أقل من 0.01 إلى أن هناك علاقة ذات دلالة إحصائية أي هناك فروق معنوية • وأيضاً الوسط الحسابي. "يؤدى تطبيق عمليات المصادر الخارجية (BPO) إلى تدعيم استراتيجيات التنافسية المختلفة وهي ريادة التكلفة والتميز والتركيز فيما ينعكس على زيادة الحصة السوقية للشركة دال إحصائيا لصالح الموافقة. ويشير اختبار "ت" حيث مستوى 
المعنوية P-value أقل من 0.01 إلى أن هناك علاقة ذات دلالة إحصائية أي هناك فروق معنوية • وأخيراً الوسط الحسابي "الترابط بين نظام المحاسبة عن استهلاك الموارد (RCA) وسلسلة التوريد البيئية مع عمليات المصادر الخارجية (BPO) يدعم أكثر الاستراتيجيات التنافسية المختلفة وهي ريادة التكلفة والتميز والتركيز فيما ينعكس على زيادة الحصة السوقية للشركة

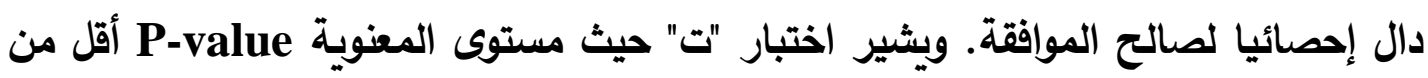
0.01

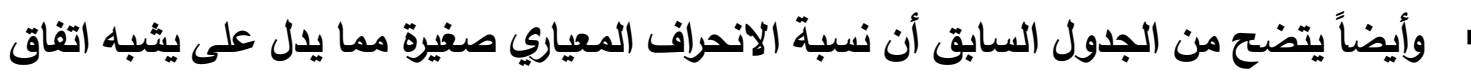
مفردات العينة على أن تكامل الأنظمة الثلاث (نظام المحاسبة عن استهلاك الموارد(RCA) و وسلسلة التوريد البيئية مع عمليات المصادر الخارجية (BPO)) يؤدى إلى تدعيم الاستراتيجيات التنافسية المختلفة وهو ريادة التكلفة والتميز ، التركيز فيما ينعكس على زيله زيادة الحصة السوقية للشركة. وهذا يثبت صحة الفرض الرابع. ويتضح من الجدول السابق وفقا لاختبار فريدمان:• أن هناك توافق بين آراء العينة حول: تطبيق نظام المحاسبة عن استهلاك الموارد(RCA) يؤدي إلى تدعيم الاستراتيجيات التنافسية المختلفة وهى ريادة التكلفة والتميز والتركيز فيما

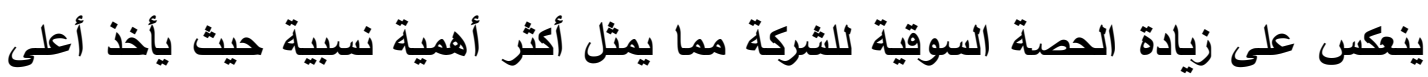
متوسط للرتب • وفى المرتبة الثانية يؤدى تطبيق عمليات المصادر الخارجية (BPO) يؤدي إلى تدعيم استراتيجيات التنافسية المختلفة وهى ريادة التكلفة والتميز والتركيز فيما ينعكس على زيادة الحصة السوقية للشركة. • وفى المرتبة الثالثة الترابط بين نظام المحاسبة عن استهلاك الموارد (RCA) وسلسلة التوريد البيئية مع عمليات المصادر الخارجية (BPO) يدعم أكثر الاستراتيجيات التنافسية المختلفة وهى ريادة التكلفة والتميز والتركيز فيما ينعكس على زيادة الحصة السوقية للثركة • وفى المرتبة الرابعة تطبيق نظام سلسلة التوريد البيئية يؤدي إلى تدعيم الاستراتيجيات




حيث مستوى المعنوية P-value أقل من 0.05 فهذا يعنى وجود اختلاف معنوي في

الأهمية النسبية لآراء المستقصي حول الترابط بين نظام المحاسبة عن استهلاك الموارد (RCA) وسلسلة التوريد البيئية مع عمليات المصادر الخارجية (BPO) يدعم أكثر الاستراتيجيات التنافسية المختلفة وهي ريادة التكلفة والتميز والتركيز فيما ينعكس على زيادة الحصة السوقية للشركة.

\section{- - المقاييس الإحصائية لبيانات الفرض اليرايع:}

ويرتكز هذا الفرض على أن: " لا توجد علاقة ذات دلالة إحصائية بين تكامل نظام المحاسبة

عن استهلاك الموارد(RCA) وسلسلة التوريد البيئية مع عمليات المصادر الخارجية (BPO)

$$
\text { ودعم المركز التنافسي للثركات الصناعية. }
$$

- توصيف لآراء المستقصي منهم حول تأثير تكامل الأنظمة الثلاثة (RCA,سلسلة التوريد البيئيةBPO) لدعم المركز التنافسي للشركات الصناعية ـ من خلال المقاييس الإحصائية

$$
\text { (الوسط الحسابي و الانحراف المعياري وإختبار "T" واختبار فريد مان) }
$$

\begin{tabular}{|c|c|c|c|c|c|c|}
\hline 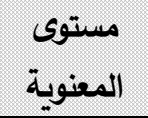 & متوسط & T-test & 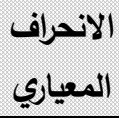 & الحسابي & 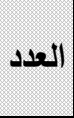 & الســـــؤال \\
\hline \multirow{11}{*}{$* * 0.000$} & 6.38 & $* * 0.000$ & 0.41 & 4.79 & 94 & 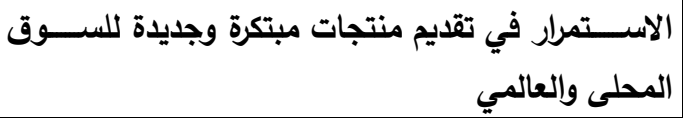 \\
\hline & 6.29 & $* * \mathbf{0 . 0 0 0}$ & 0.43 & 4.77 & 94 & زيادة رضاء العميل \\
\hline & 5.65 & $* * 0.000$ & 0.64 & 4.60 & 94 & خفض التكلفة وزيادة الحصة السوقية \\
\hline & 5.39 & $* * 0.000$ & 0.65 & 4.55 & 94 & الوصول إلى مستوى الفاق والأخطاء إلى الصفر \\
\hline & 5.21 & $* * 0.000$ & 0.65 & 4.51 & 94 & رفع مستوى الجودة وتحسين الإنتاجية \\
\hline & 5.78 & $* * \mathbf{0 . 0 0 0}$ & 0.64 & 4.64 & 94 & التسليم في الوقت المحدد للعملاء \\
\hline & 5.29 & $* * 0.000$ & 0.65 & 4.53 & 94 & تأييد الإدارة العليا للتحسين والتطوير \\
\hline & 4.70 & $* * \mathbf{0 . 0 0 0}$ & 0.64 & 4.40 & 94 & تحسين تقييم الأداء والمساعدة في اتخاذ القرار \\
\hline & 4.98 & $* * 0.000$ & 0.58 & 4.47 & 94 & ضمان الاستمرار والبقاء في الأسواق المحلية والعالمية \\
\hline & 5.33 & $* * 0.000$ & 0.54 & 4.55 & 94 & | دعم المركز التنافسي للشركات الصناعية \\
\hline & & $* * 0.000$ & 0.58 & 4.58 & 94 & الوسط الحسابي العام \\
\hline
\end{tabular}

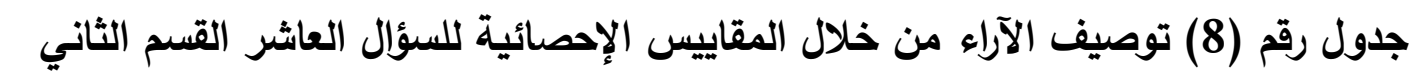

00.01

$$
\text { ويتضح من الجدول السابق: }
$$

• وفقا لاختبار فريدمان أن هناك شبه توافق في آراء العينة حول تكامل الأنظمة الثلاثة يؤدى إلى الاستمرار في تقديم منتجات مبتكرة (وreen supply chain ,RCA,BPO)) 
وجديدة للسوق المحلى والعالمي ما يمثل أكثر أهمية نسبية حيث يأخذ أعلى متوسط للرتب. وفى المرتبة الثانية يؤدى إلى زيادة رضاء العميل. و في المرتبة الثالثة يؤدي إلى تسليم

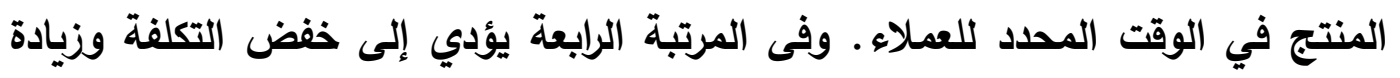



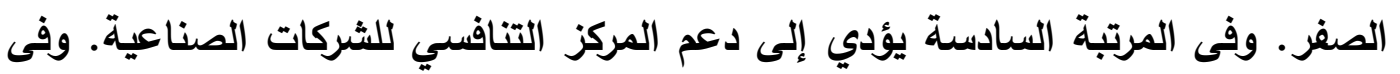
المرتبة السابعة يؤدي إلى تأييا الإدارة العليا للتحسين والتطوير ـ وفى المرتبة الثمادئ الثامنة يؤدي إلى رفع مستوى الجودة وتحسين الإنتاجية. وفى المرتبة التاسعة يؤدي إلى ضمان الاستمرار الإني والبقاء في الأسواق المحلية والعالمية. وفى المرتبة العاشرة يؤدي إلى تحسين تقييم الأداء

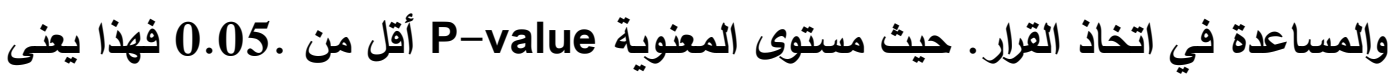
وجود اختلاف معنوي في الأهمية النسبية لآراء المستقصي حول طرق تأثير تكامل الأنظمة

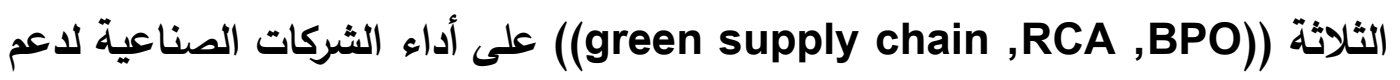
المركز التنافسي التلك الشركات. أن كلاً من الوسط الحسابي تكامل (green supply chain ,RCA ,BPO) يؤدى إلى (لقى الاستمرار فى تقديم منتجات مبتكرة وجديدة للسوق المحلى دال إحصائيا لصالح الموإفقة

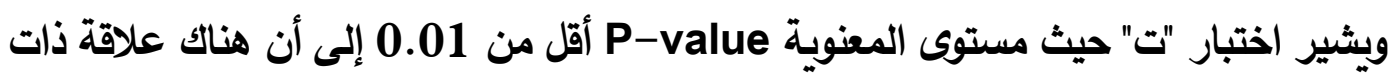

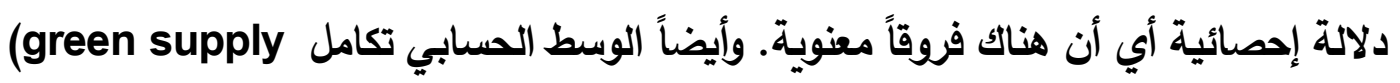
يؤدى إلى زيادة رضاء العميل دال إحصائيا لصالح الموإقة ويشير اختبار "ت" حيث مستوى المعنوية P-value أقل من 0.01 إلى أن هناك علاقة ذئة ذات دلاكيلة

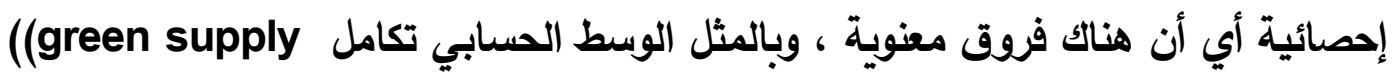

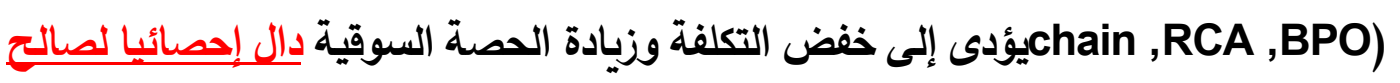
الموافقة ويثير اختبار "ت" حيث مستوى المعنوية P-value أقل من 0.01 إلى أن هناك علاقة ذات دلالة إحصائية أي أن هناك فروقاً معنوية وأيضاً الوسط الحسابي تكامل(green supply chain ,RCA ,BPO) يؤدى إلى الوصول إلى مستوى الفاقد والأخطاء إلى الصفر zero defects ورفع مستوى الجودة وتحسين الإنتاجية

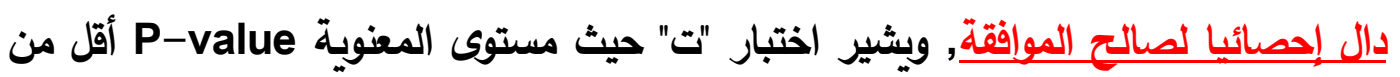
0.01 إلى أن هناك علاقة ذات دلالة إحصائية أي هناك فروق معنوية 
• وأيضاً الوسط الحسابي تكامل (green supply chain ,RCA, BPO) يؤدى إلى التسليم في الوقت المحدد للعملاء دال إحصائيا لصالح الموافقة ويثير اختبار "ت" حيث مستوى المعنوية P-value أقل من 0.01 إلى أن هناك علاقة ذات دلالة إحصائية أي هناك فروق معنوية وبالمثل الوسط الحسابي تكامل (وreen supply chain ,RCA,BPO)يؤدى إلى تأييد الإدارة العليا للتحسين والتطوير و تحسين تقييم الأداء والمساعدة في اتخاذ القرار دال

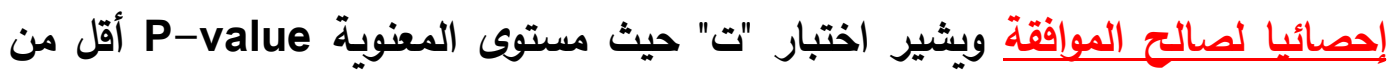
0.01 إلى أن هناك علاقة ذات دلالة إحصائية أي أن هناك فروق معنوية وأيضاً الوسط الحسابي تكامل (green supply chain ,RCA ,BPO) يؤدى إلى ضمان الاستمرار والبقاء في الأسواق المحلية وإلعالمية ودعم المركز التتافسي للشركات الصناعية دال

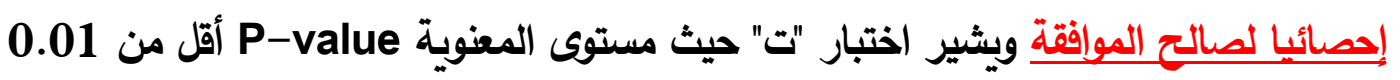

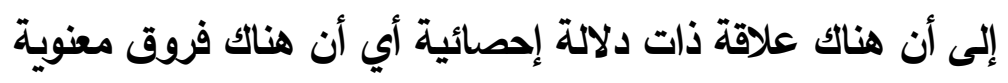

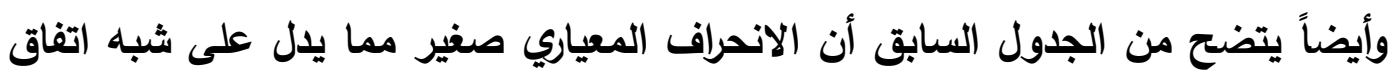

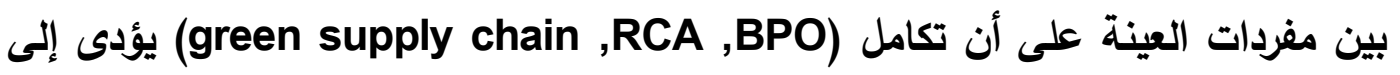

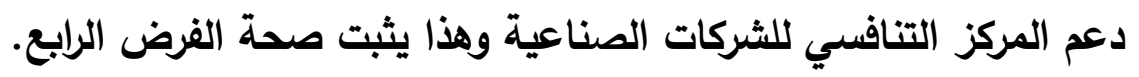

\section{خلاصة ونتائج البحث}

يهاف البحث إلي اقتراح إطار محاسبي لتكامل المحاسبة عن استهلاك الموارد (RCA) وسلسلة التوريد البيئية مع عمليات المصادر الخارجية (BPO) وذلك بهدف دعم القدرة التنافسية لمنشآت الأعمال الصناعية، وقد تم التوصل للنتائج التالية: 1. إن تطبيق مدخل المحاسبة عن استهلاك الموارد يحقق العديد من المزايا في كدالات التخطيط الفعال للموارد، فضلا عن دعمه لفلسفة التوجه نحو إرضاء العملاء. 2. يتكامل مدخل المحاسبة عن استهلاك الموارد مع مدخل لتكامل المحاسبة عن استهلاك الموارد مع سلسلة التوريد البيئية مع عمليات المصادر الخارجية في تحديد خطوات القيود

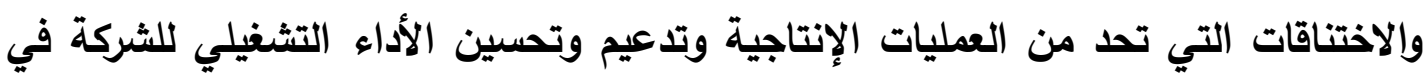
النقاط لتي بها اختناقات أو قيود. 
3. يتكامل مدخل المحاسبة عن استهلاك الموارد ومدخل تكلفة المواصفات في تحليل خطوات تحديد تكلفة مواصفات المنتج وخصائص المنتج وتحديد مجمعات الموارد ومسبباتها والعلاقات التشابكية. 4. يتكامل مدخل المحاسبة عن استهلاك الموارد ومدخل تدفق القيمة في توفير المعلومات عن

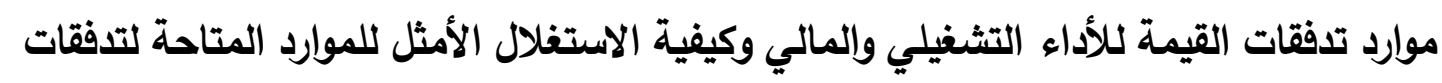
(القيمة. 5. تعتبر ممارسات إدارة سلسلة التوريد (ملخل لتحسين الأداء التنافسي من خلال تكامل الوظائف

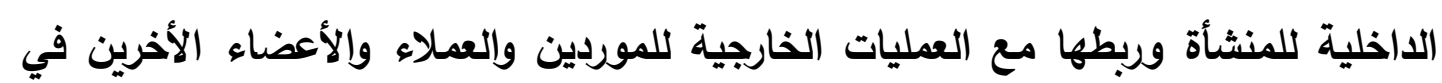

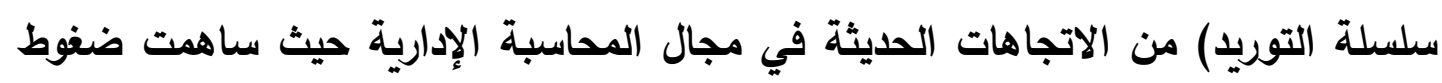
المنافسة في توجه منشآت الأعمال نحو إقامة علاقات مغلقة طويلة الأجل تحت مفهوم سلسلة

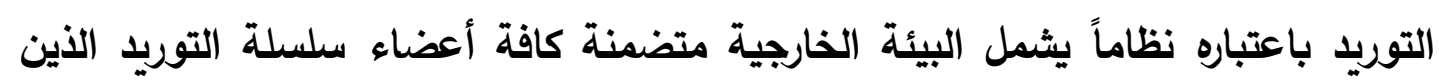

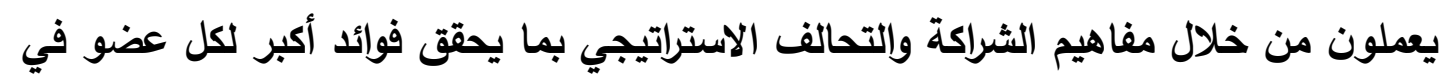
ظل الحفاظ على الحجم والثخصية المعنوية لكل وحدة من أعضاء السلسلة.

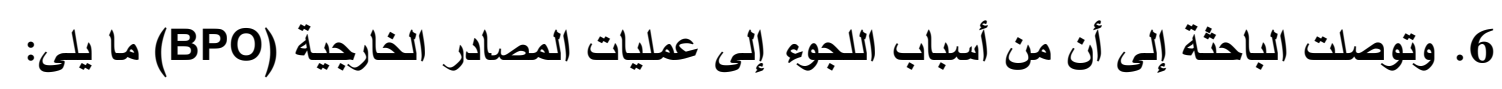
• قصور بعض الثركات عن أداء جميع أنثطتها بالجودة والتكلفة المطلوبة. • ت •تميز بعض الدول بأداء بعض الأنثطة بأعلى جودة وأقل تكلفة.

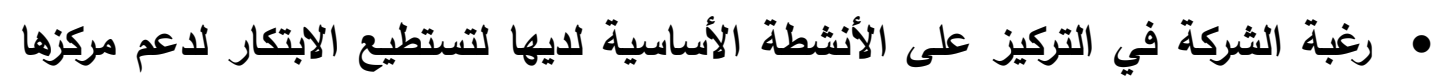
التنافسي. • رغبة الثركة في تعدد أنواع إنتاجها لتفي بمتطلبات أذواق العملاء المختلفة والمتجددة بسرعة فائقة للحصول على حصة سوقية أكبر على مستوى الأسواق المحلية والعالمية.

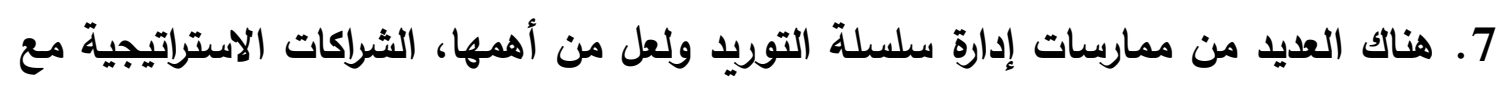

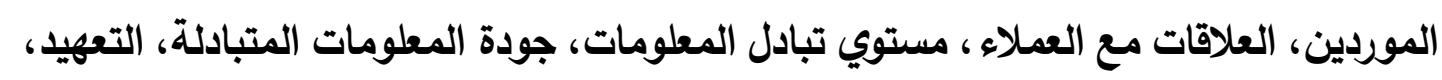

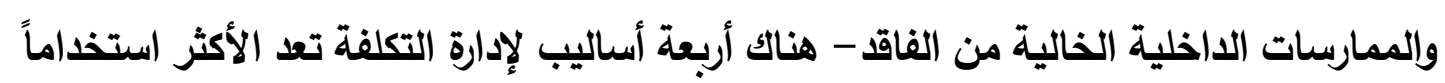

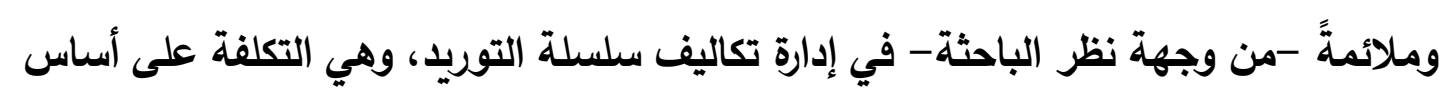
النشاط. 
8. ولكن بالرغم من الأسباب والمزايا التي توفرها عمليات المصادر الخارجية (BPO) للشركة توجد بعض العيوب والمشاكل التي لابد من التفلب عليها للاستفادة بمميزات عمليات المصادر الخارجية ومن أمثلة تلك المشاكل: أ. فقد الثركة التحكم والرقابة على الأنثطة التي يتم أداؤها عن طريق عمليات المصادر

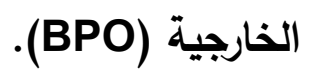

ب. الاستفناء عن بعض العاملين الذي كانوا يؤدون الأنشطة التي تم إسنادها لمورد خارجي. ج. فقد الثركة جزء من سرية معلوماتها. د. اختلاف البيئات والثقافات بين موردي عمليات المصادر الخارجية (BPO Provider) وبين مستخدمي عمليات المصادر الخارجية (BPO Client) 9. يؤدي نجاح المنشآت في تطبيق المحاسبة عن استهلاك الموارد (RCA) الي نجاحها في

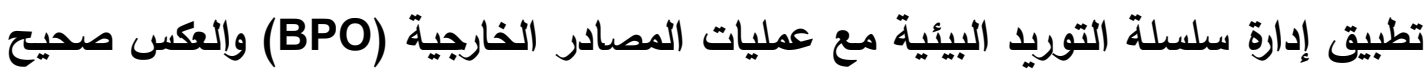

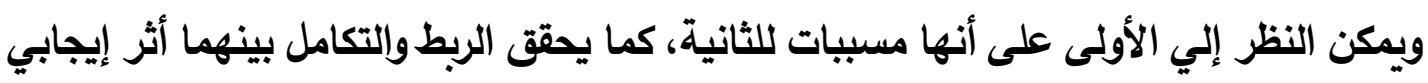

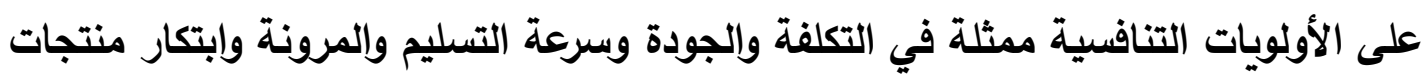
جديدة وزيادة حصتها السوقية مما يدعم من قدرتها التنافية.

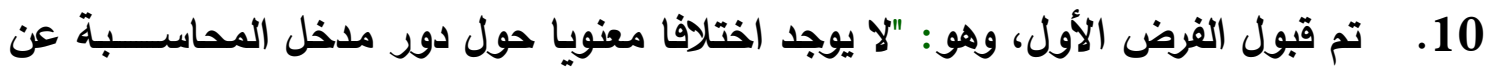

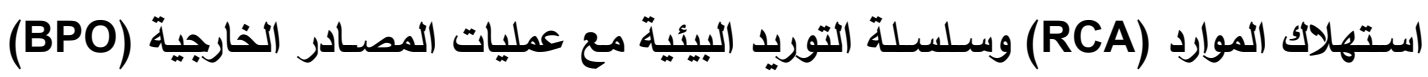
إلى تحقيق وفورات في تكاليف الثركات الصناعية"، نظرا للاعتبارات التالية: استجابات عينة الدراسة علي عبارات اختبار هذا الفرض لم تختلف جوهريا عن القيمة المثلي والتي تبلغ 86.4\% فأكثر، وقد جاءت هذه العبارات مرتبة حســب أهميتها من وجهة نظر عينة الاراسة علي النحو التالي: أولا: يعتبر مدخل المحاسـبة عن اسـتهلاك الموارد (RCA) مكملا لسـلســلة التوريد البيئية ومكملا أيضا لعمليات المصادر الخارجية (BPO) لتخفيض تكاليف الإنتاج. ثانيا: تطبيق سلسلة التوريد البيئية يؤدي إلى الاهتمام بدورة حياة المنتج.

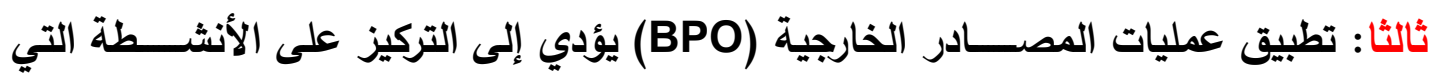
تتميز بها الشركة 
رابعا: تطبيق مدخل المحاســبة عن اســتهلاك الموارد (RCA) يؤدي إلى تخفيض تكاليف الإنتاج.

11. تم قبول الفرض الثاني، وهو : "'لا يوجد اختلافا معنويا حول دور تطبيق المحاســبة عن

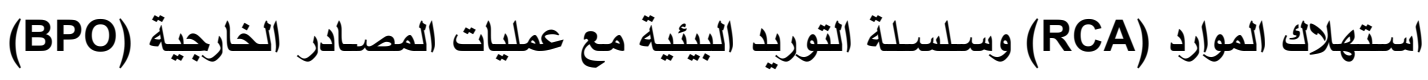
إلى إعطاء الثركة القدرة على إنتاج منتجات متعددة تفي بمتطلبات العملاء". نظرا للاعتبارات التالية: • استجابات عينة البحث على عبارات اختبار هذا الفرض لم تختلف جوهريا عن القيمة المثلي

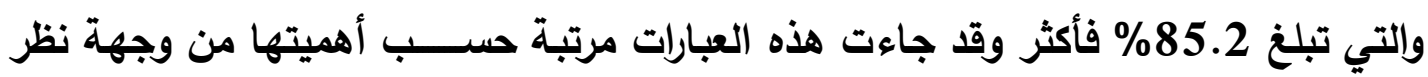
عينة البحث على النحو التالي: تلبع أولا: تطبيق نظام وسـلسـلة التوريد البيئية يعطى الثـركة القدرة على إنتاج منتجات متنوعة تفي بمتطلبات العملاء وإحتياجاتهم ثانيا: تنوع المنتجات لتفي بمتطلبات العملاء يتطلب عدم تكلس المخازن بالبضـائع غير المباعة وغير المطلوبة ثالثا: تطبيق المحاسبة عن استهلاك الموارد (RCA) يؤدي إلى إحكام الرقابة على موارد الشركة

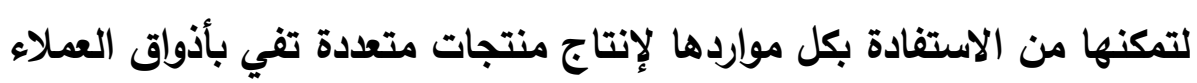
رابعا: تطبيق المحاسبة عن استهلاك الموارد (RCA) يؤدي إلى تحفيز العملاء في طلب منتجات

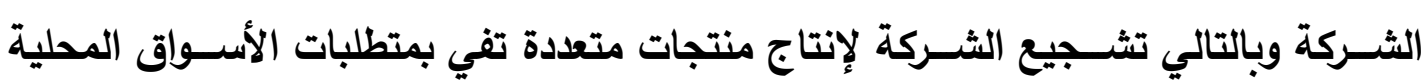
والعالمية

خامســا: تطبيق عمليات المصـــادر الخارجية (BPO) يؤدي إلى إعطاء الثــــركة القدرة على الاستعانة بالغير لإنتاج المنتجات التقليدية وتتفرغ الثـركة ذاتها لإنتاج منتجات مبتكرة وهذاء إلهاء يمكن الشركة من تنويع منتجاتها وإنتشارها على المستوى المحلي والدولي لإني

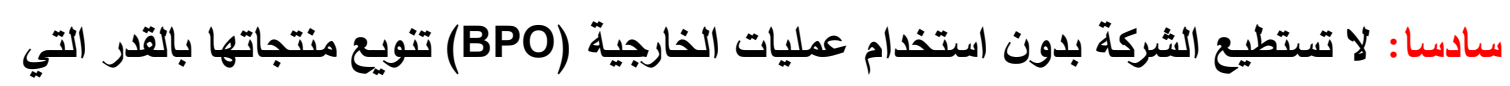
تستطيع من خلاله الإيفاء بمتطلبات العملاء الكثيرة والمتطورة

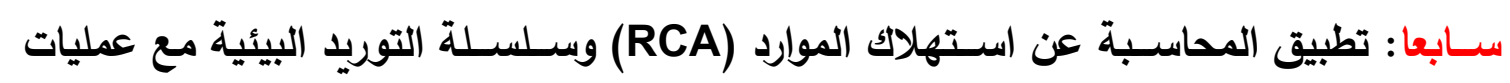

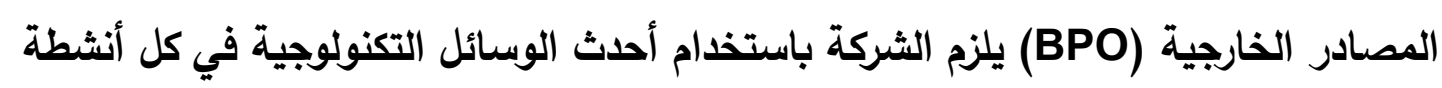


الشركة مما يؤدي إلى زيادة قدرة الثركة على تنوع منتجاتها مما يتناسب مع أذواق العملاء المختلفة المحلية والعالمية. أفادت نسـبة 89.4\% من إجمالي المسـتقصسي منهم تطبيق عمليات المصـادر الخارجية يؤدي إلى إعطاء الثــركة القدرة علي الاســـعانة بالغير لإنتاج المنتجات التقليدية

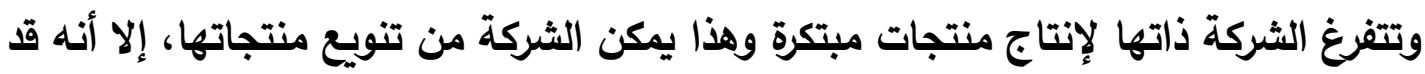

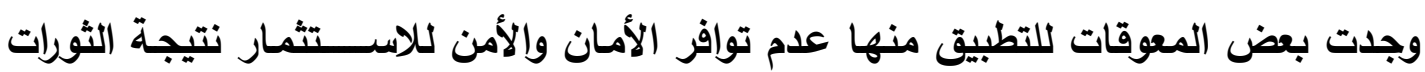
والانفلات الأمني مما أدي إلى صـعوبات مع موردي عمليات المصـادر الخارجية في تسـليم الطلبات في الوقت المناسب. لا توجد علاقة ذات دلالة إحصائية بين تكامل نظام المحاسبة عن استهلاك الموارد (RCA) وسلسلة التوريد البيئية مع عمليات المصادر الخارجية (BPO) إلى زيادة الحصة السوقية للثركة الصناعية. • تم قبول الفرض الثالث: لا توجد علاقة ذات دلالة إحصـائية بين تكامل نظام المحاسـبة عن

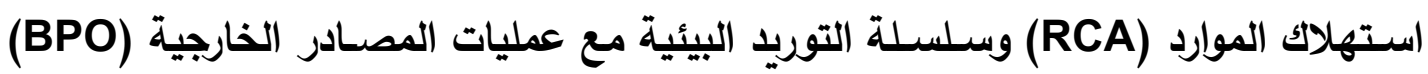
ودعم المركز التنافسي للثركات الصناعية" نظرا للاعتبارات التالية:

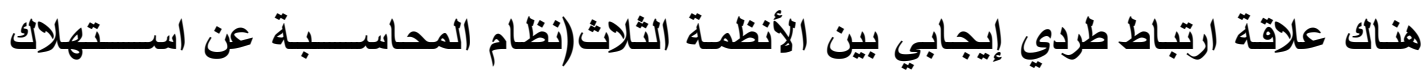
الموارد(RCA) وسلسلة التوريد البيئية مع عمليات المصادر الخارجية (BPO) وأبعاد المركز التنافسي والمتمثلة في، الاستمرار في تقديم منتجات مبتكرة وجديدة للسوق المحلي والعالمي،

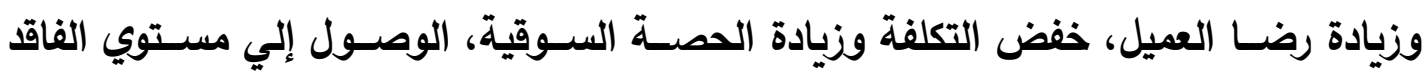
والأخطاء إلي الصـفر، رفع مسـتوي الجودة وتحسـين الإنتاجية، التسـليم في الوقت المحدد

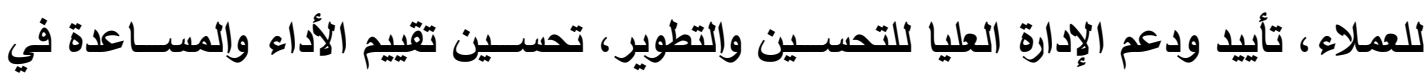
اتخاذ القرار، ضمان الاستمرار والبقاء في الأسواق المحلية والعالمية . • تم قبول الفرض الرابع: وهو "يؤدي تطبيق نظام المحاســبة عن اســــلاك الموارد (RCA)

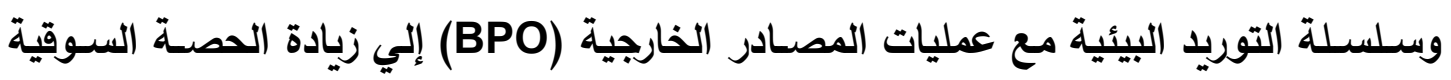
للشركة الصناعية"، نظرا للاعتبارات التالية: أولا: تطبيق سـلسـلة التوريد البيئية يؤدي إلى تدعيم الاسـتراتيجيات التنافسية المختلفة وهي

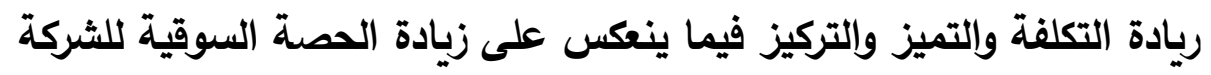




\section{مجلة البحوث المالية والتجارية ـ المجلد (22) - العدد الثاني - إبريل 2021}

ثانيا: يؤدى تطبيق عمليات المصـادر الخارجية (BPO) إلى تدعيم اسـتراتيجيات التنافسـية المختلفة وهي ريادة التكلفة والتميز والتركيز فيما ينعكس على زيادة الحصة السوقية للشركة ثالثا: الترابط بين نظام المحاسبة عن استهلاك الموارد (RCA) وسـلسـلة التوريد البيئية مع عمليات المصـادر الخارجية (BPO) يدعم أكثر الاستراتيجيات التنافسية المختلفة وهي ريادة التكلفة والتميز والتركيز فيما ينعكس على زيادة الحصة السوقية للشركة

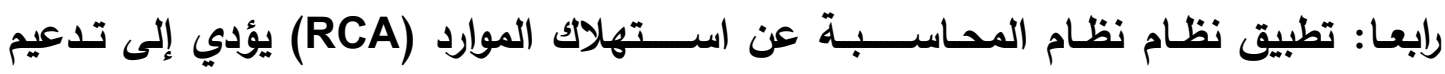

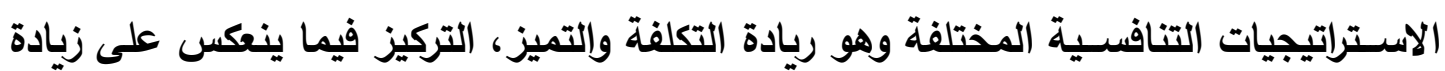
العصة السوقية للشركة استناداً لما توصلت إليه الاراسة من نتائج تقترح الباحثة التوصيات الآتية: 1-دراسة إمكانية التكامل بين مدخل المحاسبة عن استهلاك الموارد وحوكمة الشركات بغرض

تدعيم الثفافية والرقابة المالية علي الموارد المتاحة في القطاعات الصناعية أو الخدمية. 2-محاولة تطبيق مدخل المحاسبة عن استهلاك الموارد والإطار المقترح في هذا البحث علي القطاعات الصناعية أو الخذمية بغرض تدعيم القدرات التنافسية لهذه القطاعات. 3- توجيه عناية الثركات الصناعية بتبني فكرة تطبيق التكامل بين المحاسبة عن استهلاك الموارد (RCA) وسلسلة التوريد البيئية مع عمليات المصادر الخارجية (BPO) لاعم مركزها التنافسي. 4- ضرورة تكوين فرق عمل وإعطائهم دورات تدريبية مكثفة على كيفية تطبيق الأنظمة الثلاث) المسئولية الاجتماعية، وسلسلة التوريد،BPO ) وعمل لجنة لتقييم أدائهم بصورة مستمرة وإعطاء مكافاة لمن يقوم بتحسين أداءه باستمرار. 5- دراسة أنشطة الثركة بعناية فائقة وتقسيمها إلى أنثطة رئيسة وهى الأساسية لإنتاج المنتج وهى الموجودة في مراحل دورة حياة المنتج وأنثطة فرعية وهى المساعدة في إتمام عمليات

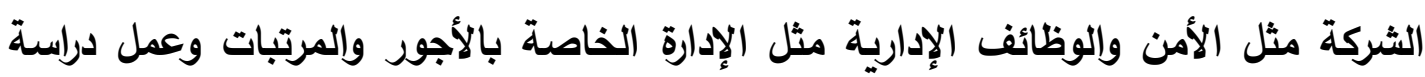

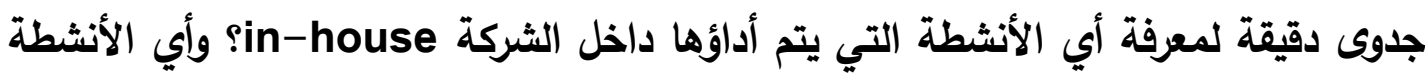
التي سوف يتم أداؤها عن طريق مورد خارجي Ooutsourcing 6- توجيه عناية وزارة الصناعة والتجارة بأن تقوم بتثجيع الثركات الصناعية لتطبيق الأنظمة الثلاث) المسئولية الاجتماعية، وسلسلة التوريدBPO عن طريق تمويلهم بالقروض الحسنة 
استخدام مدخل قياس التكاليف للمحاسبة عن استهلاك الموارد(RCA) ......... د.. ايناس جمعه شكر

لكي يستطيعوا أن يقوموا بإحلال خطوط الإنتاج بأحلث خطوط إنتاج لتلائم تطبيق الأنظمة الحديثة.

\section{المراجح}

أولا: المراجع العربية:-

1- د. احمد عبد العليم إسماعيل محمد ، (2019)، " دور إدارة التكلفة في دعم القدرة التنافسية

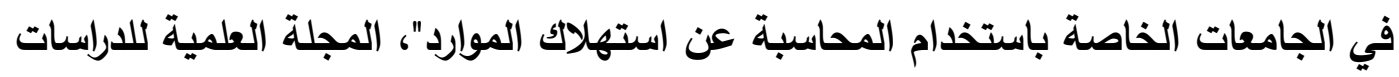

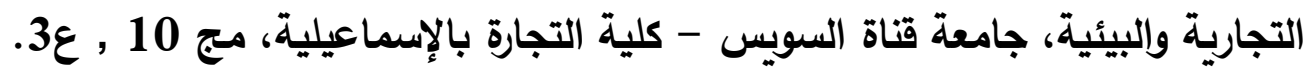

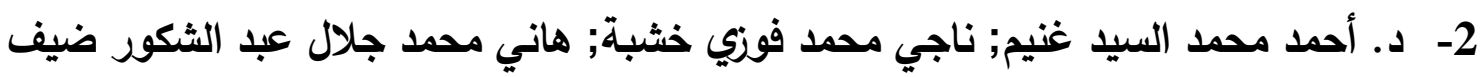

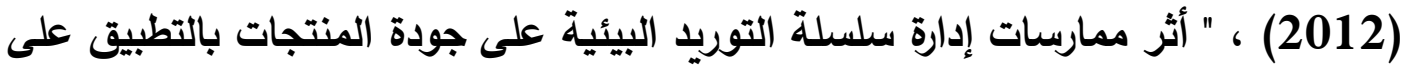

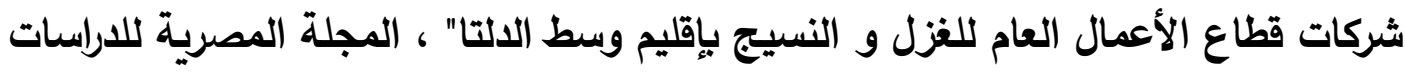

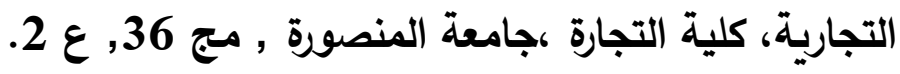

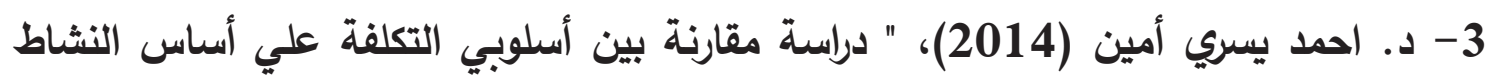

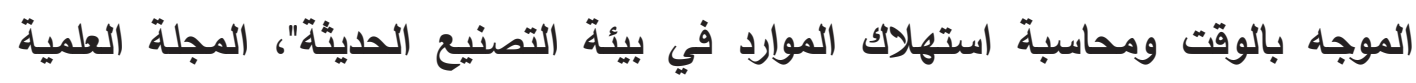

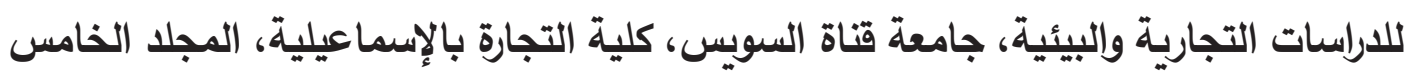

$$
\text { ، العدد الأول، ص 253- } 255 .
$$

4 - د. أمجاد محمد الكومي (2007) ، " اطار مقترح لتحقيق التكامل بين مدخل محاسبة استهلاك الموارد (RCA) و نظرية القيود (TOC) لأغراض إدارة الطاقة بالوحدات الاقتصادية"، المجلة

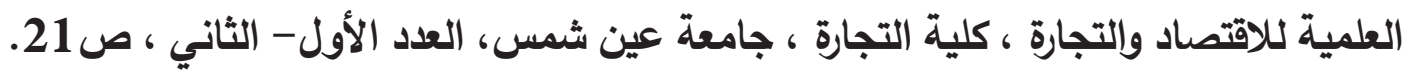

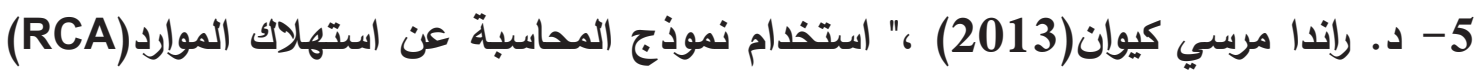

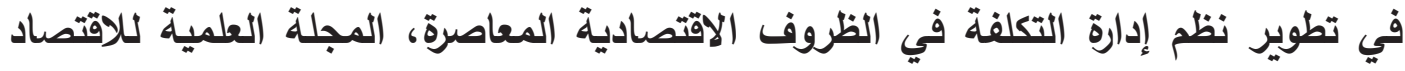
والتجارة، كلية التجارة، جامعة عين شمس، المجلد الثالث، العدد الثاني. 6- رقية محمود إسحيل محمود(2017) ،" التكامل بين أسلوب التكلفة المستهدفة TC ومدافل قياس التكلفة على أساس المواصفات ABCII بهدف تخفيض التكاليف- دراسة تطبيقية"، رسالة ماجستير غير منشورة في المحاسبة، كلية التجارة - جامعة المنصورة. 


\section{مجلة البحوث المالية والتجارية ـ المجلا (22) ـ العدد الثاني - إبريل 2021}

7 - د. صفاء محمد عبد الدايم (2014)،" مدخل مقترح للتكامل بين نظامي المحاسبة عن

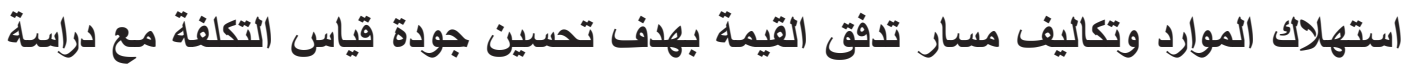

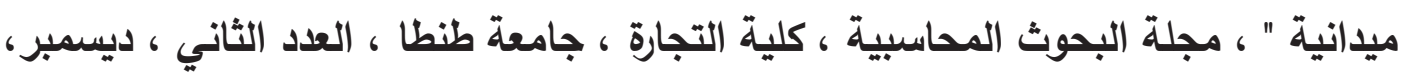
ص: 234-266. 8- د. علي مجدب سعد الغروري(2010) ، " المحاسبة علي استهلاك الموارد" ، المجلة المصرية للاراسات التجارية ، كلية التجارة ، جامعة المنصورة ، المجلد الرابع والثلاثون ، العدد الأول

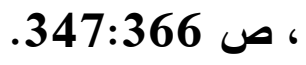

9- على عبد الله الثطبي (2016) ،" الدور التأثيري لمدخل محاسبة استهلاك الموارد في زيادة



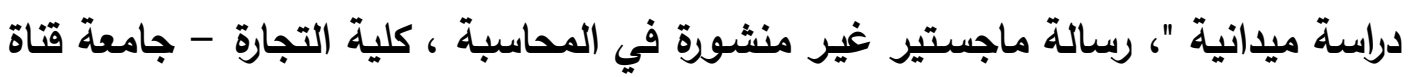
السويس.

10- د. فتحي رزق السوفيري، فه بن سليمان النافع (2013)،" تطوير عملية تخصيص التكاليف غير المباشرة وفق الأنشطة الموجه بالوقت ومحاسبة استهلاك الموارد مع التطبيق على شركة أسمنت القصيم"، مجلة كلية التجارة للبحوث العلمية، كلية التجارة، جامعة الإسكندرية، العدد الثاني، المجلد 50. 11- د. محمد شحاته خطاب (2009)، " اطار مقترح للتكامل بين نظام التكاليف علي أساس



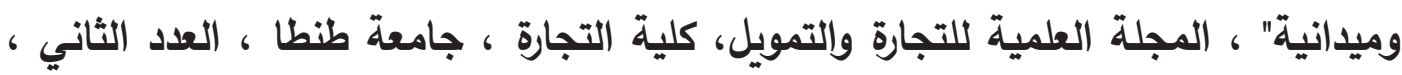
ص133-137.

12- د. محمد السيد الصغير(2011) ، " اطار مقترح للتكامل بين مدخل تكلفة المواصفات ومحاسبة استهلاك الموارد لأغراض دعم القدرة التنافية للمنثأة" ، مجلة البحوث التجارية

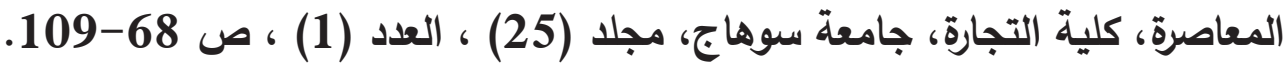
13- د. محمد احمد شاهين(2010) ،" دراسة تحليلية لمدخل المحاسبة عن استهلاك الموارد

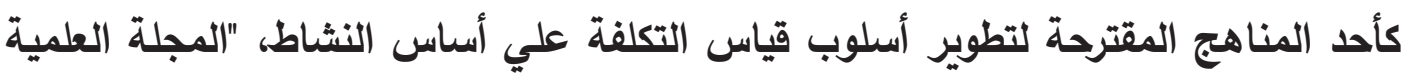
للاقتصاد والتجارة ، كلية التجارة ، جامعة عين شمس ، العدد الرابع ، الجزء الأول ، أكتوبر، الجيل ص 240:249.

14- د. هاني احمد محاريق (2017)،" أثر التكامل بين نظام تخطيط موارد المنشأة ونظام

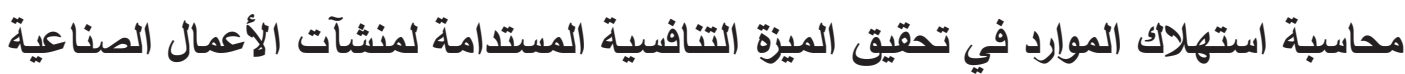


: دراسة نظرية وميدانية "، مجلة البحوث المحاسبية ، كلية التجارة - جامعة طنطا، العدد

الأول.

15- هثام سعيد إبراهيم محمد (2009)، "استخدامات نظرية القيود في مجال المحاسبة الإدارية

لأغراض التقييم وترشيد القرارات التثغيلية- دراسة ميدانية"، رسالة دكتوراه في المحاسبة،

$$
\text { كلية التجارة، جامعة عين شمس. }
$$

16 - هند ماهر طولان(2018) ، " قياس الطاقة غير المستخدمة في نظام التكاليف علي أساس

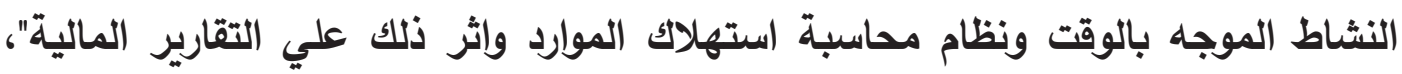

رسالة ماجستير غير منشورة، جامعة طنطا ، كلية التجارة.

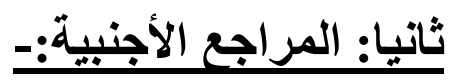

1- Barbara B. Flynn, Baofeng Huo, Xiande Zhao. (2011) "The Impact of Supply Chain Integration on Performance: A Contingency and Configuration Approach, Journal of Operations Management1 Vol. 281 No. 2.

2- Baki Yilmaz \& Mehmet Burak Ceran. (2017). The Role of Resource Consumption Accounting in Organizational Change and Innovation. Economics, Management \& Financial Markets, 12. No.(2), 131-140

3- Che-Fu Hsueh,(2014)," Improving corporate social responsibility in a supply chain through a new revenue sharing contract", International Journal of Production Economics, vol. 151, issue C, 214-222

4- Chin O.; L. Fang; H Yu, and D. Yen (2010). A Structural Model of Supply Chain Management on Firm Performance. International Journal of Operations \& Production Management. 30 (5): 526-545.

5- David Perkins \& O. Scott Stovall, (2011)," Resource Consumption Accounting - Where Does It Fit?, "Journal of Applied Business Research, Sep/Oct, Vol. 27, No. 5, PP.41-52

6- Ellram L. M. (2002). Strategic Cost Management in the Supply Chain: A Purchasing and Supply Management Perspective. Arizona State University, Institute for Supply Management, Center for Advanced Purchasing Studies.

7- Forough Karimi, and Others," An Assessment of the Use of Transaction Cost Theory in Information Technology Outsourcing", Journal of Strategic information Systems, (20), 2011

8- Gayathri Sundar, "Business Process Outsourcing - Determinants of Success", Thesis of Doctor Philosophy in Business administration, in Edward A Gene School of Business Golden Gate university Sanfrancisco, 2008. 
9- Hasan Ozyapici, Veyis Naci Tanis, (2016), "Improving Health Care Costing With Resource Consumption Accounting ", International Journal Of Health Care Quality Assurance, Vol. (29), Issue. (6), PP. $646-663$.

10- Hamister, J. (2012). Supply Chain Management Practices in Small Retailers. International Journal of Retail \& Distribution Management. 40 (6): 427-450

11- Jan Mouritsen,. (2003) Intellectual Capital and the Capital Market, Accounting, Auditing and Accountability Journal ( vol. 16, no.1, pp. 18-30)

12- Julia A. Smith, Jonathan Morris, Mahmoud Ezzamel,(2005) : "Organization Change, Outsourcing and the Impact on Management Accounting ", The British Accounting Review, (37)

13- Jonathan William Whitaker,(2007), "Implications of on Shore and off Shore Business Process outsourcing for Firms and Customers", Thesis of Doctor of Philosophy in business administration, in the university of Michigan.

14- Kauffman, R. and T., Crimi (1998). "Supply Chain Cost Reduction Strategies".83rd Annual International Conference Proceedings. Available online at: http://joaoportasio-dissertacao.googlecode.com

15- Kbelah, Sarahi \& Almagtome, Akeel. (2019). Using Resource Consumption Accounting for Improving the Competitive Advantage in Textile Industry. Journal of Engineering and Applied Sciences. 14. 575-582. 10.3923/jeasci.2019.575.582.

16- Kenyon G. and M. J. Meixell (2011). Success Factors and Cost Management Strategies for Logistics Outsourcing. Journal of Management and Marketing Research.7: 1-17.

17- Keys, David E. ; Merwe, Anton van der. (2001). The case for RCA: Excess and idle capacity. Journal of cost management, 15(4), 21-32.

18- Larry White . (2009). Resource consumption accounting: Managerfocused management accounting. Journal of Corporate Accounting \& Finance, Vol. 20 .Issue, 4 p. 64. www.interscience.wiley.com

19- Li S.; B. Ragu-Nathan; T. Ragu-Nathan and S. Rao (2006).The Impact of Supply Chain Management Practices on Competitive Advantage and Organizational Performance. International Journal of Management Science,. 34 (2): 107 - 124.

20- Li, G., Yang, H., Sun, L., Sohal, A.S., (2009).The impact of IT implementation on supply chain integration and performance. International Journal of Production Economics 120, 125-138 
21- Luo, Y., Zheng, Q., \& Jayaraman, V. (2010). "Managing business process outsourcing. Organizational Dynamics, Journal, Vol. 39 , No.3 39(3), 205-217. https://doi.org/10.1016/j.orgdyn.2010.03.005

22- Mostafa Al-Qady., \& Said El-Helbawy, (2016). "Integrating Target Costing and Resource Consumption Accounting" . Journal of Applied Management Accounting Research, 14(1), 39-54.

23-Mohamed Fathy Elshahat (2016). Resource Consumption Accounting (RCA): The Challenges and Application Obstacles in the Egyptian Automotive Industry" . International Journal of Business, Accounting, \& Finance, 10(1), 103-125.

24- Moslem Ghatebi, Elham Ramezani, Mohammad Ali Enayati Shiraz (2013), " Impact of Supply Chain Management Practices on Competitive Advantage in Manufacturing Companies of Khuzestan Province, Interdisciplinary", Journal of Contemporary Research in Business. VOL 5, NO 6 . P.P: 269- 274.

25- Niknia , B. (2007). Customer Relationship Management (CRM). Shoe industry. The fourteenth year, No. 118, pp. 52-53.

26- Nicholas B., and S. Amrik (2004). Outsourcing in Australia. International Journal of Operations \& Production Management. 24(7): 688-700.

27- nMcNair, C. J., (2007), "Beyond the Boundaries: Future Trends in Cost

Management", Cost Management, 21(1), pp. 10-21

28- Ragishekhar, G and Others, "Outsourcing to Emerging Markets: Theoretical Perspectives and Policy Implication", Journal of International Management, (15), 2009

29- Rahimi , M.,sheybani , z. , sheybani , E.,and Abed , (2014)," Recourse consumtion Accounting :Anew Approach to managmenr accounting" ,www.Absronline.Org/journalE-SSN , Vol. 3 , No. 4 .

30- Ramji Balakrishnan, Eva Labro, and K. Sivarama krishnan (2012) Product Costs as Decision Aids: An Analysis of Alternative Approaches (Part 2). Accounting Horizons: March, Vol. 26, No. 1, pp. 21-41.

31- Richard D. Janmes, "Strategic Outsourcing For Manufacturing Firms", Thesis of Doctor of Engineering, The Faculty of the School of Engineering and Applied Science, Southern Methodist University, 2011.

32-Sally Webber, \& Douglas Clinton. (2004). Resource consumption accounting applied: The Clopay case, Management Accounting Quarterly Fall , Vol. 6, No. 1, 1-14 
مجلة البحوث المالية والتجارية ـ المجلا (22) - العدد الثاني - إبريل 2021

33-Seuring, S. / Goldbach, M. (eds.): Cost Management in Supply Chains, physical-Verlag, Heidelberg 2002, ISBN 3-7908-1500-4, PP 445.

34-Syed Ajaz Ahmed \& Mehboob Moosa ,(2011),"Application Resource Consumption Accounting (RCA) in An Educational Institute", Pakistan Business Review ,PP 755-775.

35- Swink, M.; R. Narasimhan; and C., Wang (2007). Managing beyond the factory walls: Effects of four types of strategic integration on manufacturing plant performance. Journal of Operations Management. 25 (1): 148-164

36- Talib, F.; Z. Rahman and M. Qureshi (2011). A study of Total Quality Management and Supply Chain Management Practices. International Journal of Productivity and Performance Management. 60 (3): 268-288

37- Vokurka R.; Z. Gail and L. Carl, (2002). Improving Competitiveness through Supply Chain Management: A Cumulative Improvement Approach. Competitiveness Review. 12(1): 14-25.

38- Wei Z. and W. Xiang (2013). The Importance of Supply Chain Management", International Journal of Business and Social Science. 4 (16): 279- 282

39- Yong, L. and Z., Li, (2011). The Impacts of Product Design Changes on Supply Chain Risk: A Case Study. International Journal of Physical Distribution \& Logistics Management. 41(2): 162-186

40- Yodong Luo and Others, "Managing Business Process outsourcing", Organizational Dynamics Journal, Vol. 39 , No.3 , 2010

41-Zhu Q., \& Sarkis J., (2004)"Relationships between operational practices and performance among early adopters of green supply chain management Practices in Chinese manufacturing enterprises" Journal of Operations Management ,22, 265-289 


\section{(1) مطمق رقم: \\ قائمة الاستقمساء}

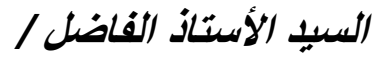

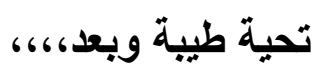

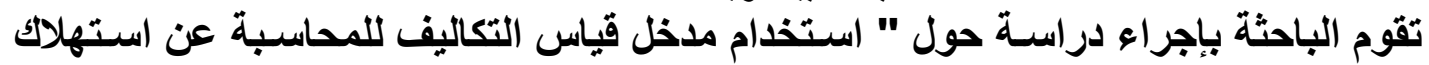

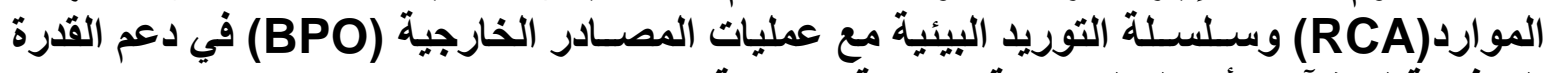

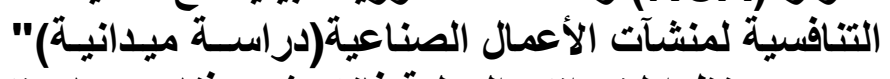

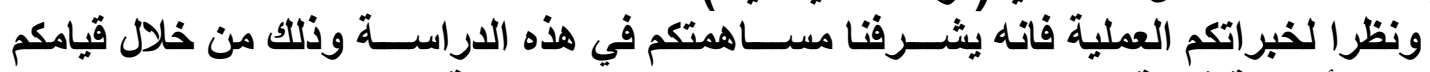

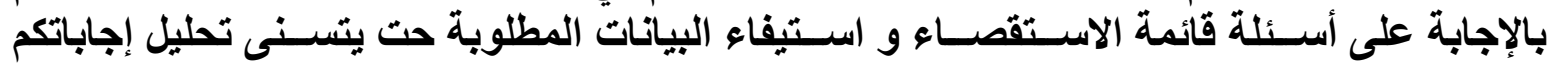
الواردة في قائمة الاستة ألقصاء

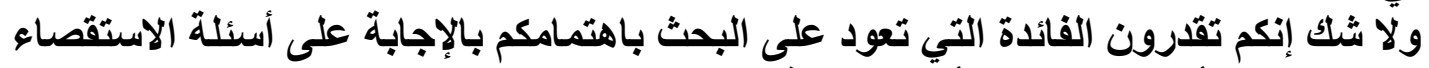

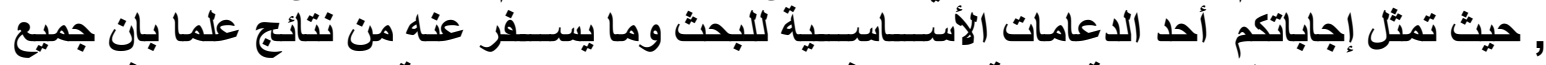

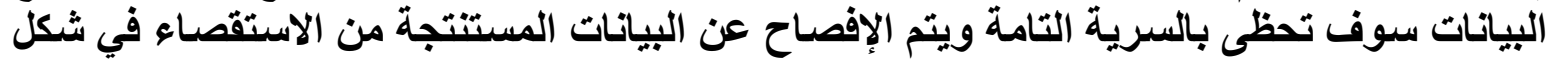

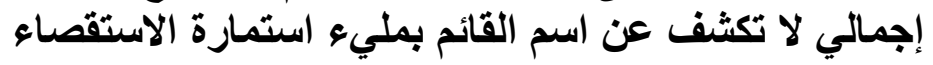
وشئرا على حسن تعاونكم

الباحثة

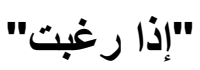

القسم الاول: مطلومات عامة عن السيد القائم بمليء الاستمارة

من فضلك استيفاء البيانات التالية:

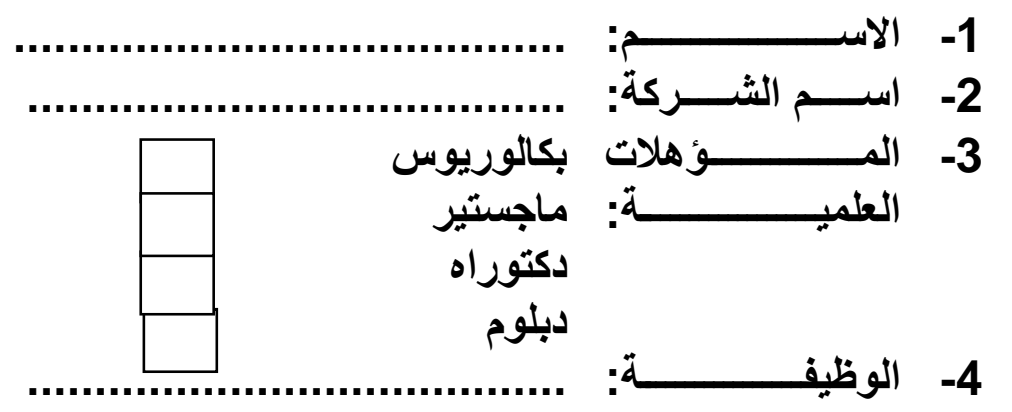

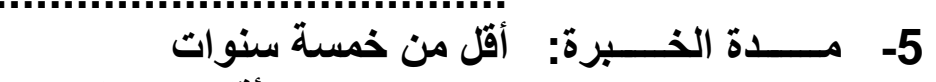

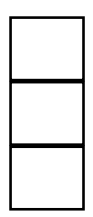

خمس سنوات وأقل من عشرة

عشر سنوات فأكثر

لـلاحظــــات عــــــــــة

يمكن اختيار العبارة التي تعبر عن وجهة نظرك بالتأثــير عليه بعلامـة (ل) في الخـانة المناسبة 


\section{القسم الثاني : تصميم قاتمة الاستقمساء:}

1- ما رأي سيادتكم بأن الدمج بين الثلاث أنظمة (JIT, TQM, PBO) يؤدي إلى:

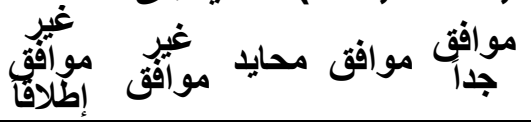

العبارات

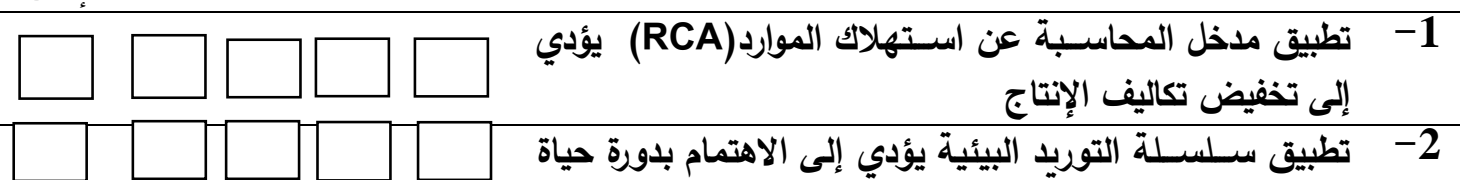
المنتج

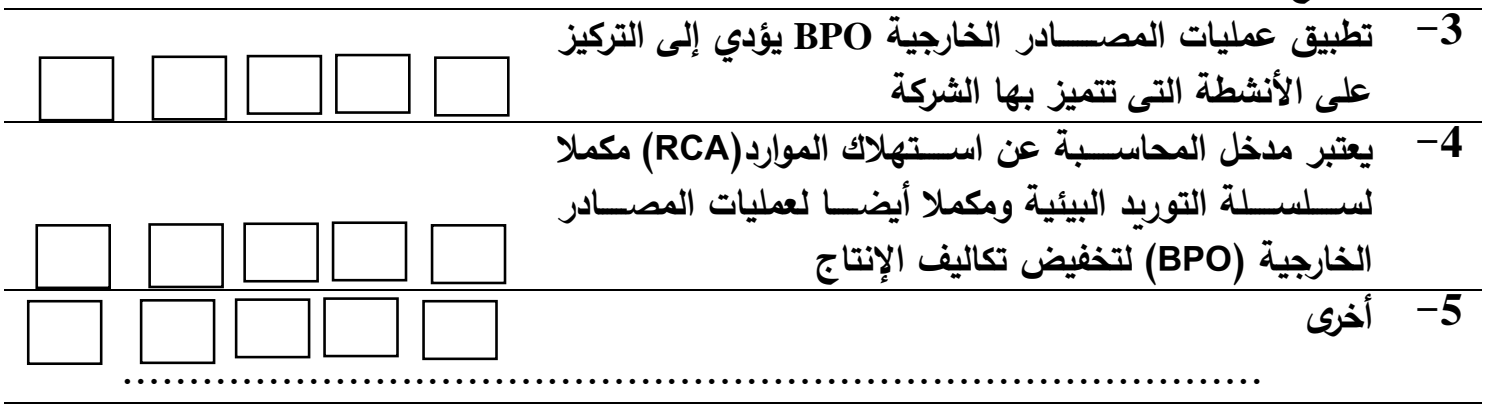

2- إذا كانت الإجابة بـ "لا" فما هي الأسباب في رأي سيادتكم:

العبارات

1- عدم معرفة أهمية الترابط بين ســلســلة التوريد البيئيةو مدخل

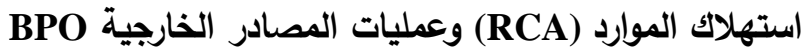

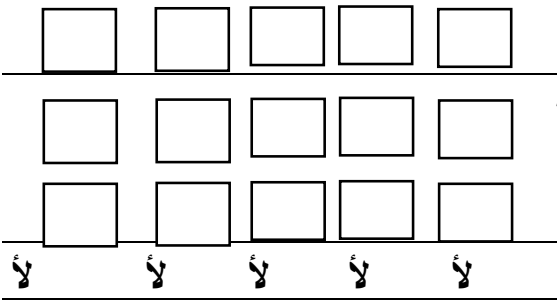

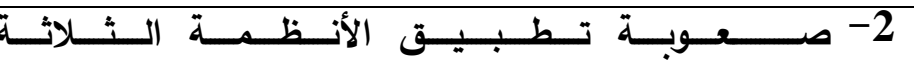

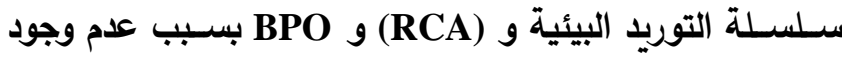

الخبرة الكافية لاى العاملين والإدارة العليا

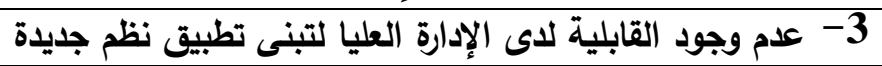

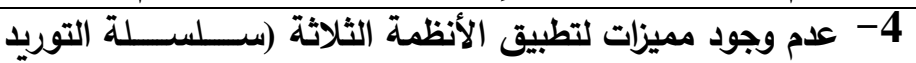

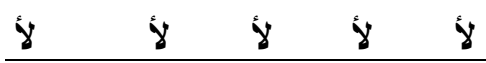
(RCA. BPO.البيئية

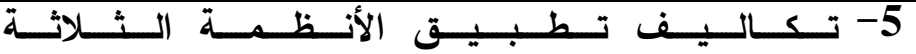

(RCA. BPO. يفلسـلة التوريد البيئية)

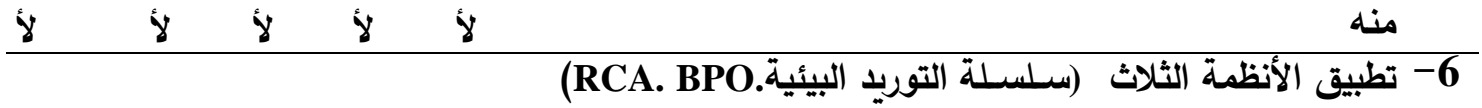

لا يؤدي وفورات في تكاليف الثركة 


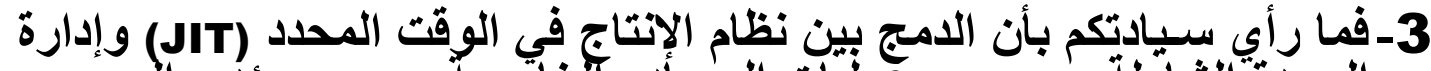

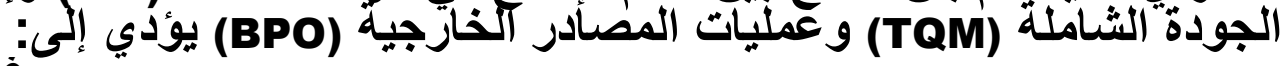

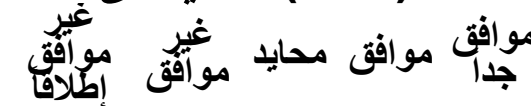

1 - ت تطبيق نظام وســســلة التوريد البيئية يعطى الثــركة القدرة

على إنتاج منتجات متنوعة تفي بمتطلبات العملاء واحتياجاتهم

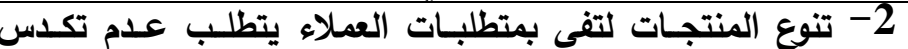

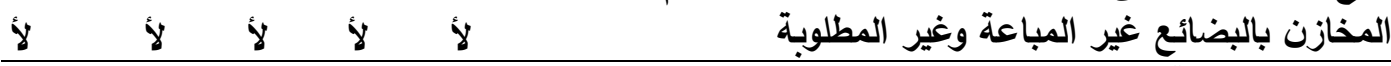

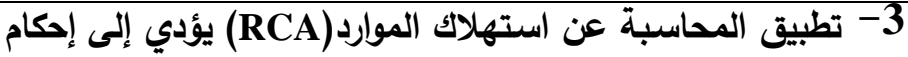

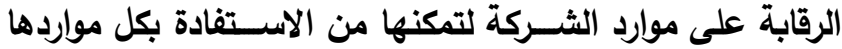
لإنتاج منتجات متعددة تفي بأذواق العملاء

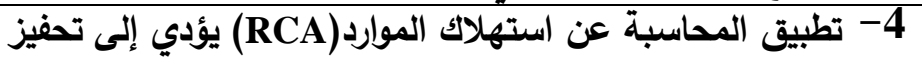

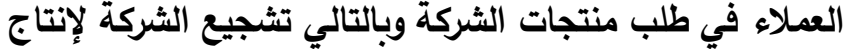

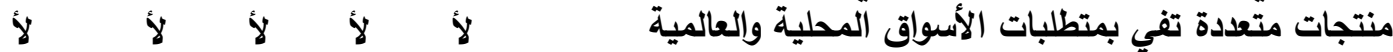

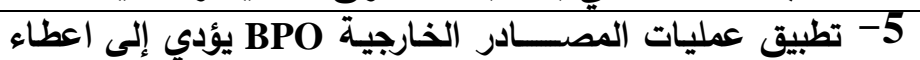

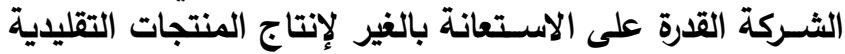

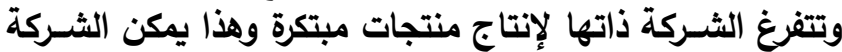

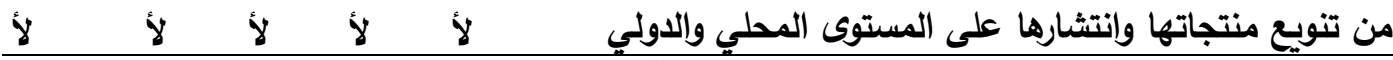

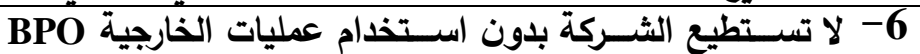
تنويع منتجاتها بالقدر التي تستطيع من خلاله الايفاء بمتطلبات الكارية

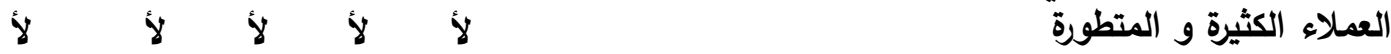

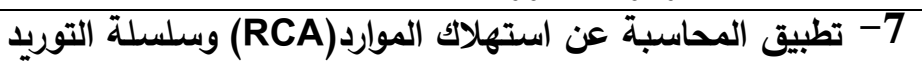

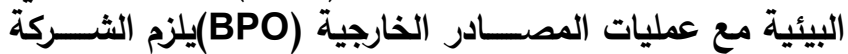

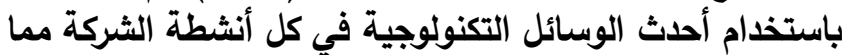

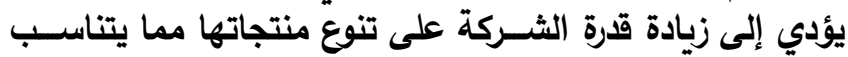

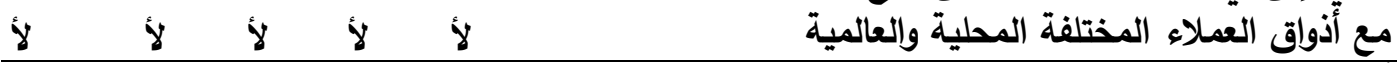

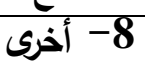

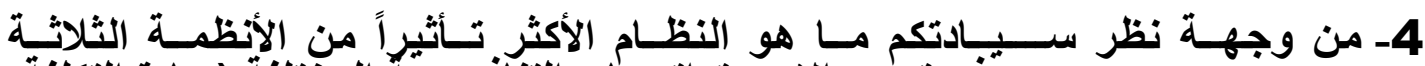

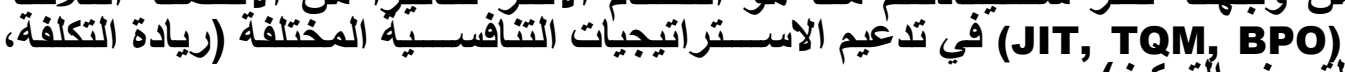

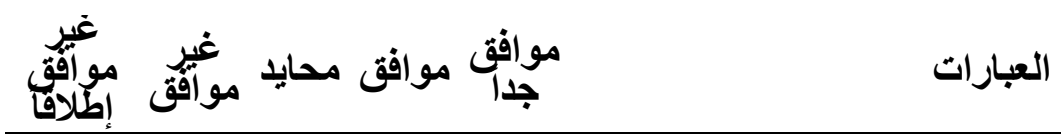

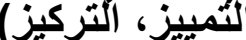

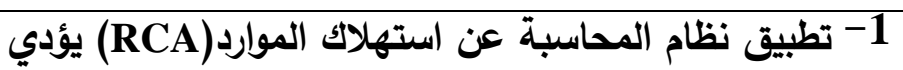

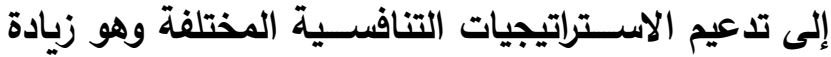

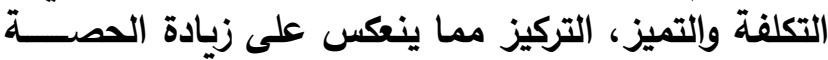
السوقية للشركة التشيز، لتركز

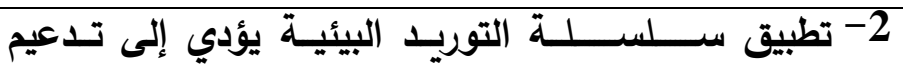

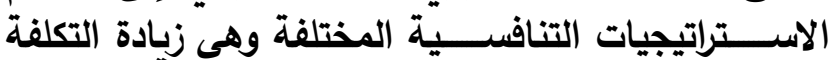

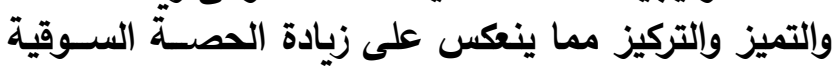
للشركة 
مجلة البحوث المالية والتجارية ـ المجلد (22) - العدد الثاني - إبريل 2021 .

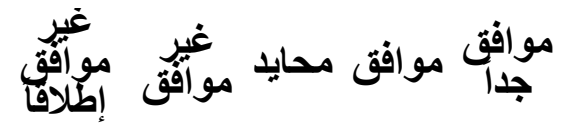

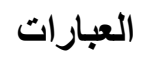

$$
\begin{aligned}
& \text { 3- يؤدى تطبيق عمليات المصادر الخارجية BPO يؤدي إلى الثى }
\end{aligned}
$$

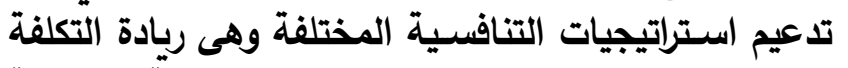

$$
\begin{aligned}
& \text { والتميز والتركيز فيما ينعكس على زيادة العصــة السـوقية }
\end{aligned}
$$

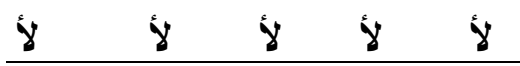

$$
\begin{aligned}
& \text { للشركة } \\
& \text { 4- الترابط بين نظام المحاسـبة عن استهلاك الموارد(RCA) }
\end{aligned}
$$

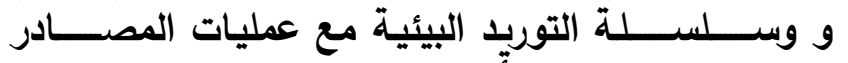

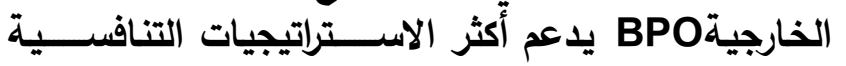

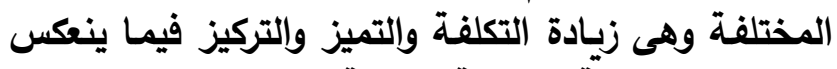

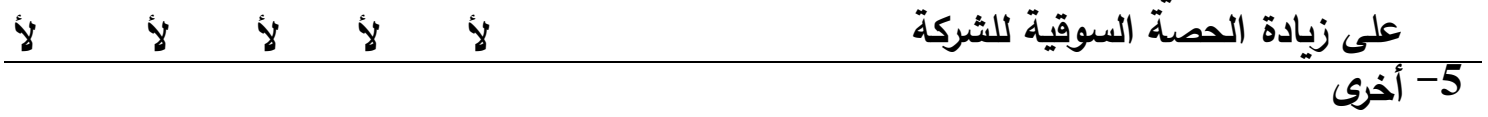

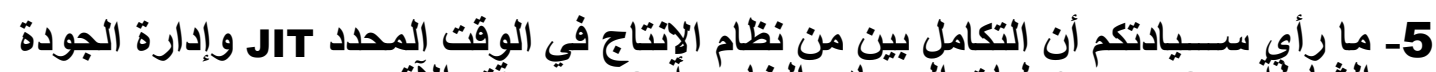
الثاملة

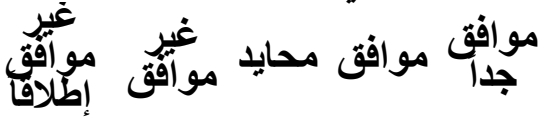

$$
\text { العبارات }
$$

1- الاستمرار في تقديم منتجات مبتكرة وجديدة للسوق المحلى

$\begin{array}{lllll}y & y & y & y & y \\ y & y & y & y & y \\ y & y & y & y & y \\ y & y & y & y & y \\ y & y & y & y & y \\ y & y & y & y & y \\ y & y & y & y & y \\ y & y & y & y & y \\ y & y & y & y & y \\ y & y & y \\ y & y & y & y & y \\ y & y & y & y & y\end{array}$

$$
\begin{aligned}
& \text { وإلعالمي } \\
& \text { 2- زيادة رضاء العميل } \\
& \text { 3- خفض التكلفة وزيادة الحصة السوقية }
\end{aligned}
$$$$
\text { 4- الوصول الى مستوى الفاقد والاخطاء الى الصفرة الصفرة }
$$

5- 5- رفع مستوى الجودة وتحسين الانتاجية

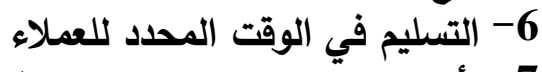

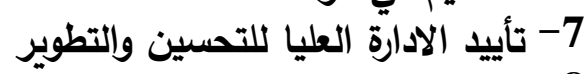

8

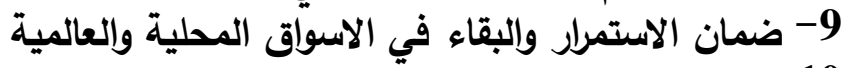

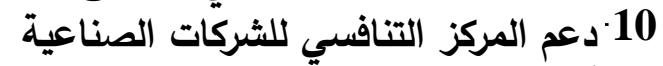

